University of Louisville

ThinkIR: The University of Louisville's Institutional Repository

Electronic Theses and Dissertations

8-2010

\title{
Academic dishonesty in online education.
}

Wren Allen Mills

University of Louisville

Follow this and additional works at: https://ir.library.louisville.edu/etd

\section{Recommended Citation}

Mills, Wren Allen, "Academic dishonesty in online education." (2010). Electronic Theses and Dissertations. Paper 987.

https://doi.org/10.18297/etd/987

This Doctoral Dissertation is brought to you for free and open access by ThinkIR: The University of Louisville's Institutional Repository. It has been accepted for inclusion in Electronic Theses and Dissertations by an authorized administrator of ThinkIR: The University of Louisville's Institutional Repository. This title appears here courtesy of the author, who has retained all other copyrights. For more information, please contact thinkir@louisville.edu. 


\title{
ACADEMIC DISHONESTY IN ONLINE EDUCATION
}

\author{
By
}

\author{
A Dissertation \\ Submitted to the Faculty of the \\ Graduate School of the University of Louisville \\ and \\ Graduate Studies and Research at Western Kentucky University \\ in Partial Fulfillment of the Requirements \\ for the Degree of
}

\author{
Doctor of Philosophy \\ Department of Leadership, Foundations, and Human Resource Education \\ University of Louisville \\ and \\ College of Education and Behavioral Sciences \\ Western Kentucky University
}

August 2010 


\title{
ACADEMIC DISHONESTY IN ONLINE EDUCATION
}

\author{
By \\ Wren Allen Mills \\ B.A., Western Kentucky, 1996 \\ M.A., Western Kentucky, 1999 \\ M.A.E, Western Kentucky, 2004
}

A Dissertation Approved on

July 20,2010

by the following Dissertation Committee:

Dissertation Director 


\section{DEDICATION}

I dedicate this dissertation to my husband

\section{Robert Mills}

for his unending support and patience throughout my doctoral journey

and to my grandparents

Marilyn and James B. Tomes, Jr.

for their constant encouragement to work hard and finish. 


\section{ACKNOWLEDGMENTS}

Special thanks goes to my committee for their advice throughout this long process, and especially to my chair, Dr. Ric Keaster, who was always willing to answer questions and keep me focused and who helped me construct a good committee. Much appreciation also goes to Dr. Douglas Smith, my methodologist and "Spinal Tap drummer," who helped me more than he may ever know.

I would also like to thank my extended cohort--Dr. Lynn Austin, Dr. Libby Greaney, Dr. Paula Upright, Dr. Sue Parrigin, Dr. Stacy Edds-Ellis, Dr. Sherry Lovan, and Dr. Audrey Cornell--for their support and friendship during our coursework and research. Without these seven women, and Dr. Steve Miller's advice to have no "lost souls," my dissertation process would not have been as enlightening, or as entertaining.

To Dr. Sally Kuhlenschmidt, for her very, very early guidance and continued support, and to Dr. John Bruni, who was always happy to answer questions and offer advice, I also give thanks. Both of you did much to support and encourage me without even being on my committee, and I will always remember you both for that.

Last, I would like to thank the Graduate Student Research Committee of the Graduate Council of Western Kentucky University for their generous grant. This allowed me to offer such a substantial incentive to mimic the drive for a high grade in an actual course. Without their support, the incentive would not have been possible. 


\section{ABSTRACT \\ ACADEMIC DISHONESTY IN ONLINE LEARNING}

Wren Allen Mills

July 20, 2010

This dissertation examined cheating attitudes and behaviors of undergraduates, especially those enrolled in online courses. While cheating is an established problem within the academy, it is also an issue on the job and has been in the spotlight in recent years, with ethics scandals in corporate America and plagiarism in the media. With this in mind, and the foundational philosophy of the Cardinal Principles of Secondary Education (Bureau of Education, 1928) and the American Council on Education's (1937) Student Personnel Point of View, this study sought insight into students' attitudes about cheating behaviors and practices of them in online courses in comparison with students in face-toface courses.

A unique study design enabled examination of these ideas. In this deception study, a convenience sample of participants in face-to-face and online general education courses consented to a study on testing formats in online learning. They answered 18 items querying background information, took a 10-question reading quiz over an original topic, and answered 49 items about attitudes toward cheating and cheating behaviors. To mimic the drive for a good grade and encourage participants to do their best, the researcher offered a chance at a $\$ 400$ incentive to those who scored high on the quiz. On the quiz, participants could answer only 7 of the 10 open-ended questions using the 
materials provided: to answer the others, participants had to cheat by looking up the remaining 3 on the Internet. The questionnaire's final item asked them to report if they had used outside sources on the quiz to check the accuracy of self-reported cheating.

While analysis via $t$-tests revealed no significant differences between face-to-face and online students in their attitudes toward learning, nor did Pearson's $r$ reveal any significant associations between online students' background variables and cheating, the study did provide a rate of accuracy of self-reported cheating. Analysis of qualitative data gave insight into undergraduates' ideas on what cheating is, how students might cheat, what causes cheating, and how educators and administrators might work to prevent academic dishonesty. 


\section{TABLE OF CONTENTS}

\section{PAGE}

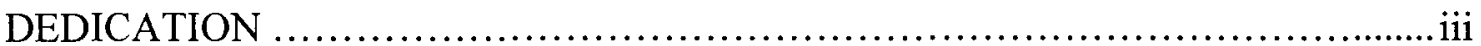

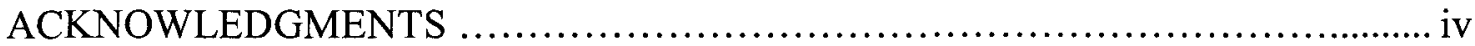

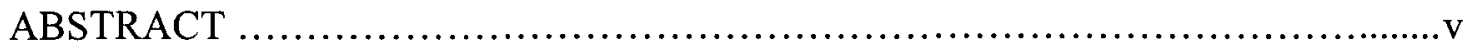

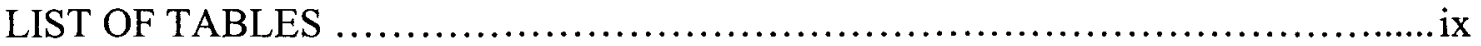

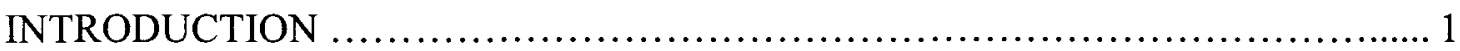

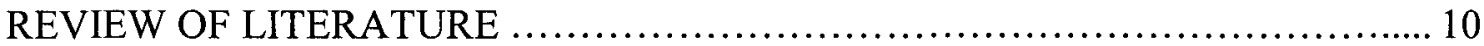

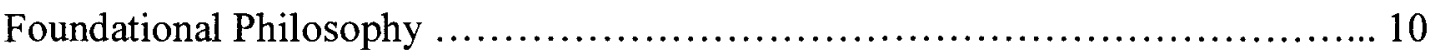

The Relationship between Cheating in Schools and Dishonesty in the Workplace .. 11

Predictors of Cheating ..........................................................

Student and Faculty Attitudes toward Cheating ................................ 38

Effects of Policy on Academic Dishonesty ...................................... 45

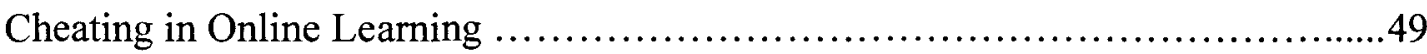

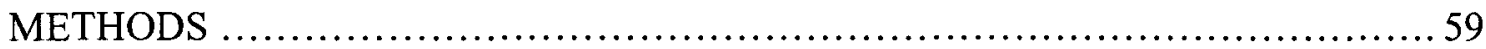

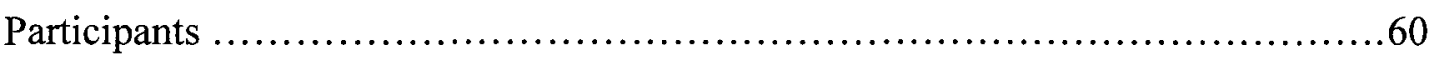

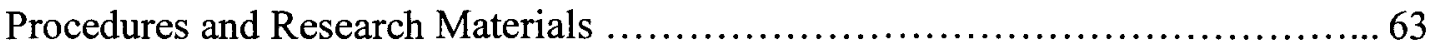

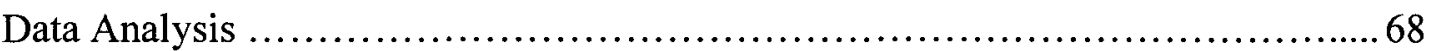

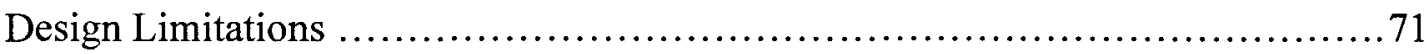

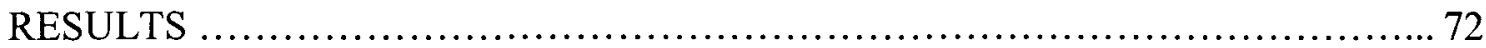


Descriptive Statistics of Background Variables ................................ 73

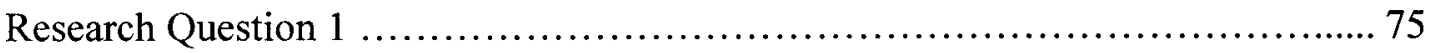

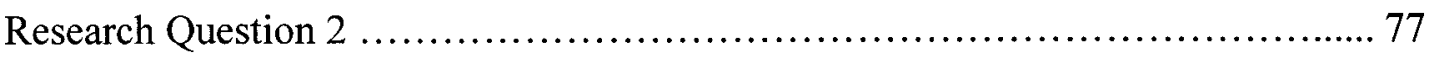

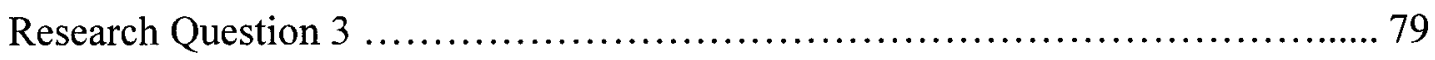

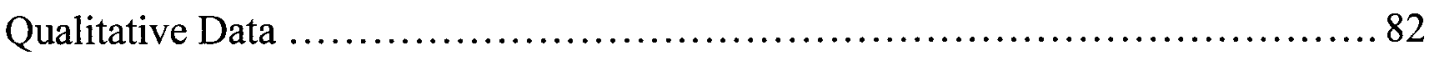

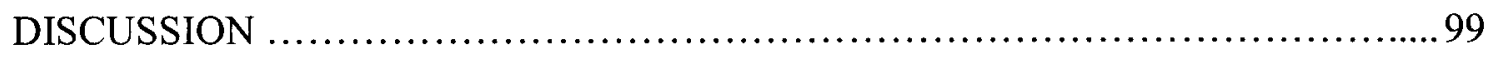

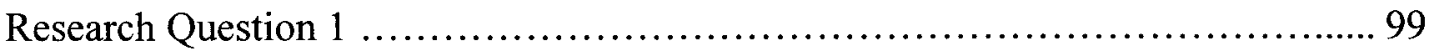

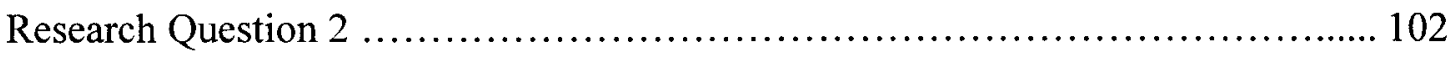

Research Question 3 .................................................... 106

Concerning Online Cheaters and Other Ideas about Cheating Behaviors ............ 108

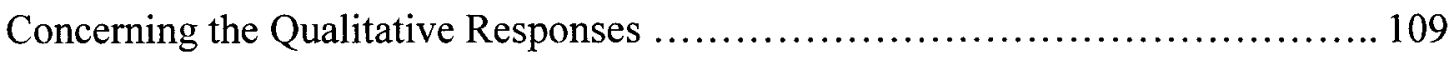

Implications of Response Rate ..............................................110

Implications for Educators and Administrators .................................. 113

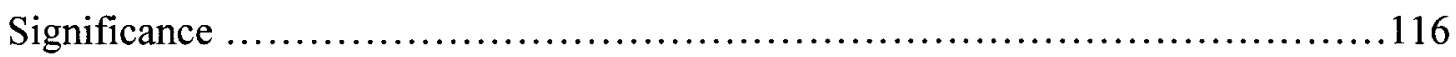

Considerations for Repetition of the Current Design .............................. 116

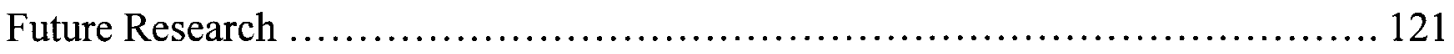

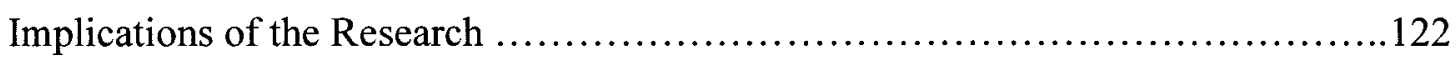

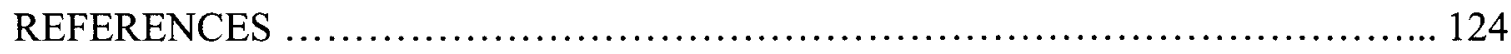

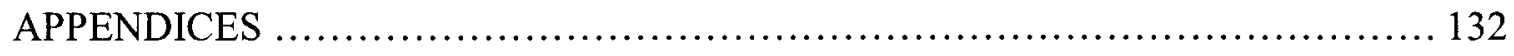

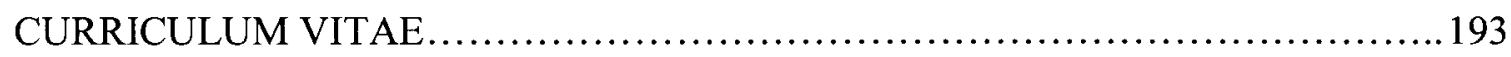




\section{LIST OF TABLES}

TABLE PAGE

1. Attitudes Toward Cheating Behaviors ...................................... 76

2. Cheating Frequency by Class Type …..................................... 77

3. Cheating Admission by Class Type …....................................... 78

4. Accuracy of Cheating Admission by Class Type .................................79

5. Differences in Background Variables Among Online Students ....................8 80

6. Associations between Background Variables and Cheating in Online Students ..... 81

7. Server Logs for http://www.byzant.com/Wonders ..................................................105

8. Demographics of the Institution Studied and the Study's Sample Compared ........ 111

9. Class Type of Participants ................................................ 174

10. Gender of Participants ................................................... 174

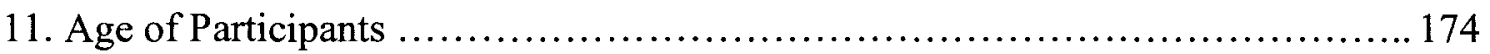

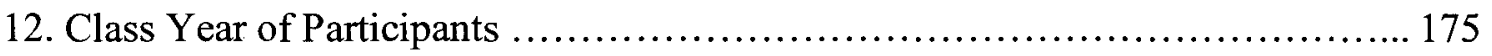

13. Grade Point Average of Participants ........................................... 175

14. Student Status of Participants .................................................. 176

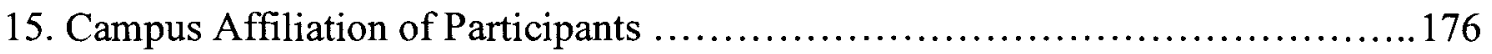

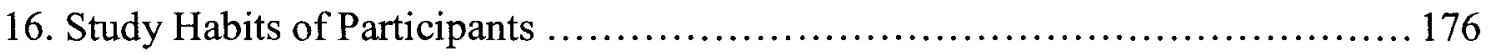

17. Major/Program of Study of Participants (by College) ......................... 177

18. Participants Receiving Financial Support from Parents/Guardians .............. 177 
19. Types of Financial Aid Received by Participants ............................. 178

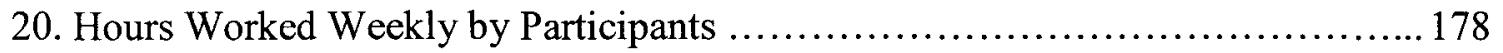

21. Citizenship of Participants ............................................. 178

22. Extra- and Co-curricular Involvement of Participants ........................ 179

23. Types of Extra- and Co-curricular Involvement of Participants .................. 179

24. Living Accommodations of Participants ................................... 180

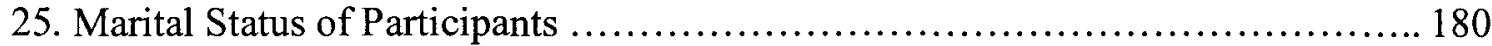




\section{CHAPTER I}

Research Problem

Online learning is a valuable commodity to higher education via which institutions can extend their academic missions beyond their brick and mortar campuses. Although online learning has become a definite asset to institutions and learners alike, the problem of academic dishonesty-- in ways both similar and dissimilar to traditional oncampus, face-to-face classes-- has emerged as an important issue for this new educational medium (Etter, Cramer, \& Finn, 2006; Grijalva, Nowell, \& Kerkvliet, 2006; Kennedy, Nowak, Raghuraman, Thomas, \& Davis, 2000; Lanier, 2006; Underwood \& Szabo, 2003). While many studies of face-to-face classes have investigated what types of students are most likely to cheat and have provided information on how many students cheat, very few studies have tackled the same for online learning, such as the studies previously mentioned. Further, reports of cheating have been compiled primarily from self-reporting rather than "catching" students actually cheating, leaving questions about the accuracy of such reports.

Additionally, there is the concern that perhaps educators and administrators are not fulfilling the basic mission of higher education as laid out by the Commission on the Reorganization of Secondary Education, which in 1918 published its Cardinal Principles of Secondary Education (Bureau of Education, 1928); the American Council on Education (1937) reiterated this in their Student Personnel Point of View. These bodies felt strongly that graduates of higher education should be persons of good character who 
would be good citizens of their communities; however, if academic dishonesty is rampant throughout colleges and universities, and since online education may provide greater opportunities for such behavior, then researchers should examine online learning while it is still in relative infancy and see what can be done to identify ways in which educators and administrators can help to churn out better graduates and, thus, citizens. Indeed, the headlines of the last decade have given numerous examples of poor character development and bad citizenship: the Enron and WorldCom scandals, Jayson Blair's plagiarism at the New York Times, and, more recently, the failed Madoff Ponzi scheme. The likelihood that cheaters in school will turn into cheaters in the workplace and in our communities--as per Harding, Carpenter, Finelli, and Passow (2004); Nonis and Swift (2001); and Sims (1993)--makes the need for this study even more timely.

\section{Literature Summary}

In 1918, the Commission on the Reorganization of Secondary Education published its Cardinal Principles of Secondary Education (Bureau of Education, 1928). In that document, the Commission cited that when students graduated from high school, they should be in possession of, from among a list of several other traits and competencies, an ethical character, developed through specific instruction in the schools should such be lacking at home. Nineteen years later, the American Council on Education (1937) presented the Student Personnel Point of View and stated that there needed to be greater cooperation between secondary schools and institutions of higher education in carrying out educational missions and reinforcing the Commission's 1918 Cardinal Principles. Still today educators can see the same call to action for more ethical students to matriculate from American universities, as seen in the National Leadership Council for 
Liberal Education \& America's Promise (LEAP) (2007) report, College Learning for the New Global Century. Indeed, Principle Six--Foster Civic, Intercultural, and Ethical Learning--makes two recommendations as to why today's students still need education on ethical behaviors and social responsibility and how to accomplish incorporating such into a curriculum at the post secondary level so that when student leave the academy, they are in possession of a clear idea of what their "ethical, professional and civic responsibilities [are] as they move forward" (LEAP, 2007, p. 39).

Studies discussed below concerning academic dishonesty suggest through their high rates of self-reported cheating that development or possession of an ethical character may not be a priority for today's graduates, and academic dishonesty in both secondary and higher education has become commonplace. Indeed, cheating is spilling over into the workplace and thus into communities, further jeopardizing the fulfillment of the Commission's Principles. The arrival of Web-based courses demands that researchers study academic dishonesty in ways that they have not before, but still with an eye to past literature to guide them in how to best predict and eliminate cheating. Gaining insight into academic dishonesty in this new learning venue can ensure that educators and administrators are still on the path to fulfilling the Commission's Principles and the Council's Point of View so that current pupils will matriculate into honest employees and community members, a challenge with which the National Leadership Council's (2007) LEAP report recommendations are also hoping to assist.

In their studies, Harding, Carpenter, Finelli, and Passow (2004); Nonis and Swift (2001); and Sims (1993) found a link between academic dishonesty and dishonesty in the workplace. This was stronger for those who had been dishonest in high school (Harding 
et al., 2004). In looking to how educators can predict which students will act dishonestly, the body of literature is large, as shown by Whitley's (1998) review of the literature. Leming (1980) suggested that academic dishonesty is situation-specific and that its likelihood decreased in high risk situations. McCabe and Trevino (1997) discussed multiple personal and contextual variables that may contribute to whether or not a student will engage in such behavior, as did Chapman, Davis, Toy, and Wright (2004); DeBruin and Rudnick (2007); and Williams and Janosik (2007). Sometimes motivations, peer perception, and policy can influence students, as Jordan (2001) found, and at other times, the type of work assigned can elicit a desire to cheat (Passow, Mayew, Finelli, Harding, \& Carpenter, 2006).

Additionally, the type of school students attend might also affect the possibility of cheating (Brown \& Choong, 2003; Rettinger \& Jordan, 2005; Smyth \& Davis, 2003). Other studies have found that a student's area of study can indicate the probability that cheating will occur (Brown, 1996; Iyer \& Eastman, 2006; Kerkvliet \& Sigmund, 1999; Rakovski \& Levy, 2006). Looking away from personal traits and toward attitudes, how students and faculty feel about cheating can determine whether students will be dishonest in their coursework, as suggested in Keith-Spiegel, Tabachnick, and Allen (1993); Pickard (2006); and Roig and Ballew (1994). Lastly, whether or not a school employs an honor code or a policy on academic dishonesty can also predict student cheating rates, as found by Brown and Howell (2001) and McCabe, Trevino, and Butterfield (2002), for instance.

The focus of the current study, however, is academic dishonesty in online learning. Research in this area is limited as the medium is still new to most faculty, 
although institutions around the world are offering more online classes each year. Some of the same factors can predict if students will cheat in their online classes, as seen in Kennedy, Nowak, Raghuraman, Thomas, and Davis's (2000) examination of faculty and student views of cheating in online courses. However, there are new considerations, and who cheats in online courses (Grijalva, Nowell, \& Kerkvliet, 2006; Lanier, 2006) and how they cheat (Etter, Cramer, \& Finn, 2006; Underwood \& Szabo, 2003) deserve further investigation.

\section{Research Questions}

1. Do undergraduates in online classes report the same attitudes toward cheating as undergraduates in face-to-face classes?

2. How accurately do undergraduates in online classes report their cheating in online classes?

3. What background variables are associated with undergraduates' cheating behaviors in online classes?

\section{Purpose}

This study explored cheating in online learning and how academic dishonesty may be undermining the ideas about and standards for higher education as set forth by the Commission on the Reorganization of Secondary Education (Bureau of Education, 1928) and the American Council on Education (1937) and leading to graduates who are not prepared to be good citizens in today's society. The purpose of this study was to determine if online and face-to-face students have the same attitudes about cheating, the accuracy of undergraduates' self-reports of cheating, and if the same types of 
undergraduate students report cheating in online classes as in prior studies of face-to-face classes.

\section{General Methodology}

This is a brief discussion of the methods employed in the study. For full details, refer to Chapter 3.

This mixed-methods study was a deception study due to the sensitivity of the topic. Researchers have used deception studies in studies involving topics like sexual behavior, drug use, and alcohol use to obtain more honest answers from participants (Sales \& Folkman, 2000). Like those topics, academic dishonesty is a subject that lends itself to social desirability bias (as noted by Whitley, 1998), where participants may feel inclined to answer in a way that presents them most favorably to researchers (Groves, Fowler, Couper, Lepkowski, Singer, \& Tourangeau, 2004). This could confound results (Sales \& Folkman, 2000). As stated by Sales and Folkman (2000), in some studies, the true purpose of the research, due to its nature, cannot be fully disclosed to participants until after the completion of data collection to "preserve the validity of the data collected" (p. 42). The current study was such a study.

Participants in this study were a convenience sample from general education courses from a regional comprehensive university. Before to data collection, the researcher created and placed dummy information on the Web about an invented, original topic. This was done well in advance to allow search engines to index said information.

Participants consented to a study on testing formats in online courses. First, participants responded to items querying background variables. Next, they took a reading quiz that contained an excerpt of the invented, original topic writing that the researched 
placed on the Web prior to the study and 10 open-ended questions; the excerpt also cited the full-version as a matter of good practice. The quiz instructed participants to answer the questions using only the information in the excerpt; the researcher encouraged them to do their best and said that those with the highest scores would have the chance to enter a drawing for a $\$ 400$ Visa gift card at the end of the survey. Immediately upon completion of the reading quiz, participants completed an amended form of Underwood and Szabo's (2003) Cheat QTR questionnaire and answered questions concerning their attitudes about the seriousness of certain cheating behaviors. They also answered a single item querying whether they used any resource other than the excerpt on the quiz to obtain answers to those 10 questions. Before the participants submitted their data, the researcher debriefed participants as to the true purpose of the study, reassured them of their anonymity, and gave them the chance to remove their data from the analysis pool. Last, the survey software redirected all participants to a second survey that collected only their student identification numbers to enter the drawing for the incentive.

\section{Definition of Important Terms}

\section{Academic Dishonesty}

Academic dishonesty, or cheating, includes all practices involving some sort of fraud, including those in which students represent someone else's work as their own or assist other students in doing the same (Prescott, 1989).

\section{Online Class}

An online class is one in which student and instructor are typically in separate locations and coursework takes place through a variety of technological media, but primarily through the Internet (Rubiales, Steely, Wollner, Richardson, \& Smith, 1998). 


\section{Assumptions}

The researcher assumed that participants would cheat during this study as prior literature supports that students do cheat and studies cited in Chapter 2 show. Whether they are accurate or not in their self-reporting of cheating will be determined by their answers on the quiz and their answers on the amended Cheat QTR (Underwood \& Szabo, 2003).

\section{Limitations and Delimitations}

1. Some of the early study participants may have alerted later participants to the items concerning cheating that they answered after the quiz. Those who received such information may not have been as likely to cheat or may have avoided the study.

2. This study did not cover all background variables discussed in previous research. To do so would have been laborious and unfocused; therefore, the researcher focused on the background variables covered most commonly and most consistently by prior research, as they provided a solid basis for comparison.

3. This study focused only on undergraduates enrolled in general education courses. The literature reflects that cheating does not occur only in such courses or only in undergraduate populations. The current study chose to focus on undergraduates in general education courses in order to obtain the most representative sample possible since the institution used in the study requires all students to take such courses. 
4. This study focused only on undergraduate students enrolled at a public, fouryear institution. Prior literature showed no significant difference in cheating a private vs. public or two-year vs. four-year institutions (Smyth \& Davis, 2003); thus, the researchers made the decision to focus on this single type of institution.

\section{Significance}

Online learning is a relatively new venue for education, and academic dishonesty is a problem that has the potential to explode within Web-based courses, especially since cheating is an issue that traditional, face-to-face learning environments have not solved at this point. There is very little research available concerning cheating in online learning, and even less that "proves" a rate of cheating rather than accepting self-reported levels. The information gained from this study will contribute toward knowledge of cheating and of how online classes compare to traditional classes on college campuses. The findings may help faculty and administrators in their battles against academic dishonesty.

Conclusion

Online learning is a new and fast-expanding facet of higher education's academic offerings. As with traditional, face-to-face classes, educators and administrators should recognize the risks for academic dishonesty and the future implications such behaviors may have, including but not limited to the possible degradation of the integrity of degrees awarded and the institution as a whole. Because of these concerns, this study explored academic dishonesty in online learning and compared the cheating behaviors found with findings from prior studies, a relevant selection of which the researcher discusses in the following chapter. 


\section{CHAPTER II}

\section{REVIEW OF LITERATURE}

Cheating has been a problem in education for many decades (Finn \& Frone, 2004). This chapter reviews literature concerning (a) predictors of academic dishonesty, (b) attitudes of students toward academic dishonesty, (c) effects of policy on academic dishonesty, and (d) cheating in online learning.

\section{Foundational Philosophy}

As mentioned in Chapter 1, the Commission on the Reorganization of Secondary Education published its Cardinal Principles of Secondary Education in 1918 (Bureau of Education, 1928). Among other character traits and competencies that high school graduates should possess, stated the document, was an ethical character that schools worked to develop and hone in the case that such lessons were not taught in the home (Bureau of Education). In 1937, the American Council on Education offered the Student Personnel Point of View and encouraged more collaboration between high schools and institutions of higher education to help educate students and to meet the goals of the Cardinal Principles. Seventy years later, the National Leadership Council's (2007) LEAP report offered seven principles of its own that revisited some of the same found in the Cardinal Principles and the Student Personnel Point of View, including the need for ethics education in today's students at the post-secondary level.

Studies discussed in this chapter concerning academic dishonesty suggest through their high rates of self-reported cheating that ethical character may not be characteristic 
of, possessed by, or a priority for today's graduates; that students characterize cheating as a socially acceptable behavior; and that academic dishonesty in both secondary and higher education has become commonplace. Indeed, dishonesty in academia is spilling over into the workplace and thus into communities, further jeopardizing the fulfillment of the Commission's 1918 Principles (Bureau of Education, 1928). With the advent of online learning, researchers should examine academic dishonesty in a new light but with the torches of the past still lighting the path of sound student development. Understanding academic dishonesty in the newest medium of learning will help today's educators and educational administrators to ensure that the Commission's Principles and the Council's Point of View will be upheld for current and future students and that today's students become tomorrow's ethical workers and citizens, which is the goal of the National Leadership Council's (2007) LEAP report.

The Relationship between Cheating in School and Dishonesty in the Workplace The Commission on the Reorganization of Secondary Education (1918) felt strongly that once leaving the educational setting, graduates should be good citizens, and the National Leadership Council's (2007) LEAP report hoped that students will graduate from college with an appropriate sense of ethics to use in both their personal and professional lives because of a well-executed post-secondary education. However, today's cheaters in higher education will become tomorrow's cheaters in the workplace if something is not done to curb the urges to be dishonest and the instances of cheating in academia. Sims (1993) collected data using an instrument that queried attitudes toward and participation in 18 cheating behaviors and analyzed the data by computing descriptive statistics and correlations. Her purpose was to see if dishonest students 
evolved into dishonest workers, and the data showed strong correlations between admitted academic dishonesty and admitted unethical business practices. She determined that a relationship existed between the scope and severity of cheating engaged in during college and dishonesty practices in a work setting. Sims's findings give strong support for the idea that there is a statistically significant relationship between student and subsequent worker dishonesty.

Nearly 10 years later, Nonis and Swift (2001) also cited many studies that found students who cheat in college will do so later in life and in their careers. The researchers reasoned that if dishonest activities are situation-specific, there should not be a relationship between those activities at school and those later at work. Nonis and Swift hoped to build on Sims's (1993) study, one limited in its findings due to a small sample size, by testing two hypotheses: (a) people who believe unethical acts are acceptable forms of behavior will participate in them more frequently than those who see such acts to be less acceptable, and (b) the number of incidents of cheating in college is positively related to dishonest acts at work. They did this by utilizing a variety of instruments to measure beliefs about dishonest activities at work, academic dishonesty, and work-related dishonest behaviors. Pearson product moment coefficients showed positive, significant correlations for both.

While Nonis and Swift (2001) admitted their findings to be very similar to those of prior research, they did note a worrisome finding in that more than $10 \%$ of the participants considered 12 of the 21 dishonest behaviors on their instrument as "probably not" or "definitely not" cheating. These included not telling the whole truth to hide mistakes and doing less than one's share of the work in a group assignment, both 
situations commonly found in today's educational and workplace settings. However, Nonis and Swift pointed out that prior research also has noted high levels of tolerance for such behaviors in business.

Harding et al. (2004) similarly investigated whether participation in one deviant behavior, such as cheating, could be a predictor for participation in another deviant behavior in a different setting. Two hypotheses drove the research: (a) there are similarities in the decision-making processes students use when considering whether to cheat in college and whether to violate workplace policies, and (b) prior cheating in a school setting is an indicator of future dishonest behavior. In this mixed-methods study, participants answered an instrument that obtained both quantitative and qualitative data from each subject. The survey consisted of 13 items in 3 sections that queried demographics and high school cheating, cheating in college, and violations of workplace policies. The researchers computed simple percentages and Friedman non-parametric tests for the quantitative data and used the constant-comparative analysis technique for the open-ended survey questions' qualitative data yields.

In comparing the data, Harding et al. (2004) found that $37.5 \%$ of those who reported never cheating during high school did violate workplace policies, and $63.6 \%$ of those who did cheat also violated the policies. This led Harding et al. to accept both of their hypotheses that similar processes are used to decide whether to participate in deviant behaviors in different situations and that deviant behavior in high school can be a strong indicator of deviant behavior in other situations later in life, as well. 


\section{Conclusion}

The studies completed by Sims (1993), Nonis and Swift (2001), and Harding et al. (2004) each suggest that a clear relationship between cheating at school and at work does exist. These findings can have significant implications for the future of education should administrators and educators wish to fulfill the Commission on the Reorganization of Secondary Education's Cardinal Principles of Secondary Education (Bureau of Education, 1928), the American Council on Education's (1937) Student Personnel Point of View, and the National Leadership Council's (2007) aspirations.

Predictors of Cheating

Beyond the relationship between cheating in school and dishonesty at work is the question of what background variables may help educators and administrators to predict who might engage in acts of academic dishonesty. This would allow them to work to prevent such behaviors among those aggregates so that they can graduate better citizens from their institutions. Of interest to the current study is past research concerning what demographic variables may predict who might cheat. The following studies give a broad look at many of these variables.

\section{Literature Reviews Offering Overviews}

In a review of the literature, Whitley (1998) took a broad view of what causes cheating and analyzed more than 100 studies conducted on cheating since 1970 because of the few reviews of the literature conducted since then. He proposed to examine the prevalence of cheating characteristics as well as the correlates of cheating in the studies. To be included in the review, studies had to report the frequency of cheating in samples 
of American or Canadian college students, and Whitley included a few studies that showed correlations between reported cheating in college and graduate school.

Whitley (1998) found two types of data in the articles he reviewed and among which he calculated correlations: (a) that which considers the frequency of cheating among college students and (b) that which reviewed the possible correlates of cheating. Through his review, five categories arose from the two types of data collected, and Whitley used these to classify the studies: (a) student characteristics, (b) attitudes toward cheating, (c) personality variables, (d) situational characteristics, and (e) factors that do not fit in with any of the others. Whitley reported on four types of estimates that he found in the literature: (a) cheating on tests, (b) cheating on homework and other assignments, (c) plagiarism, and (d) total cheating (no categories given in the study). Findings of interest to the current study are below.

Whitley (1998) found that $n=46$ of his selected studies provided frequency estimates for cheating. Reports of the prevalence of cheating ranged from $9 \%$ to $95 \%$, with a mean of $70.4 \%$. Reported cheating on tests ranged from $4 \%$ to $82 \%, M=43.1 \%$, and on homework $3 \%$ to $83 \%, M=40.9 \%$. Reported plagiarism ranged from $3 \%$ to $98 \%$, $M=47 \%$. Correlations between the date of data collection and the frequency of cheating estimate were not significant for any of the forms of cheating. Through multiple regression analysis, Whitley found a nonlinear relationship with cheating on tests consistent with other studies' predictions that cheating had risen in recent years. This suggests that more than ever, institutions of higher education need to purposefully work toward fulfilling the Cardinal Principles of Secondary Education (Bureau of Education, 1928) and meeting the mission of the Student Personnel Point of View (American 
Council on Education, 1937). Cheating is still prevalent in today's schools, and with the onset of online education, dishonesty likely will find new ways to rear its ugly head.

Whitley's (1998) examination of background variables shed light on many predictor variables of who is prone to cheating. Two demographic variables had moderate relationships with cheating: (a) age and (b) marital status: younger and unmarried students were more likely to cheat than older unmarried ones. Four demographic variables had small relationships with cheating: (a) number of hours worked per week, (b) amount of financial support from parents, (c) living on campus, and (d) gender of student. Male students who worked less, received more money from home, and lived on campus were more likely to cheat. Also notable is Whitley's finding that cheating was not correlated with year in college. Although this may mean that age and not academic level is related to cheating, or that the relationship between the academic level and cheating is nonlinear. Whitley encouraged further research on this point. Also of minimal significance was that Whitley found cheating to be related to parents' level of education.

When examining students' attitudes toward cheating, Whitley (1998) found that those with more favorable attitudes toward cheating were more likely to do it. Students who felt social norms permitted cheating were more likely to cheat, and those who thought themselves to be good at cheating were more likely to engage in it. Likewise, those who felt a moral obligation not to cheat were not as likely to cheat. This echoed the finding that students who rated themselves as less honest were more likely to cheat.

While not a relevant demographic variable within the current study, Whitley (1998) did find that students who attended institutions with honor codes were less likely to cheat. When they felt they would not be caught, students were more likely to cheat, but 
if the students perceived a risk, this inhibited higher performing students more than lower performers. Whitley acknowledged that cheating research suffered from the effects of social desirability answers, thus rendering reported cheating rates lower than actual cases of cheating, a point of particular interest to the current study.

Because cheating is a subject that lends itself to social desirability bias (as noted by Whitley, 1998), the actual reasoning for the research completed during the current study was not revealed to participants until after the completion of data collection to "preserve the validity of the data collected" (Sales \& Folkman, 2000, p. 42). If the researcher does not take steps to withhold the true intent of the data collection, social desirability answers could confound results (Sales \& Folkman). Therefore, deception of participants in this study was justified to preserve the integrity of the data. Chapter 3 discusses this further.

In a somewhat different approach to a review of the literature, Brown and Emmett (2001) investigated the relationship in the literature between the overall levels of reported cheating of college students and four independent variables: (a) year of study publication, (b) number of academically dishonest practices looked at in the study, (c) sample size, and (d) type of survey. Brown and Emmett sought to determine if any of the independent variables affected the overall level of cheating reported, which was the dependent variable. Using linear and nonlinear regression analysis, only the number of academically dishonest practices looked at in the study was significant and explained $36.9 \%$ of variation in the overall level of cheating. Brown and Emmett stated that their results corroborated Spiller and Crown's (1995, as cited in Brown \& Emmett, 2001) reports of no increase in the levels of cheating over time, but their study did not support Baird's 
(1980, as cited in Brown \& Emmett, 2001) or Cole and McCabe's (1996, as cited in Brown \& Emmett, 2001) ideas that sample size could affect reported levels of cheating. Brown and Emmett's findings also did not support Nelson and Schaefer's (1996, as cited in Brown \& Emmett, 2001) or Karlins, Michaels, and Podlogar's (1988, as cited in Brown \& Emmett, 2001) accounts that students overstate their cheating behaviors.

\section{General Predictors}

To more closely examine the generalized findings of Whitley (1998) and Brown and Emmett's (2001) reviews, the current researcher offers here a close discussion of several background variables of interest to the current study as possible predictors of academic dishonesty.

Leming (1980) tested five hypotheses for his experimental correlation study, but only three of these are of interest to the current study: (a) students of lesser academic ability would cheat more than those of higher ability, (b) women would not cheat more than men, and (c) only women and students with higher academic ability would report significant decreases in cheating in high risk conditions. Leming selected students in two sections of an undergraduate psychology course and administered the Hartshorne and May (1928, as cited in Leming, 1980) Circles Test, which a control group also took to generate a baseline score for those who cheated in the sample. He gave the participants the Circles Test in two groups under two sets of conditions. The first group received harsh warnings against cheating, and Leming and three colleagues paced the aisles during the test. In the second, only the instructor was present, and he gave no warning and read a magazine with only occasional upwards glances toward the participants. In both groups, the researchers offered the incentive of extra credit for subjects who made above average 
scores and told participants false average scores to encourage cheating. Leming used oneway ANOVA and Scheffe tests to analyze the data.

Leming (1980) found that both the high-risk and low-risk groups cheated more than the control group, and the low-risk group cheated more than the high-risk group. Leming found that $24 \%$ of high risk group members cheated and $36 \%$ of low risk group members cheated. Participants with more ability cheated less than those with less ability in high risk conditions. He also found that women cheated more than men, and the finding was a result of a dramatic increase of cheating by women in the low risk group.

Moving toward a broader look at cheating, McCabe and Trevino (1997) believed that cheating could be influenced by myriad variables. In their study, they sought to determine the relative role of personal and contextual variables that contribute to academic dishonesty among college students across campuses through examining the relationship among dishonesty and age, gender, academic achievement, parents' education, and extracurricular participation. McCabe and Trevino used their own instrument from their 1993 study and used descriptive statistics, Cronbach's alpha reliabilities (where applicable) and inter-correlations among all variables for analysis of the data, as well as multiple regression.

Results indicated that academic dishonesty correlated significantly with many background variables, several of which are of interest to the current study: age, gender, GPA, Greek membership, peer behavior, peer disapproval, peer reporting, severity of penalties for cheating, and the relationship with faculty/support of campus academic integrity policies (McCabe \& Trevino, 1997). The overall findings support McCabe and 
Trevino's notion that a variety of individual and contextual factors influence academic dishonesty, which is consistent with previous research they cited.

Cheating can be localized with an individual or program area, or it can be widespread across a campus. Kerkvliet and Sigmund (1999) explored the determinants of class-specific cheating, including student characteristics and activities and prevention methods. In this estimation study, they hypothesized that prevention measures are not effective and that teachers have little choice but to accept that cheating will happen in the classroom. After computing descriptive statistics and using randomized response survey data, Kerkvliet and Sigmund found a student's GPA and year in school to be determiners of their likelihood of cheating, but gender and study time were not. Nearly one-third of the students reported that faculty serving as instructors and proctors were more likely to prevent cheating rather than graduate teaching assistants serving in those roles. They also found that there is an $M=13 \%$ chance of a student cheating in a specific class, and this ranged from a $.2 \%$ chance to a $32 \%$ chance depending on the deterrents used by faculty. Kerkvliet and Sigmund rejected their hypothesis that prevention methods do not work but found that neither non-multiple choice tests nor increased physical space between test takers would discourage students from trying to cheat. However, simply announcing that being honest is a part of the test did seem to decrease cheating by $12 \%$, and giving more than one version of an exam decreased the likelihood of cheating by $25 \%$.

These final two findings are of interest to the current study. Although instructors of online courses have the option of requiring proctored exams (indeed, some institutions require such), many assessments are given with no proctor or a non-attentive proctor present, as in Leming (1980), to act as a deterrent to cheating. Luckily, today's course 
management software makes the issues of announcing expectations and multiple versions of tests simple. For an instructor to insert a question into any test or quiz that asks students if they will be honest on the assessment or to include an honesty stipulation in the instructions is not difficult. Likewise, the testing mechanism in most course management systems makes multiple or unique tests for each class, or even each student, as easy as a few clicks of the mouse if the teacher is willing to spend the time entering multiple questions to diversify the pool of questions. Hence, both of Kerkvliet and Sigmund's final findings are notable ways in which to decrease the problem of cheating in online learning.

Looking toward other predictors of cheating, Jordan (2001) investigated motivation, peer social norms, student attitudes and student familiarity with institutional policy and how those variables related to cheating behaviors among college students. Of interest to the current study is that Jordan also connected these factors to actual cheating frequencies in the multiple courses that students took during the semester of the survey's administration. Using multiple instruments to obtain data on cheating rates, motivation, perceived social normal, attitudes, and knowledge of the school's honor system, Jordan used ANOVA, correlation, and principal component extraction (PCA) with varimax rotation to analyze the data.

As a result of responding as either having cheated or not, Jordan (2001) coded each subject as a "cheater" or "non-cheater" and reported all findings in this manner. As such, $54.9 \%$ of respondents became known as "cheaters," leaving $45.1 \%$ as "noncheaters." Of particular interest to the current study, analysis of background variables did not show any relationship of cheater status based on program of study, gender, or GPA. 
Jordan also found that the mean cheating score for Year 1 students was significantly higher than the means for Year 3 or Year 4 students, but there was no significant difference for the Year 2 mean, and Year 3 and 4 were not significantly different from one another. Further analysis showed that all factors were significant predictors of cheating, with knowledge of the honor system, mastery motivation, and attitudes toward cheating being the strongest.

Jordan (2001) also compared motivation scores for cheaters and non-cheaters. Because cheaters may differ in their motivation level in courses in which they cheat as compared to courses in which they do not and as compared to non-cheaters, Jordan compared the groups on mastery and extrinsic motivation. For mastery motivation, cheaters scored significantly lower, and extrinsic motivation scores were significantly higher for cheaters. In analyzing each type of motivation, with non-cheaters and those who cheated in every course excluded from the analyses, mastery motivation scores ranked significantly higher in the courses in which cheaters did not cheat than in those in which they did. Extrinsic motivation scores were significantly higher in courses in which cheaters cheated than in those where they did not cheat. Lastly, Jordan compared cheaters to non-cheaters in the courses where the former did not cheat across the motivation variables, but neither analysis was significant.

However, Jordan (2001) found a difference in perceptions of how much others cheat between cheaters and non-cheaters. Participants estimated what percentage of the student body at their college cheated. As predicted, cheaters' estimates were significantly higher than non-cheaters'. The participants' cheating scores also correlated with their percentage estimates, so not only did cheaters believe that more people cheated than what 
non-cheaters believed, but the more someone cheated, the higher that student's estimate of peer cheating was. How much a participant had seen cheating influenced that person's cheating, with $70.8 \%$ of cheaters reporting such compared to $40.5 \%$ of non-cheaters. Additionally, cheating scores were significantly higher for those who saw cheating firsthand compared to scores of those who did not.

When Jordan (2001) examined the data on knowledge of the college honor code, he found that cheaters and non-cheaters reported a difference in their understanding, with non-cheaters reporting more understanding the cheaters. This was not due to not being exposed to the honor code, as $95 \%$ reported they had received information about the code, $73.1 \%$ stated they had read it, and $86.3 \%$ stated the code was fair. Only $40 \%$ believed that signing the code had any impact on cheating levels, and $37.1 \%$ were unsure if the code had a positive effect.

Last, only $10.8 \%$ of participants reported that cheating was "sometimes justified in college," and as an example of when cheating was not justified, $85 \%$ felt cheating not to be justified when a friend asked for help (Jordan, 2001). Cheaters and non-cheaters differed significantly on these types of items. Cheaters were more likely than noncheaters to justify cheating. Of all variables, Jordan found that knowledge of the honor code was the best predictor of cheating, followed by motivation and attitudes about cheating.

Jordan's (2001) findings shared anonymously collected data on what motivates students to cheat but did not ask students for reasoning behind those behaviors. Due to the many ethics scandals in the business world, Chapman et al. (2004) examined the impact of several situational and individual difference variables associated with academic 
dishonesty. First, Chapman et al. held two discussion groups and queried the students about their attitudes toward cheating, why they did it, how it could be decreased, and how honest they would be when completing research surveys about cheating. Information from the students during these sessions shaped the survey used in the study. The students had clear ideas of what they considered cheating and not cheating and showed a clear knowledge of two types of cheating: self-interest (getting a better grade for oneself) and social-interest (helping a friend get a better grade, which they did not consider to be immoral). When asked about how they would respond to cheating-study questionnaires, students said they would be honest if the results would not be used to create stronger anticheating policies at the school; sharing how the data would be used would help to increase honest answers.

After the discussion groups, Chapman et al. (2004) created a four-part questionnaire that asked about students' attitudes and behaviors toward seven cheating situations, what they would do in four different cheating scenarios, how they would rank belief statements about cheating, and demographic questions. Data analysis by simple frequencies showed that most students (more than $85 \%$ ) felt that six of the seven situations presented to them in the survey represented cheating. Nearly $75 \%$ reported cheating in some way based on the given definition of cheating, and $11 \%$ of students reported cheating "a lot" in at least one category. When queried about intentions to cheat, $68 \%$ said they had cheated in the past, and $75 \%$ would do it again. When asked about cheating with a friend, reported numbers were high for those who would (75\%), but when asked about doing so with an acquaintance, the numbers dropped greatly (45\%). Of interest to the current study is that despite the newness of Web-based testing at the time 
of Chapman et al.'s study, $24 \%$ of students reported having already cheated in this setting, and a further $42 \%$ said they would cheat in a Web-based exam if given the chance.

In congruence with previous research (e.g., Jordan, 2001), Chapman et al. (2004) found that the phenomenon of peer perception is common regarding cheating. For instance, while only $26 \%$ of students reported having stolen an exam, $92 \%$ expected their peers to have done so. Further analysis revealed that on average, students imagined their peers cheated at a rate four times greater than their own, and students who cheated regularly believed that their peers also cheated at the same levels.

In looking toward specific predictor variables, analysis of data concerning cheating based on student major, analysis showed that only marketing students accounted for a significant finding. Because of this, Chapman et al. (2004) created a new variable of marketing students compared to all other business students and found that the former had a significantly higher cheating score than the latter. Chapman et al. concluded that their study showed that, like previous research, most students will cheat at some point despite knowing it is wrong because of the benefits cheating can offer them. They also found that students do fall prey to peer perception and that marketing students cheat more than other business students, though they were not able to determine why.

Also focusing on discipline-specific groups were Passow et al. (2006), who sought to understand the factors that explain the cheating behaviors of undergraduate engineering students on exams and homework assignments using Ajzen's Theory of Planned Behaviors as their theoretical backdrop. Passow et al. created eight "blocks" of variables for this study: (a) demographics, (b) pre-college cheating behavior, (c) co- 
curricular participation, (d) moral obligation not to cheat, (e) attitudes about cheating, (f) evaluation of the costs and benefits of cheating, $(\mathrm{g})$ perceived social pressures to cheat or not to cheat, and (h) perceived effectiveness of cheating policies. They addressed three questions: (a) Which of the constructs represented by the five blocks of variables predict the frequency of cheating on an exam? (b) Which predict cheating on homework? and (c) Among engineering students, what are the differences in the predictive power of the constructs for cheating on homework and exams?

Participants completed a 7-page, 139-item survey in 7 parts that addressed definitions of cheating; attitudes, beliefs, and situational factors that might affect a student's decision to cheat or not; deterrents to cheating and students perceptions of their effectiveness; and demographics (Passow et al., 2006). The researchers conducted descriptive and exploratory analyses on the items, which when summed and standardized comprised the two dependent variables. To reduce the number of independent variables, the researchers conducted factor analyses and used loadings with a score of at least .69 or higher to develop summated scales, with Cronbach's $\alpha=.69$ to .95 . The researchers used hierarchical multiple regression analyses to see how the eight blocks of variables worked to predict the two dependent variables. Below is a discussion of findings of interest to the current study.

Passow et al. (2006) found that five of the eight blocks contributed significantly to cheating on exams: pre-college cheating, co-curricular involvement, moral obligations, attitudes, and evaluation of the costs and benefits of cheating. Of the demographic data collected, only students in their fifth year (or more) reached significance and showed they were more likely to report cheating on exams than first-year students. Also, fourth-year 
students reported being more likely to cheat on exams in college than first-year students after adding pre-college cheating to the model. Students who participated in Greek life were more likely to cheat on an exam, findings later corroborated by Williams and Janosik (2007). Students who believed cheating to be morally wrong were less likely to cheat on an exam. Students who would cheat to get out of stressful situations were more likely to cheat on tests.

Three of the eight variables (demographics, moral obligations, and perceived effectiveness of policies) contributed significantly to explaining the variance in cheating on homework (Passow et al, 2006). The data revealed that students with higher GPAs were less likely to report cheating on homework. Students who reported cheating as "wrong" were less likely to report cheating on homework, and when considering schoolyear, second-year students were more likely to report cheating on homework than firstyear students. However, GPA stopped being significant with this variable. Students who agreed that they would cheat to alleviate a stressful situation and students who believed that academic honesty policies deterred cheating were more likely to report cheating on homework. These findings clearly demonstrate that correlates of cheating vary by the type of assessment given and that the type of student to report cheating can be predicted using certain variables, as well.

Sometimes personality traits can predict the likelihood of cheating. De Bruin and Rudnick (2007) used the Basic Traits Inventory to examine how conscientiousness, excitement seeking, and self-reported planned cheating related to one another to better understand why students cheated. They hypothesized that participants who reported high levels of conscientiousness would have a significant negative relationship to cheating, but 
those who reported high on excitement seeking scale items would show a significant positive relationship toward academic dishonesty. They assessed cheating with one question that asked how often, approximately, participants had engaged in planned cheating on tests or exams, with answers recorded as ordinal data. The researchers analyzed the data using descriptive statistics and ANOVA.

When examining the data for conscientiousness and excitement seeking traits as they related to reported cheating, the data revealed that when excitement seeking was high, conscientiousness was low, and cheating was high (DeBruin \& Rudnick, 2007). The inverse was also true: when conscientiousness was high, excitement seeking was low, and cheating was low. Post hoc Tukey tests showed statistically significant differences between the no cheating and limited cheating groups, as well as between the no cheating and more cheating groups, but not between limited and more cheating groups. Overall, the results of the study agreed with their hypotheses.

Besides to personality characteristics, demographic variables, and program of study, involvement with an extracurricular group or even just intent to become involved can be a predictor of cheating behaviors. Williams and Janosik (2007) used a survey to examine attitudes and behaviors toward academic dishonesty among four groups of undergraduate women who were involved in or interested in being involved in Greek life.

Data analysis by ANOVA revealed women with an interest in Greek life and Greek women were more likely to participate in cheating behaviors than non-Greek and non-interested women (Williams \& Janosik, 2007). Analysis also revealed that incoming women with no interest and upper-class unaffiliated women were less likely to cheat. Upper-class sorority women reported significantly higher rates of cheating than non- 
affiliated women, and incoming women with an interest in Greek life reported the most cheating of the four groups.

Analysis of the responses about attitudes toward academic dishonesty revealed that the lower the mean score reported, the lower the group's perception of the severity of the cheating behavior (Williams \& Janosik, 2007). The scores of Greek women and women interested in affiliating suggested these groups were less likely to believe the items on the scale were not cheating or were minor forms of academic dishonesty. On the other hand, women with no interest and non-affiliated upper-class women rated higher, indicating that the items on the scale rated as moderate to serious academic offenses.

Williams and Janosik's (2007) findings support ideas in the literature that students who have prior cheating experiences carry those into college with them, just as Harding et al. (2004) and Passow et al. (2006) reported. They suggested that the findings reflect that when students involve themselves in extracurricular activities, there is less time to study or prepare for class, and hence more cheating behaviors occur. As students come to college after having been highly involved in high school, the researchers expect the rates of academic dishonesty will increase. The researchers further suggest that their findings show that on average, each group found most examples of academic dishonesty on the scale to be "moderate" cheating, and considering this may help campuses find solutions for the problem of cheating in college. Williams and Janosik (2007) suggest that encouraging students to be more responsible for and to "take ownership" of their work might instill a greater sense of ethics within them, which may reduce cheating behaviors and ideas about academic dishonesty and enforce the ideas of the Commission on the 
Reorganization of Secondary Education (Bureau of Education, 1928) and the American Council on Education's Student Personnel Point of View (1937). Type of School and Its Influence

Sometimes predictors can be found outside the person of a student and instead as a component of the type of institution in which a student is enrolled. Smyth and Davis (2003) examined cheating at a public community college. For this comparative study, they hypothesized that major and cheating level are not related in community college students. The researchers administered a survey and then analyzed data using two-tailed independent $t$ tests to look for differences between demographic groups (independent variables) and cheating (dependent variable) and Levene's $F$ test for each demographic variable. They also used chi-square tests to look for independence between major and the variable measuring student attitudes toward cheating.

Most of the participants--61.4\%--reported noticing less cheating in college than high school (Smyth \& Davis, 2003). While $82 \%$ reported witnessing cheating while in college, only $43.2 \%$ of this took place in a classroom setting. Fewer than half admitted cheating in college at least once, and there was no significant difference for cheating between freshmen and sophomores, on- or off-campus residents, or full- or part-time students, but gender was significant, with men cheating more than women.

While $66 \%$ of students in Smyth and Davis's (2003) study stated they had been asked to cheat, only $24 \%$ admitted that they would help another student do so, with a significant difference between full- and part-time students being asked (full-time students reported this more). Most participants reported cheating to be ethically wrong, but $45 \%$ stated that it is socially acceptable. Smyth and Davis found a significant difference 
between off-campus students and on-campus students with these two variables; $95 \%$ of off-campus students found cheating wrong compared to $85 \%$ of on-campus, and $41 \%$ of off-campus students found cheating to be socially acceptable compared to $55 \%$ of oncampus students. Predictably, $58 \%$ of cheaters believed cheating to be socially acceptable as compared to only $34 \%$ of non-cheaters.

Smyth and Davis (2003) found that business students, just as in studies on fouryear colleges and graduate schools, admitted to cheating more than other students. After comparing to prior literature, Smyth and Davis found all of these findings suggest that community college students are cheating at the same rates as their four-year college counterparts.

Unlike Smyth and Davis (2003), who found no real difference in cheating rates between four-year and two-year college students, other researchers have suggested predicting cheating by the type of school a student attends might be possible. Brown and Choong (2003) compared the academic dishonesty levels among business administration majors at a state university and a private Catholic university. Based on prior literature, they posited that no differences would exist between the two groups and offered five hypotheses that there would be no differences in the following: (a) levels of participation in the cheating practices queried, (b) the types of students who were likely to participate in academic dishonesty, (c) the frequency of academic dishonesty, (d) the reported ethical levels, or (e) the reasons for academic dishonesty. Junior and senior students in various business classes at two universities completed an amended form of Brown's (1995, as cited in Brown \& Choong, 2003) questionnaire that queried thoughts on and practices of academic dishonesty. The researchers used chi-square tests to analyze the data. 
Brown and Choong (2003) found that public school students were more likely to have someone review a paper before its submission and more likely to work with others on an individualized school project, and private school students were more likely to copy from another student's exam. Overall rates of participating in academic dishonesty were $97.5 \%$ for the public school and $95.1 \%$ for the private. In keeping with prior findings, male students were more likely to commit academic dishonesty than female students, and those with lower GPAs were more likely to cheat.

When Brown and Choong (2003) examined the likelihood of cheating as it related to class rank, they found that seniors were slightly more likely in the private sample while juniors were more likely in the public sample. In all, the findings were consistent with prior studies cited by Brown and Choong with results showing that little to no differences exist between public and private, religious-affiliated schools in their cheating levels and reasoning.

\section{Program of Study as a Predictor}

Sometimes scholars wish to examine a characteristic other than a personality trait or predisposition in a study regarding cheating, such as the type of school that subjects attend, or their chosen area of study. In a correlation study, Brown (1996) compared responses to an academic ethics survey given to graduate students in business, education, and engineering at a graduate-only college. The survey asked participants how likely they would be to participate in the certain cheating activities. The instrument also asked students to rate the ethical level of the behavior of graduate students compared to undergraduates on a 5-point scale. Brown analyzed the data by computing means and chisquare tests for significance of variations in scores between schools and used ANOVA to 
test variations in school means on the 5-point rating scales for significance. When he found significant differences, he also ran Tukey tests.

Brown (1996) found that education students $(85.7 \%)$ reported more than infrequent participation in at least one unethical practice, which was higher than both business (81.2\%) and engineering (80.2\%) students but did not reach a level of significance; this did not correlate with prior research Brown cited, which showed business undergraduates to be the least ethical. The practices ranked the most unethical by students in all three schools were the following (in order): (a) copying off another's exam, (b) passing answers during an exam, (c) turning in someone else's work as one's own, and (d) letting others see test answers; however, none of these ratings was statistically significant. The students ranked those four behaviors as those in which they participated the least, as well. Considered least unethical by students at all three schools was having someone look over a paper before its due date, likely because students are taught in entry-level college English courses that peer-review is an important part of the composition process.

When asked about reasons for acting unethically, students again answered similarly (Brown, 2006). Education students were more likely than engineering students to do so "to get a high grade" and were more likely than engineering or business students to do behave dishonestly because of peer pressure. Results also showed that students generally wanted good grades but did not want to study for them, and they felt that no one suffered for their cheating. Lastly, when asked about the ethics of graduate students as compared to undergraduates, all three groups rated graduate students' ethical behavior 
much higher than undergraduates; however, the actual rates of unethical behavior in both groups were similar.

In continuing an examination of prior literature that focused on program of study as a predictor variable, Iyer and Eastman (2006) tested 17 hypotheses in hopes of describing characteristics of the academically dishonest student and whether or not business students differed from other types of students in cheating practices. McCabe and Trevino's (1993, as cited in Iyer \& Eastman, 2006) academic dishonesty scale and Brown (1996, 2000, as cited in Iyer \& Eastman, 2006) and Kidwell et al. (2003, as cited in Iyer \& Eastman, 2006) supplied items for an instrument that gathered data on the use of technology. First, the researchers ran independent samples $t$ tests. Then, Iyer and Eastman (2006) used two-way ANOVA to compare variables reported in the literature that affected the cheating of business students and compared these to the reported cheating of non-business students. Results of the 11 hypotheses of interest to the current study are discussed here.

Contrary to other studies cited thus far, Iyer and Eastman (2006) found that nonbusiness students engaged in more cheating than business students, men reported higher levels of academic dishonesty than women, and Greek students reported more cheating than non-Greek students, which supports the findings of Williams and Janosik (2007). The data showed no evidence that differences exist between cheating reported by juniors and seniors or by freshmen and sophomores or that there were differences between students with lower and higher GPAs regarding reported cheating behaviors. Last, Iyer and Eastman found no significant difference between students who were less innovative with their use of technology and those who were more innovative. 
Only employment and innovation significantly affected cheating behaviors for business and non-business students (Iyer \& Eastman, 2006). Business students who are more innovative in their use of technology reported engaging in more cheating behaviors than non-business students. None of the variables of year in college, gender, GPA, or Greek involvement were significant. A comparison of the main effects of these variables showed the main effect of the students' major was significant; non-business students' year in school, gender, and Greek status may have the biggest impact on their levels of cheating as compared to business students. The mean for business students was higher than non-business students only for GPA, which suggested that business students engaged in more cheating than non-business students when considering students' GPAs. Continuing an examination of the link between program of study and academic dishonesty, Rakovski and Levy (2007) queried business students' attitudes and behaviors toward cheating. They investigated four hypotheses. Of interest to the current study was their final hypothesis: the researchers expected differences in cheating levels across demographic variables. After collecting data via a survey, Rakovski and Levy calculated sample means and correlations and used factor analysis to group similar responses about severity of cheating behaviors to make a scale with which students could be classified according to cheating behavior.

Analysis of demographics showed management and accounting majors to be significantly different from all other students, with management majors being more dishonest and accounting majors being more honest (Rakovski \& Levy, 2007). They found no significant difference due to individual undergraduate class level, but when they grouped freshmen and sophomores and compared them to juniors and seniors as a group, 
the latter was significantly more dishonest. Men engaged in more cheating than women, and students with higher GPAs were less likely to cheat.

Studies Where Students Were "Caught" Cheating

The studies previously discussed examined data collected from students about their attitudes and behaviors. Other studies have collected information from students who were actually caught in the act of cheating. An analysis of these studies follows.

Flynn, Reichard, and Slane (1987) investigated "Machiavellianism" and academic dishonesty, but of interest to the current study is that during this study, Flynn et al. "caught" students cheating in a face-to-face class to give the literature an "actual" cheating rate as opposed to reliance on self-reports of cheating. The current study is similar in that it endeavors to do so in an online environment. The test booklet used in this test contained the actual test, a dummy test, NCR paper (pressure sensitive), the dummy test answers, and a blank sheet. Seals held each section of the test in place to prevent participants from looking through the test booklets. Flynn et al. told the participants that the book beyond the test to be taken contained Parts 2 and 3 of the experiment. Instructions informed all participants that the average score was 20 , and the researchers told the avoidance group that scores of 20 or better would allow them to move to Part 3 , but if they scored below 20 , they must take another version of the test. A score of 20 could not be achieved without cheating. Flynn et al. told the attainment group that if they scored a 20 or above on Part 2, they could leave the test and omit Part 3.

Once instructions were clear, subjects had 10 minutes to take the test (Flynn et al., 1987). Upon completion, they removed their answer sheets and self-graded them using the answer key. The researchers determined cheating by stray marks on the pressure 
sensitive paper that did not occur on the answer sheet and answers on the answer sheet that did not occur on the pressure sensitive paper. When participants had completed the grading, the experimenters told them that the test was actually about motivations and test taking behavior but did not tell them that measuring cheating was part of the experiment, as well. Flynn et al. found that participants were more likely to cheat under the avoidance motivation. These findings show the importance of considering motivation as a way of determining if cheating will occur, as participants motivated to avoid more work were more likely to cheat in order to achieve that avoidance.

Like Flynn et al. (1987), Ward and Beck's (1990) study also measured actual cheating. They examined neutralization theory through the relationship between excusemaking tendencies and actual cheating, while controlling for gender, which is of interest to the current study, and they also "caught" students cheating, again supplying actual cheating rates rather than relying on self-reported data. First, students completed a questionnaire that included a "techniques of neutralization" scale and demographic information. Eight weeks later, the same students took a multiple choice exam, which the researchers then photocopied and marked but handed back the originals to the students and asked them to self-grade them. A research assistant, to maintain the anonymity of the participants, then computed score differences between the actual graded exam and the self-graded exams. Analysis of the data by descriptive statistics and regression revealed that $28.1 \%$ cheated on the midterm exam that the researchers allowed them to self-grade. Of the men who rated low on the neutralization scale, $39.29 \%$ cheated compared to $10 \%$ of women, and of the men who rated high, $37.5 \%$ cheated compared to $41.18 \%$ of women who rated high. These findings corroborated their hypothesis that cheating among women 
was highly related to excuse making (the more a woman makes excuses, the more likely she is to cheat), and cheating among men was fairly independent of neutralizing tendencies. Ward and Beck then analyzed cheating by the frequency of cheating opportunities used. After this additional analysis, Ward and Beck believed that the cheating in the study represented a single cheating event rather than a pattern of cheating. Conclusion

As Whitley (1998) found, approximately $70.4 \%$ of students across all studies he reviewed admitted to cheating in their classes, and Chapman et al. (2004) found that $42 \%$ of those who cheat would do so again. Background variables such as age, gender, GPA, year in school, motivations, extracurricular involvements, program of study, personality traits, and attitudes toward cheating can all be predictors of cheating as well (for instance, Chapman et al., 2004; McCabe \& Trevino, 1997; Whitley, 1998). However, other studies produce conflicting results on the influence of gender, GPA, program of study, and year in school on academic dishonesty (for instance, Whitley, 1998; Leming, 2001).

\section{Student and Faculty Attitudes toward Cheating}

How students and faculty feel about cheating can sometimes predict it. How faculty and institutions handle instances of and work to prevent cheating can also act as a predictor of academic dishonesty. The following studies present findings on these ideas.

\section{Student Attitudes}

Most research on cheating is survey by method, but Ashworth and Bannister (1997) took a qualitative approach to the subject by clarifying the meaning of "cheating" through students' eyes to see how students perceive the issue of cheating in the context of their experiences in post-secondary education. They used data from $N=19$ unique and 
informal interviews conducted by graduate students enrolled in a qualitative research course to gather data; they analyzed it using the constant comparative method. Findings revealed three common themes: (a) cheating and plagiarism, (b) personal reactions to cheating, and (c) the role of the institution in combating cheating. The participants Ashworth and Bannister interviewed felt that cheating and plagiarism were moral issues, but the participants felt that what the institution considered to be cheating or plagiarism was not necessarily appropriate. Sometimes, they reported, it was hard to tell what was or was not plagiarism or cheating. Examples of this also can be found in Brown (1996) and Brown and Choong (2003), where students did not consider having a paper reviewed before its submission as cheating. This is understandable considering freshman composition courses generally teach peer review as an integral part of the composing process. When asked about their attitudes toward cheating, participants shared that judging those who cheat was not fair, as no one but the cheaters know why they cheat, and they could have good reasons for doing so. Participants stated they felt cheating on exams to be more severe than other forms of cheating; they regarded cheating on lowerlevel coursework as much less serious.

As for why they cheated, participants reported that they did so for many reasons-laziness, lack of preparation time for assignments and exams, lack of interest in the subject matter, and even rebellion (Ashworth \& Banister, 1997). Some also stated that though they knew cheating to be morally wrong, they felt it justified because they must remain competitive in today's competitive society. Other reported contributors to cheating included poor assessment formats, the environment of the institution, poor 
resources and teaching, and that the work being asked of them did not seem to have any greater or lasting significance.

Additionally, participants reported reasons they would not cheat, which included self-respect and being able to find other ways to complete the assigned work (Ashworth \& Banister, 1997). Nonetheless, when they did cheat, they said that they had to consider if there would be a "victim" of their immorality. If the participants knew the "victim," they were less likely to cheat than if they did not. One participant reported he had stolen work from someone he did not know to copy it, but he admitted he could not do the same to someone he knew. The same participant also said that if a teacher put obvious effort into a lesson or unit, he was less likely to cheat because he knew that the faculty member valued that information and wanted the students to value it, too.

When the conversations turned to perceptions of how the institution handled cheating, participants claimed to have had little to no education of what plagiarism was or what would happen if they did it (Ashworth \& Banister, 1997). Their student handbooks contained only small two- to three-line blurbs about the topic, and they were vague. Participants also felt that if someone did not know the penalties for cheating or what counted as cheating, surely that was a difficult problem to adjudicate. They also thought that judicial proceedings should take into account a student's record, or lack thereof, when someone caught a student cheating. Some participants even reported the university itself to be at fault for students' cheating since some behaviors that tutors and teachers actively endorsed and encouraged were cheating by the school's definition. Indeed, the question of what is considered by an institution to be cheating varies, as seen in Brown (1996) and Brown and Choong (2003), and can be problematic. Because the policy on 
cheating was vague, the policy and included definition themselves were thereby possibly contributing to cheating, as well.

Participants also shared that varying types of assignments, various subjects, and various settings all contributed to cheating (Ashworth \& Banister, 1997). Tests where participants had only a pencil, paper, and a table were far more difficult to cheat on than tests that might be stolen or passed down through the years or essays assigned term after term. In science classes, facts rather than ideas or interpretation are of interest, participants said, and that made cheating in science classes easier. Group work also provided more opportunities for cheating, as most tutors never checked to make sure each member worked equally as hard or submitted work he or she actually did.

Ashworth and Bannister (1997) felt that students would not cheat when they felt it affected other students or when they were taught by tutors who showed that they put hard work into their teaching and expected the same from their students. Students also appreciated an exam format that did not make cheating easy: no opportunity to cheat meant no temptation to cheat. Last, if schools wanted to be serious about cheating, they needed to work harder at defining and consistently enforcing their plagiarism and cheating policies.

Student understanding of what "cheating" is. As suggested by Ashworth and Bannister (1997), perhaps students cheat because they are not aware that they are cheating. Roig's (1997) purpose was to determine college students' ability to identify plagiarized work and to gauge their comprehension of plagiarism. He did this in two studies, reported together here. For the studies, he created the PKS--Plagiarism Knowledge Survey--which presented an original paragraph and 10 variations, of which 
only 2 were paraphrased correctly. Subjects were to identify plagiarized passages, those not plagiarized, or those that were indeterminate. He then calculated percentages of how many students were correct in their assessments.

For the first study, most of the participants could identify the two correctly paraphrased paragraphs (Roig, 1997). Despite this, nearly half the participants incorrectly identified plagiarized paragraphs as correctly paraphrased. These findings indicated that students are not completely sure of how to correctly modify a text to avoid plagiarism or when a citation is needed. For Study 2, Roig added an instructional sheet to clarify what "correct" and "plagiarized" paragraphs might be. Similar to Study 1, participants correctly identified the two correct versions of the original paragraph. Results of two questions showed that $36 \%$ of participants admitted to plagiarizing, and $3 \%$ reported being caught doing so. Roig felt the most significant finding of the two studies was that the data suggested that many students do not understand the need for complete and correct citations in their work.

Other than a lack of comprehension of the nuances of cheating and plagiarism, what else might contribute to student cheating? Love and Simmons (1998) wanted to discover and describe the factors that influence graduate students in a college of education to cheat and plagiarize. While the current study focuses on undergraduate student behaviors, previous research (e.g., Brown, 1996) has shown that undergraduates and graduates behave in comparable ways regarding cheating. Love and Simmons (1998) conducted $N=6$ interviews and used Guba and Lincoln's (1989, as cited in Love \& Simmons, 1998) constructivist inquiry method to separately analyze the data to enhance authenticity of the analysis. 
Love and Simmons (1998) found that the students' clear understanding of cheating and plagiarism arose from the interviews. However, the students either were not aware of or did not consider some practices commonly viewed as cheating to be cheating, such as submitting the same paper for more than one class, also known as self-plagiarism, or collaborating on individually assigned work. They also viewed plagiarism as a subset of cheating behaviors, and one participant pointed out that students know when they cheat but may not be aware that they plagiarize. Each participant admitted to being aware of other students' cheating. Two participants admitted to activities that are cheating, but they did not see as such.

Data analysis revealed to Love and Simmons (1998) many factors that contributed to students' cheating and plagiarism activities. Seven internal inhibiting factors arose from the data, five of which were positive (personal confidence, positive professional ethics, fairness to authors, the desire to work or learn, and fairness to others), and two of which were negative (fear and guilt). The data also revealed six external inhibiting factors (professor's knowledge, risk of being caught, time pressure, the danger of cheating, type of work required, and need for the knowledge in future). Love and Simmons identified five sets of factors that contributed to the likelihood of cheating. External factors were pressure (grade pressure, time pressure, and task pressure) and professors. Internal factors were negative personal attitudes, lack of awareness, and lack of competence.

Pickard (2006) aimed to produce evidence of, to raise awareness of, and to encourage debate about the pedagogical issues associated with plagiarism. She sought to address four matters, only two of which were of interest to the current study: (a) the differences in understanding of plagiarism between staff and students, and (b) the 
differences in perception of plagiarism between staff and students. Though she claimed to use a mixed-methodology of survey and interviews, only percentages of each item's answers are given, and sparse interview information is given in segments of quotations that support the questionnaire data.

In analyzing the data, Pickard (2006) found that more teaching staff than students believed plagiarism to be a greater problem, and she reported that in interviews students shared an "everyone does it" attitude. When questioned about actual detection of plagiarism, $72 \%$ of staff members reported doing so in the past year. These findings support Roig's (1997) findings in that if students do not fully understand what plagiarism is, how can they see it to be as great a problem as their instructors do?

\section{Conclusion}

Multiple studies (e.g., Ashworth \& Banister, 1997; Love \& Simmons, 1998; Roig, 1997) show that part of the problem of academic dishonesty among college students is due to a lack of understanding about what constitutes cheating, and they do not consider some activities to be cheating, which corroborate Brown's (1996) findings. Love and Simmons (1998) also reported that students cheat because they feel various pressures to succeed and do not always possess the capabilities to do so on their own in an honest and ethical manner, but inversely, personal ethics and a healthy self-confidence keep them from cheating, as well. Adding to these reasons for and against cheating by students were the findings of Ashworth and Banisher (1997), who reported students would not cheat if they felt there was a "victim" of their cheating, if there was an alternative way to achieve the grades they desired, or if instructors had put obvious effort into their lessons. When Pickard (2006) compared students' and faculty members' attitudes toward academic 
dishonesty, and as one might predict, faculty members found cheating to be much more serious an issue in higher education than students reported it to be.

Effects of Policy on Academic Dishonesty

In recent years, there has been a debate concerning whether or not honor codes can or do influence the rate of cheating on college campuses. The discussion below covers studies that have addressed honesty statements, honor codes, and other policies designed to curb students' urges to engage in academic dishonesty.

Brown and Howell (2001) investigated what can be done to combat plagiarism by examining the efficacy of statements about academic fraud. In their experiment, they compared the effect of two statements and responses to a questionnaire about plagiarism. The researchers created three different groups and gave each separate material: educational information on plagiarism, information of warning about plagiarism, and no information at all. Of interest to the current study was that the instrument queried how seriously the participant viewed plagiarism: how seriously the participant thought plagiarism would be viewed by staff, how frequently the participant thought plagiarism occurred, how well the student understood plagiarism, and how well the participant thought other students avoided plagiarism. The researchers used repeated measures ANOVA to analyze the data using Type III sums of squares because the three groups' sizes were not equivalent. Because the researchers predicted that ratings of severity of plagiarism might be related to frequency estimates or understanding of plagiarism, they examined these relationships using the non-parametric Spearman's rank correlation. Analysis showed only the educational passage affected responses. Participants who read the warning statement responded no differently than those who read no 
statement. Those who read the educational statement considered plagiarism as more serious than the other conditions and reported the same in their view of staff. Those who read the educational material also reported lower frequency estimates of plagiarism than those in the other groups. In all conditions, participants considered copying material verbatim more serious an offense than unacknowledged paraphrasing and in their perceptions of the views of staff. Participants thought that verbatim copying happened less often than unacknowledged paraphrasing.

Also considering how policy might influence cheating, McCabe, Trevino, and Butterfield (2002) examined the effect of modified honor codes on collegiate cheating as compared to traditional honor code and a lack of an honor code. They compared the data for this study to data from previous studies by McCabe and Trevino $(1993,1999)$ and used descriptive statistics, intercorrelations, regression, and $t$ tests to analyze the data on its own. Of great interest to the researchers was the finding that cheating levels at schools with modified codes showed an intermediate value between traditional and no code schools. A $t$ test showed that cheating at modified code schools was significantly greater than at schools with traditional codes, and cheating is lower at modified code schools than at schools with no code. The perception of peers' behavior made the most significant contribution to the regression models, which suggested the strong role of this variable in understanding why students cheat. The perceived certainty of being reported was also significant under all three honor code conditions.

When an institution-wide policy may not be in place, or when a policy may not be strong enough to suit members of faculty, individual instructors may take policy matters into their own hands. Levy and Rakovski (2006) wished to determine how students would 
react to a professor with zero tolerance for cheating. They hypothesized that a professor's high expectations regarding honest behavior would attract honest students and deter dishonest students. They queried participants via survey about penalties for cheating, the dishonesty of different acts, the dishonest behavior of students, students' reactions to different professors, and demographic data. Participants also answered questions regarding a professor who takes the college's academic honesty policy seriously and has in the past filed reports about incidents compared to a professor who has a zero tolerance policy and issues course grades of $\mathrm{F}$ for any dishonest act.

Levy and Rakovski (2006) computed responses about the zero tolerance professor according to the students' reactions to the other professor and to their cheating behavior. They used a logistic regression model to examine what kinds of students would avoid a class with the zero tolerance professor. Findings were consistent with previous studies. Participants felt penalties should be severe for not citing Internet sources, but conversely, among other behaviors, using an Internet source with citing received one of the lowest ratings as to how dishonest the behavior was. Concerning frequency of cheating, participants reported copying from the Internet without citing the source among the most frequently engaged in behaviors. Findings on frequency of cheating behaviors were also consistent with previous studies.

When asked about their perceptions about their own honesty, most participants rated themselves very honest or honest and thought that others considered them very honest (Levy \& Rakovski, 2006). Only a nominal amount considered themselves or thought others considered them very dishonest. When examining how the participants would respond to a zero tolerance professor, Levy and Rakovski found that most 
participants thought that honest students would be indifferent in their selection of professor. However, $10.6 \%$ of participants who responded to that question changed their response to indicate that honest students would avoid or avoid at all costs the zero tolerance professor, which suggests a professor may lose about $10 \%$ of honest students by taking a zero tolerance stance. The data suggested that professors who take a zero tolerance stance will deter most dishonest students from registering for their classes if not keep them from registering completely as the "avoid at all costs" responses suggest. When asked to respond with what they themselves would do regarding the two professors, most responded that they were "indifferent" to the professors (Levy \& Rakovski, 2006). The data suggested $15.3 \%$ who were indifferent about the other professor would avoid or avoid at all costs the zero tolerance professor, and $7 \%$ of those who would register for the other professor would avoid the zero tolerance professor at all costs. In all, $13 \%$ of all respondents would try to avoid the zero tolerance professor because of his/her attitude toward academic dishonesty when compared to the other professor. In examining the $13 \%$ who would avoid at all costs, Levy and Rakovski found them to be more likely to be young and dishonest, with the young group being four times more likely to avoid the zero tolerance professor. The most dishonest participants were three times more likely to withdraw from the course than the most honest participants. The researchers did not find any significant differences by gender or domestic vs. international student status. Overall, professors who adopt zero tolerance policies concerning academic honesty may find nearly one-third of the most dishonest students avoiding enrollment in their classes. 


\section{Conclusion}

The literature does support that policies against cheating, be they institutionally issued or stated by a single professor, will deter students from acting dishonestly. Brown and Howell (2001) found that giving an educational statement about plagiarism to students in institutional materials was more effective than a warning statement or no statement at all in preventing students from cheating and in guiding their attitudes about plagiarism and cheating. McCabe, Trevino, and Butterfield's (2002) data supported the idea that both modified and traditional honor codes can lead to a decrease in cheating, with traditional honor codes being more influential, and Levy and Rakovski (2006) discovered that a single professor's zero-tolerance policy can prevent dishonest students from even enrolling in a course.

\section{Cheating in Online Learning}

To turn the focus more toward cheating in online learning, the researcher examined several studies that specifically targeted the topic of academic dishonesty in online classes. Kennedy et al. (2000) explored student and faculty views about cheating and distance learning courses by collecting data via a survey and then performing chisquare analysis. Faculty responses regarding whether cheating would be worse in online courses revealed that the distribution of responses was related significantly to the sex of the respondent. When examined in the light of faculty who had actually taught an online course, the genders divided equally on whether online classes would promote more cheating. When asked about methods to cheat, faculty members felt that: (a) someone else would do the work, (b) methods used in a regular classroom would still be used, and (c) students would get papers off the Internet. Regarding methods to counteract cheating, 
faculty members felt that certain techniques would help: (a) supervised, on-site final exams that counted for most of the course grade, (b) new assignments each term, (c) personalized assignments and verification software, (d) open-book, practical application exams, and (e) required interaction with the instructor.

Kennedy et al. (2000) examined student responses, which revealed five important findings. First, faculty and students were similar in their perception of the ease of cheating in online classes (faculty $=64 \%$, students $=57 \%$ ). Students felt that whether cheating was easier in an online class depended upon whether or not they had taken an online class before. Nevertheless, both genders felt cheating was easier there than in a regular class. The distribution of seniors and graduate students who felt cheating was easier differed significantly. Finally, whether participants had cheated in school or not was not related to their perception of how easy cheating in an online course was. In all conditions, Most of the students felt cheating was easier in online classes.

With students using the Internet more each year to do research for coursework, examining its effects on cheating is important, as well. Underwood and Szabo (2003) investigated the willful involvement of students in cheating practices related to the Internet. They hoped to identify predictive characteristics of students who would cheat using the Internet, including students' perceptions of their peers' cheating behaviors and their instructor's responses to cheating behaviors, Internet use and experience, and gender. They developed and used the Cheat QTR scale to collect data.

Correlations showed that as students progressed through their studies, their level of familiarity with the Internet, their Internet use, and their use of the Internet for assignments all increased (Underwood \& Szabo, 2003). While there was no effect of 
gender for familiarity, the data showed a positive correlation between use of information from the Internet for assignments and gender, with women reporting more Internet use than men. There was a negative correlation between gender and acceptance of cheating as a way to keep from failing an assignment. Men reported being more likely than women to do such. Women also reported that no matter how bad the situation, $60 \%$ would "never" cheat, while only $35 \%$ of men reported the same.

Underwood and Szabo (2003) found a positive correlation when they asked students to consider the risks of cheating, such as their instructors being able to catch them cheating because of the instructors' expertise in using the Internet. Women feared this more than men. However, $60 \%$ of students reported being unable to assess if their instructors would police cheating behaviors. The longer a student was at the university, the more likely the student was to perceive inappropriate use of the Internet by their peers, with students in the third year reporting that they would feel guilty if they cheated. The data showed a positive correlation between gender and guilt, with women stating they would feel more guilt than men. Further, $62 \%$ reported they would feel guilty about cheating, yet $18 \%$ would have no problem with it.

Underwood and Szabo (2003) determined the extent to which the measures of experience, acceptability of cheating, and considerations of risk predicted a student's acceptance of cheating. How often a student used the Internet to do assignments predicted the most common form of cheating (copying source material without documentation). They also determined that the assessment of risk/the cost-benefit analysis, perceived peer cheating levels, level of personal guilt, and gender predicted if a student would cheat by using the Internet to avoid failing an assignment. Additionally, self-reported level of guilt 
predicted situations in which the participant found cheating to be acceptable, and the data also indicated that a student's anticipated guilt predicted if the student would tell others about having cheated. While the study upheld previous findings that men cheat more and showed this is true for cheating with the Internet, Underwood and Szabo's data showed that women used the Internet more and were more adamant about not cheating.

Because of a concern that students misused information technology to aid in the completion of assignments, Etter et al. (2006) conducted two studies. The purpose of Study 1 was to develop a list of technology-assisted cheating behaviors, and the purpose of Study 2 was to test the generalizability of Study 1 by giving the same questionnaire to a second group of students plus a tool to measure participants' personality traits concerning ethical behavior. Of interest to the current study was only their first question: What methods do students currently use to cheat with technology? While none of the activities in Etter et al.'s instrument would be applicable to the instrument used in the current study, the behaviors queried to show that students are aware of many different ways in which technology can be used to cheat.

In Study 1, Etter et al. (2006) assembled two focus groups and asked them what types of IT sources they used to complete assignments and which they considered cheating if they used them. Then, students in a computing course took a survey developed by using the results of the study group to gain their perceptions of the same subjects. In Study 2, participants answered the same instrument as the Study 1 students did as well as Forsyth's (1980, as cited in Etter et al., 2006) Ethical Position Questionnaire and two subscales of Zuckerman's (1979, as cited in Etter et al., 2006) Sensation-Seeking Scale. For both studies, Etter et al. also asked participants to give their year in school, their field 
of study and program, gender, year of birth, and opinions on how much they used certain IT-based applications. The researchers used descriptive statistics, ANOVAs, and chisquare tests to analyze the data.

In both studies, of the academically dishonest behaviors rated, turning in a purchased paper rated highest, but for Study 1, using software to manipulate the length of a paper rated lowest, while for Study 2, using a program from the Internet to complete an assignment (i.e., translation software) rated lowest (Etter et al., 2006). Students from Study 1, all of whom attended a church-affiliated school, consistently rated activities on Etter et al.'s instrument to be more serious than the students in Study 2, who attended a public university. This is contrary to the findings of Brown and Choong (2003), whose data showed no differences between students at public and private, religious-affiliated schools.

Grijalva et al. (2006) examined cheating behaviors in online courses. They used a survey to query students in both online and face-to-face courses to help give validity to the online sample's results. The researcher will also take this step in the current study. The face-to-face students showed nearly identical behavior to that reported by the online participants. After using logistical regression for data analysis, Grijalva et al. reported the rate of self-reported cheating to be approximately $3 \%$. Grijalva et al. found that being aware of others cheating in a class increased the likelihood of a student's cheating in that same class, with having better grades being inversely related to cheating activities. Grijalva et al. stated that these findings are similar to those of studies of students in traditional classrooms (e.g., Kerkvliet \& Sigmund, 1999; McCabe \& Trevino, 1997). 
Continuing to examine the literature on predictors of cheating in online classes, Lanier (2006) conducted his study to determine whether previous studies on academic dishonesty could be used to accurately predict who might cheat in online classes. He collected data on both traditional lecture courses and online courses through surveys and focus groups and compared results. Lanier performed descriptive statistics, regression, correlations, and multivariate analysis in his analysis of the data. Nearly $60 \%(58.9 \%)$ of students reported "never" cheating in online classes, with a substantially higher report of 78.7\% "never" cheating in traditional classes. In support of prior studies concerning cheating in online courses, Lanier found that men reported cheating more than women, and only $25 \%$ of married students reported cheating compared to $42 \%$ of single students. Students with GPAs of 2.0 were most likely to cheat, and those with GPAs of 3.0 were close behind, which corroborated previous research cited by Lanier. Students who reported being business majors had the highest incidence of cheating in online courses $(47.1 \%)$, followed by hard sciences $(42.6 \%)$, social sciences $(30 \%)$, and medicalprofessions (18.8\%), again agreeing with prior studies. Graduate students were least likely to cheat in online classes $(17.8 \%)$, with freshmen $(29.6 \%)$, seniors $(42.4 \%)$, sophomores $(42.4 \%)$, and juniors $(43.8 \%)$ rounding out the category.

In analyzing demographic data for lecture classes, Lanier (2006) found that nearly one-quarter of the men reported cheating (23.6\%) compared to only $19.4 \%$ of the women, which follows previous findings. Only $11.4 \%$ of married students reported cheating, compared to $22 \%$ of single students, and using GPA to determine the likelihood for cheating in a lecture class was identical in rank order to the online class findings. Education majors were more likely to cheat in traditional courses $(30.4 \%)$ than those in 
hard sciences $(28.3 \%)$, business $(25.6 \%)$, social sciences $(18.1 \%)$ and medical students $(25 \%)$. Concerning class standing, graduate students $(7.7 \%)$ were again the least likely to cheat with seniors $(15.1 \%)$, juniors, $(22.3 \%)$, freshmen $(28.9 \%)$, and sophomores $(29.4 \%)$ reporting more cheating behaviors in traditional classrooms.

Age, gender, class standing, GPA, marital status and major/program of study all had significant correlations with cheating in lecture courses. Findings suggested older students, women, and those with higher class standing and GPA were all less likely to admit cheating, and single students were more likely to report it. Older students and those with higher GPAs were not as likely to cheat in online classes, and single students were. Those who admitted to cheating in lecture classes were more likely to cheat in online classes, as well.

Lanier (2006) found that students with higher GPAs were not as likely to cheat in lecture classes, and social science majors reported less cheating than non-social science majors. Students who were in higher class standings also reported less cheating, as did older students. In online classes, Lanier found that like lecture courses, students with higher GPAs, who are older, and who are women are less likely to cheat than men. However, social science majors are more likely to cheat in online classes. This is the opposite of what was found for lecture classes. Single students also reported being more likely to cheat, but neither of the final two findings was significant.

\section{Conclusion}

In focusing on studies that referenced cheating in online classes, the literature revealed that Kennedy et al. (2000) found that students reported they would use the same methods to cheat in online classes as they would in face-to-face classes, though Etter et 
al. (2006) found using technology to manipulate the length of a paper to be the most common form of academic dishonesty in online classes. Kennedy et al's (2000) findings suggested that instructor involvement or participation in online classes might decrease cheating in courses conducted via that medium, similar to Ashworth and Banister's (1997) finding for face-to-face classes. Kennedy et al. (2000) also reported both faculty and students to believe cheating in online classes would be easy, and Grijalva et al. (2006) found that the myth of peer perception holds true regarding cheating for online students just as just like McCabe, Trevino, and Butterfield (2002) found peer perception to influence those enrolled in face-to-face classes: students who think their peers are cheating in online classes are more likely to cheat in online classes themselves.

Underwood and Szabo (2003) examined who is most likely to cheat in online classes and found that while women will use technology more often, men still report cheating more; Lanier's (2006) findings corroborated this idea about men. Lanier also found for online classes, as Brown and Choong (2003) found for face-to-face classes, juniors with lower GPAs will cheat more. Contrary to Brown (2006) and Iyer and Eastman (2006), whose findings suggested that business students do not cheat more than non-business students in face-to-face classes, Lanier's (2006) data supported the idea that business students cheat more than other majors in online classes.

\section{Conclusion}

Educators and administrators should work to find ways to decrease incidents of academic dishonesty in higher education. Research by Brown and Howell (2001); McCabe, Trevino, and Butterfield, (2002); and Levy and Rakovski (2006) showed that there is a clear correlation between student cheating and policy, either institutionally or 
individually created, but such policy cannot be fully effective if the causes of cheating and knowing who is likely to cheat are not well-understood. Studies show that many students may not necessarily even understand what cheating is, as supported by multiple studies (Ashworth \& Banister, 1997; Love \& Simmons, 1998; Roig, 1997), but with proper education, this can change.

While findings on what type of student-male or female, younger or older, business or non-business major, Greek or independent—have been corroborated and rebuked time and again (e. g., Chapman et al., 2004; Leming, 2001; McCabe \& Trevino, 1997; Whitley, 1998), most studies cover traditional, brick and mortar, face-to-face classes. Only a handful of studies (e.g., Etter et al., 2006; Grijalva et al., 2006; Kennedy et al., 2000; Lanier, 2006; Underwood \& Szabo, 2003) have investigated the same for online classes. Even fewer studies (e.g., Flynn, Reichard, \& Slane, 1987; Ward \& Beck, 1990) have reported actual, rather than self-reported, cheating rates that can help those who must craft policy to erase doubts of social desirability answers and instead focus on who really is cheating and why.

The time has come that educators and administrators finally fulfill the goals of the Commission on the Reorganization of Secondary Education's Cardinal Principles of Secondary Education (Bureau of Education, 1928) and the American Council on Education's (1937) Student Personnel Point of View. The National Leadership Council's (2007) LEAP report updated and reiterated these two older documents and still considers ethics education a pressing need for undergraduates today. Institutions of higher education should work to provide the workforce with more honest and ethical employees, something the National Leadership Council's (2008) LEAP report says that $56 \%$ of 
employers desire (p. 11). Because of an apparent link between dishonesty in academia and in the workplace (Harding et al., 2004; Nonis and Swift, 2001; Sims, 1993), the literature should include more research into cheating in online learning. With such information, educators and administrators may work together to identify students who may be prone to such behavior and to create more effective policies to curb further occurrences of academic dishonesty both in their traditional face-to-face and their online courses, which should, in turn, benefit society by leading to a decrease of unethical behavior in the workforce. 


\section{CHAPTER III}

\section{METHODS}

This mixed-methods study explored academic dishonesty in online learning. A mixed methods study is one that utilizes both qualitative and quantitative design methods (Caracelli \& Green, 1997; Mark \& Shotland, 1987; Tashakkori \& Teddlie, 1998). The researcher chose such an approach to gain not only a quantitative perspective on students' attitudes toward cheating behaviors but to solicit qualitative responses as to their individual reasoning on certain issues concerning academic dishonesty, as well. Because of the importance of institutions of higher education graduating persons of good character who will be citizens positively contributing to their communities, educators and administrators should understand the potential for, causes of, and student reasoning for cheating in online learning. This chapter fully details the methods and procedures utilized in this study.

\section{Purpose of Study}

The purpose of this study was to determine if online and face-to-face students have the same attitudes about cheating, the accuracy of undergraduates' self-reports of cheating, and if the same types of undergraduate students report cheating in online classes as in prior studies of face-to-face classes.

\section{Research Questions}

1. Do undergraduates in online classes report the same attitudes toward cheating as undergraduates $\mathrm{n}$ face-to-face classes? 
2. How accurately do undergraduates in online classes report their cheating in online classes?

3. What background variables are associated with undergraduates' cheating behaviors in online classes?

\section{Hypotheses}

- $\mathrm{H}_{1}$ : Online students will not report the same attitudes toward cheating as students in face-to-face classes.

- $\mathrm{H}_{2}$ : Students will not accurately report their cheating in online classes.

- $\mathrm{H}_{3}$ : Male students will cheat more than female students in online classes.

- $\mathrm{H}_{4}$ : Business students will cheat more than all other students in online classes.

- $\mathrm{H}_{5}$ : Greek students will cheat more than non-involved students in online classes.

- $\mathrm{H}_{6}$ : Students with lower GPAs will cheat more than other students in online classes.

\section{Participants}

To obtain a representative sample for the current study, the researcher utilized a convenience sample of students enrolled in both traditional and online undergraduate general education English classes and those enrolled in various general education courses offered online at a regional, comprehensive four-year university in the mid-southern United States. The study used English classes because the institution requires two of the three of them of all degree-seeking students for general education. Due to this, the courses have a good cross-representation of students in them. A convenience sample is acceptable in a study such as this where a random sample may not allow for gathering of 
information from all selected participants, whereas those who choose to participate are more likely to complete the study (Thomas, 2003).

\section{Prior Exposure to Research Personnel}

Because the researcher is a faculty member at the institution and within a department from which she collected data, some students may have been exposed to her through prior enrollment in her courses. However, to protect participant anonymity, the researcher used none of her own current courses in the sample and assured prior students of their anonymity through the consent process.

\section{Sampling Frame}

The sampling frame for this study consisted of all face-to-face sections of three general education English courses (ENG 1XX, ENG 2XX, and ENG 3XX) that the institution offered in the spring 2010 semester ( $n=152$ sections) as well as all online sections of general education courses offered across the institution during that same semester $(n=61)$. The researcher excluded two online sections of ENG $3 X X$ because she was the instructor of record for those courses and did not wish her students to feel compelled to participate.

This study included all face-to-face sections of the three English courses in the sampling frame with the hopes of achieving a demographically representative sample of students in the study since all students are required to enroll in general education courses, with two of the three English courses being required of all students. Despite this requirement, some students may opt to take the CLEP examination in place of ENG $1 \mathrm{XX}$, hence excluding a few of potential participants, and students scoring higher than a 26 in 
English on the ACT may not be required to take ENG $1 \mathrm{XX}$ and instead opt for credit to be given for the course.

In selecting online courses for inclusion in the sampling frame, the researcher decided to broaden the scope of which courses to include because of the limited number of online offerings of the English courses. Therefore, the researcher included in the sampling frame all online sections of general education courses offered during the term of the study.

\section{Sample Selection}

The researcher obtained from the institution a listing of all sections, both face-toface and online, of general education courses offered during the spring 2010 semester. The researcher then contacted instructors of the sections by email to request that they allow their course sections to participate in the study (Appendix K). Because the study took place entirely online, no classes forfeited instruction time. The researcher then sent an email to all instructors who consented that they could then forward to their students in each class or post on Blackboard as an Announcement; the email contained a link to the instrument (Appendix L). One week after the start of the study, the researcher sent a second email reminder to the instructors to pass on to students to encourage any students who had not yet participated in the study but wanted to participate to do so (Appendix M). This second email emphasized the chance at the $\$ 400$ incentive.

Response Rate

Of the $n=213$ courses invited to participate in this study, instructors of $n=53$ consented to sending out the invitation and reminder emails to their students. There were 
$n=1,317$ possible participants in these courses, $n=858$ of which were face-to-face students, and $n=459$ of which were online students.

In total, $n=112$ students participated in the study; however, $n=1$ asked for his/her data to be withdrawn, which resulted in $n=111$ as the total number of participants who submitted data for analysis. This was a response rate of $8 \%$. Of the responders, $n=$ 32 were face-to-face students, for a face-to-face response rate of $4 \%$, and $n=79$ were online students, for an online response rate of $17 \%$.

\section{Procedures and Research Materials}

A mixed methods study can use both qualitative and quantitative methods concurrently or successively (Morse, 1991; Tashakkori \& Teddlie, 1998); this study used them concurrently. The discussion below details this concurrent use.

Before data collection, the researcher created and placed dummy information on the Web about an invented, original topic: Hymenosaurus Rex, a fictional one-hit-wonder band from the 1970s (Appendix A). The researcher placed this material on the Internet well ahead of data collection in order to allow search engines to index said information. The researcher also included meta tags in the Web page's design to increase chances of indexing.

In this study, the researcher collected data from two groups: students enrolled in traditional, face-to-face courses, and students enrolled in online courses. Participants consented to a study on the efficacy of testing formats in online learning rather than the study's true focus of academic dishonesty. This study utilized deception in this manner due to the sensitivity of the topic. As previously discussed, Sales and Folkman (2000) stated that due to the sensitivity of the true purpose of some studies, the researcher should 
not fully disclose the actual reasoning for the research to participants until after the completion of data collection to "preserve the validity of the data collected" (p. 42). Cheating is one such sensitive subject and one that also lends itself to social desirability bias (as noted by Whitley, 1998), where participants may feel inclined to answer in a way that presents them most favorably to researchers rather than being honest (Groves et al., 2004). Such answers could confound results should the researcher not take steps to prevent them (Sales \& Folkman, 2000). Therefore, since the researcher placed the participants in this study where they might have chosen to cheat and then asked them to admit to such behavior, deception of participants to preserve the integrity of the data was warranted.

After their consent to a study concerning online testing formats (not the actual study topic), the participants completed a reading quiz over the dummy information placed on the Internet and an amended form of Underwood and Szabo's (2003) Cheat QTR that queried background variables, participants' attitudes toward online learning and cheating behaviors, and whether or not the participants had just cheated on the reading quiz (Appendix B). To mimic the drive to achieve a high grade as a student would wish to achieve in a real course, the researcher told participants that those with the highest scores on the reading quiz from each class would have the chance to enter a random drawing for an incentive, much like Leming (1980) did in his study to encourage better performance from his participants. However, all participants were equally eligible for the incentive for simply participating to avoid rewarding cheating behaviors and as a way of thanking all participants who took the time to participate, even if they did not submit their 
data. The researcher randomly awarded the incentive, a $\$ 400 \mathrm{Visa}$ gift card, after the close of data collection.

The researcher requested that instructors of the selected course sections who responded to the appeal to help with the study (Appendix K) link to the instrument in Blackboard on in an email to the class via the consent form (Appendix L), and the link transported participants to an off-Blackboard survey application (Easy Survey Package) to ensure anonymity. One week into the study period, the researcher asked faculty whose courses were participating in the study to forward or post the reminder email in (Appendix M). Participants first answered questions about the following background variables: type of course through which they accessed the study, name of the course through which they accessed the study, gender, age, academic year, major, GPA, relationship status, student status, campus location, financial support from parents/guardians, financial aid status, hours worked in a week, living arrangements, study time per week, citizenship status, and extra- and/or co-curricular involvement. These were Items 1-18 on the instrument (Appendix B).

Next, participants took an online "reading quiz" regarding the invented topic (Appendix C). The reading quiz consisted of reading a passage about the invented topic given at the top of the quiz and then answering 10 open-response questions, whose answers were unambiguously correct or incorrect, about that topic. Rather than containing the full-text of the dummy information placed on the Internet, the reading quiz contained only an excerpt and correctly cited a link to the full posting at the bottom of the excerpt as a matter of good practice. However, the directions instructed participants to use only the information from the excerpt. Participants could find answers to seven of the 
questions in the excerpt on the reading quiz, which students had access to throughout the test. Three of the items' answers, however, were only available via the full-text version placed on the Web by the researcher. The researcher carefully considered the wording of the questions and ensured that no context clues existed in the excerpt. To assess the "actual cheating" by participants, the only way the answers could be gained for the three items would be via the participants' using either the link on the excerpt to reach the full version or by participants searching the Web for the full version to find answers for the items not addressed in the excerpt on the reading quiz.

After finishing the reading quiz, participants completed an instrument on cheating behaviors, an amended form Underwood and Szabo's (2003) Cheat QTR questionnaire. Beyond the questions on cheating attitudes and behaviors, a single question queried if they cheated on the reading quiz. Finally, participants answered four open-ended questions generated on the basis that they self-reported cheating or did not and if they were online students or face-to-face students; finally, the instrument asked participants to define "cheating" and give examples of what they consider to be cheating (Appendix D). After participants completed all of the items on the instrument, the researcher debriefed them as to the true purpose of the study and reassured them of their anonymity prior to submitting their data (Appendix E). An item queried if participants wanted to have their answers deleted and to withdraw from the study, or if they wished for their data to be submitted for analysis. If participants selected that they wished to be withdrawn, they were asked to confirm this, if their background variable data only could be kept for analysis, and if they would share their reasoning for withdrawal. 
After completing the instrument and submitting their data, regardless of whether or not the participants allowed the researcher to keep their data for analysis, the survey software redirected participants to a second survey separate from their data that offered them the chance to enter in their university identification numbers for a chance to win the incentive. The separate collection of these numbers helped to preserve participants' anonymity; the researcher was not able to identify the names of participants while evaluating the reading quiz answers to determine if cheating took place or not, but yet the research was able to easily identify the single winner of the random drawing for notification. The researcher used a random number generator (www.random.org) to select the winner.

Instrument Used to Assess Cheating

Attitudes toward cheating. The current study measured attitudes toward cheating of participants using an amended form of Underwood and Szabo's (2003) Cheat QTR questionnaire with 11 of their original 15 questions (for the original document, see Appendix F) and supplemented it with 16 questions that queried specific attitudes and behaviors (Appendix G), many of which could be considered cheating. The researcher removed questions concerning mastery of the English language (which was of no interest to this study) and familiarity with the Internet (which had poor options) for this study, as well as questions on gender and academic standing, which she had already included as part of the background variables queried.

The researcher requested and received permission from Underwood and Szabo (2003) to utilize this instrument in the current study (Appendix H). However, they did not 
answer repeated requests for validity and reliability information. This information was not available in their 2003 report, either.

Accuracy of self-reported cheating in online learning. The current study measured the accuracy of self-reported cheating in online learning by comparing the number of correct answers to questions on the reading quiz that participants could only answer by cheating to participants" answers to the question, "Did you use any source other than the excerpt provided for you on the reading quiz that you took as part of this study?" on the amended Cheat QTR. Because of the phrasing of the open-ended questions and the lack of context clues within the excerpt, simply guessing the correct answers to the three questions that could not be answered by using only the excerpt on the quiz was highly unlikely if not impossible since the topic was an original, invented topic. With this in mind, any participant who gained the correct answer to any or all of the three questions whose answers could not be found in the excerpt on the amended Cheat QTR would have had to have accessed the full version of the Hymenosaurus Rex passage on the http://www.byzant.com/Wonders Web page.

Associations between background variables and cheating. The current study measured associations between background variables on cheating by computing correlations among the queried background variables and the actual rate of cheating. Appendix I contains a list of these questions.

\section{Data Analysis}

\section{Quantitative Analysis}

In this study, the researcher collected quantitative data because it gives "precise measurement and comparison of variables, identifying patterns and regularities that might 
not be apparent to the people in the settings studied, and making inferences from the sample to some population" (Maxwell \& Loomis, 2003, p. 253). The researcher chose to use a traditional .05 level of significance as the criterion necessary for establishing significance or lack thereof for the tested hypotheses (Dillman, 2006).

To determine if there was an association between a background variable and a participant's likelihood of cheating, the researcher utilized bivariate analysis and reported findings in Chapter 4. These bivariate tests provided information on the relationship between background variables and likelihood of cheating and actual cheating.

To determine if a combination of background variables might predict a participant's likelihood of cheating, the researcher planned to use multivariate analysis and report findings in Chapter 4. Factor analysis is a "large sample" test that requires a minimum of $n=300$ participants (Costellow \& Osborne, 2005), and reliable multiple regression models require $n=15$ for each predictor (Stevens, 1992). Additionally, Tabachnick and Fidel (1996) stated that $n=104$ plus the number of variables determines the minimum sample size for multivariate analysis. Because of the sample size $(n=111)$, the researcher was not able to complete multivariate analysis.

Qualitative Analysis

The researcher analyzed answers to the five open-ended questions asked at the end of the instrument using the constant comparative method, which allowed attention to be directed toward any categories that emerged through open, axial, and selective coding. The researcher divided each participant's answers into segments of meaning and transferred these to $3 \times 5$ cards. During open coding, the researcher made connections and found any relationships that existed in the data and assigned all carded data to a category 
or several categories (Creswell, 1998). Through axial coding, the researcher compiled these categories, clustered them through theoretical lineages, and reviewed them for emerging concepts, typifications, themes, and patterns (Creswell). Once these relationships emerge from the data, using selective coding, the researcher constructed a narrative that described the relationship (Creswell). Using the constant comparative method allowed findings to be grounded in the raw data (Creswell).

The answers to the open-ended questions hopefully revealed students' true thoughts on cheating, which allowed the researcher to have insight into what their conceptions of cheating are, why they engage in cheating behaviors if they do, how they see cheating occurring around them, how they cheat, and how to prevent cheating. Knowing answers to the open-ended questions may lead educators and administrators toward better programming and enforcement of rules concerning cheating.

Trustworthiness. To build trustworthiness and assure credibility of the findings, the researcher strove to see through the participants' eyes and to convey an understanding of their thoughts and ideas (Erlandson, Harris, Skipper, \& Allen, 1993). Authenticity should be evident since "naturalistic inquiry takes its strength from the separate realities that have been constructed by different individuals," in this case the participants who completed the open-ended questions (Erlandson et al., p. 151). Should the study be subjected to auditing, proper use of participants' statements should not be a matter of concern because care was taken to assure participant anonymity during the collection and analysis of the data, as well as accuracy in coding and completing the narrative in Chapter 4 (Erlandson et al.). 


\section{Design Limitations}

While the researcher deliberately chose general education courses for participation in this study, the researcher relied upon participants to self-select to complete the instruments used in the study and for instructors to pass on the information on how to participate. To encourage participation, the researcher did offer an incentive.

Some may argue that an incentive cannot be offered that will match the drive students have to achieve a good grade in an online course. The incentive offered was of a significant amount $(\$ 400)$ to encourage students to try their best to achieve the top grade on the quiz much like they might strive for an A grade in a course. Lastly, participants may not cheat on the quiz. Finding an answer to Research Question 2 relies upon sufficient numbers of students cheating.

Also of concern is that while the findings of this study may help to prevent cheating behaviors on college campuses and in the workplace, the researcher sampled only one institution. Due to this, findings may be limited to this region or this type of institution.

\section{Generalizability}

Sims (1993), Nonis and Swift (2001), and Harding (2004) all found a relationship between cheating in an academic setting and engaging in dishonest practices in the workplace. Because of this, the findings of this study may help to preclude such behaviors in future generations of both students and workers. However, as noted previously, the current study examined only one institution and students enrolled in general education courses within that institution, which may not be adequate to determine the prevalence of cheating in online courses in higher education. 


\section{CHAPTER IV}

\section{RESULTS}

The purpose of this study was to determine if online and face-to-face students have the same attitudes about cheating, the accuracy of undergraduates' self-reports of cheating, and if the same types of undergraduate students report cheating in online classes as in prior studies of face-to-face classes. The prior chapter discussed the methodology used to determine the answers to the research questions and hypotheses. This chapter examines findings from the statistical analysis of the instrument presented in Appendix B, which includes the amended Cheat QTR questionnaire (original is in Appendix F) and a reading quiz (Appendix C).

The first research question concerned whether undergraduates in online classes reported the same attitudes toward cheating as undergraduates in face-to-face classes. The second research question queried how accurately undergraduates in online classes reported their cheating in online classes. The third research questions investigated the associations between background variables and undergraduates' cheating behaviors in online classes. The researcher also posed six hypotheses:

- $\mathrm{H}_{1}$ : Online students will not report the same attitudes toward cheating as students in face-to-face classes.

- $\mathrm{H}_{2}$ : Students will not accurately report their cheating in online classes.

- $\mathrm{H}_{3}$ : Male students will cheat more than female students in online classes.

- $\mathrm{H}_{4}$ : Business students will cheat more than all other students in online classes. 
- $\mathrm{H}_{5}$ : Greek students will cheat more than non-involved students in online classes.

- $\mathrm{H}_{6}$ : Students with lower GPAs will cheat more than other students in online classes.

As mentioned in the previous chapter, $n=112$ persons from $n=53$ general education courses at a regional comprehensive public university agreed to participate in the study and submitted data. Each participant completed the instrument that collected demographic data, answers to a "reading quiz," and queried attitudes and behaviors concerning academically dishonest behaviors.

Additionally, the survey software used, Easy Survey Package, collected each participant's IP address, date participation, and time of participation; the methodologist removed IP address and time of participation before data analysis to protect the anonymity of participants. The researcher utilized the date of participation to help solve a matter regarding Research Question 2 that she discusses in this chapter and in Chapter 5. At the end of the instrument, only one participant requested that his/her data not be $\mathrm{kept} /$ analyzed, and as such, the methodologist removed that data from the data set before analysis for a final sample size of $n=111$.

\section{Descriptive Statistics of Background Variables}

Of the $n=111$ participants, $n=79(71.2 \%)$ were students in online classes, and $n$ $=32(28.8 \%)$ were students in face-to-face classes (Table 9). More than $77 \%$ were female $(n=86)$ (Table 10). Most of the students were traditionally aged (18-21 years old, $n=61$, or 55\%), with $n=33$ falling between the ages of $22-35(29.7 \%), n=10(9 \%)$ aged $36-45$, and $n=7(6.3 \%)$ of participants reporting an age of 46 or older (Table 11). Distribution among year in college was distributed as follows: $n=36(32.4 \%)$ freshmen, $n=28(25 \%)$ 
sophomores, $n=16(14.4 \%)$ juniors, $\mathrm{n}=25(22.5 \%)$ seniors, and $n=6(5.4 \%)$ in their fifth year of undergraduate education or beyond (Table 12). Most of the students reported GPAs above 2.51 on a 4.0 scale $(n=96,86.5 \%)$ (Table 13$)$ and as being full time students $(n=92,82.9 \%)$ (Table 14$)$ on the main campus of their school $(n=93,83.8 \%)$ (Table 15). The study habits of participants varied, with $n=1$ participant reporting not studying at all, $n=30(27 \%)$ logging fewer than 5 hours a week, $n=50(45 \%)$ studying 5-10 hours a week, $n=19(17.1 \%)$ studying $11-15$ hours a week, and $n=11(9.9 \%)$ studying more than 15 hours in a week (Table 16).

The researcher recoded participants' majors by college, as double majors across colleges, or undecided students. Represented most heavily was the College of Science and Engineering $(n=17)$, followed by the College of Education and Behavioral Sciences $(n=15)$, the College of Health and Human Services $(n=13)$, the College of Arts and Letters $(n=10)$, the University College and College of Business (each being $n=8$ ), double majors across colleges $(n=15)$, undecided $(n=3)$, and the Community College and Honors College (each with $n=1$ participant) (Table 17).

Concerning financial status, the data showed an even split of subjects who did ( $n$ $=55,49.5 \%)$ or did not $(n=56,50.5 \%)$ receive financial support from a parent or guardian (Table 18). Most of the participants reported receiving a loan to pay for college $(n=73,65.8 \%)$, with $43.2 \%$ reporting receiving grants $(n=48)$ and/or scholarships $(n=$ $39,35.1 \%) ; 14.4 \%$ of subjects $(n=16)$ received no financial assistance at all (Table 19$)$. Thus, it is not surprising to see that $2 / 3$ of the participants reported working, with $27 \%$ ( $n$ $=30$ ) spending 30 or more hours a week at work (Table 20). All but one participant reported to be an American citizen or legal resident $(n=110)$ (Table 21). Less than half 
of participants $(n=48,43.2 \%$ ) reported extra- or co-curricular involvement (Table 22 and Table 23). Most lived off campus, not with a parent or guardian ( $n=59,53.2 \%)$, with $29.7 \%$ living in a residence hall $(n=33)$ and $17.1 \%$ living off campus with a parent or guardian $(n=19)$ (Table 24). Most of the participants $(n=73,65.8 \%)$ reported being single, with $n=33,29.7 \%$ married or living with a partner, and $n=5(4.5 \%)$ divorced (Table 25).

Tables for the descriptive statistics of these background variables are located in Appendix $\mathrm{J}$.

\section{Research Question 1}

The first research question concerned whether undergraduates in online classes reported the same attitudes toward cheating as undergraduates in face-to-face classes. The first hypothesis predicted that online students would differ from face-to-face students in their attitudes toward cheating. Analysis of data via $t$-tests showed that across $n=16$ questions concerning cheating behaviors, there were no significant differences between online and face-to-face students when reporting their attitudes about how serious they considered a particular behavior to be. Participants rated the cheating behaviors as "I don't consider this cheating" (recoded for analysis to "0"), "not very serious" (recoded to "1"), "somewhat serious" (recoded to "2"), or "very serious" (recoded to "3"). The researcher, therefore, rejects $\mathrm{H}_{1}$ : online and face-to-face students reported the same attitudes toward cheating. 
Table 1

Attitudes Toward Cheating Behaviors

\begin{tabular}{lllll}
\hline Behavior & Student Type Mean & SD & $t(109)$ & $p$
\end{tabular}

Looking up information on the

Web to get help/answers

Texting to get help/answers

Emailing to get help/answers

Using social media to get help/ answers

Telling students in other classes test questions

Telling students in other classes test answers

Copying and pasting from the Web without citing/referencing

Having someone look over your paper for you before you submit

Using a paper for more than one class

Sharing homework answers

Purchasing a paper from a

Web site

Submitting another student's paper as your own with their permission

Submitting another student's paper as your own without their permission
Face to face $\quad 2.3750 \quad .75134$

Online $\quad 2.4810 \quad .69542$

$0.711 \quad .470$

Face to face $\quad 2.7813 \quad .42001$

Online

$2.7342 \quad .44459$

$0.513 \quad .609$

Face to face $2.5625 \quad .75935$

Online

2.6582

.59670

$-0.706 \quad .482$

Face to face $2.5625 \quad .65991$

Online

2.6582

.59670

$-0.258 \quad .797$

Face to face $2.4063 \quad .79755$

Online

2.6582

.59670

$-1.822 \quad .071$

Face to face

2.8125

.47093

Online

2.8734

.33463

$-0.768 \quad .444$

Face to face $2.8750 \quad .33601$

Online

2.9241

.31100

$-0.735 \quad .464$

Face to face $\quad 0.3750$

.65991

Online

0.5063

.73158

$-0.880$

Face to face $\quad 1.4375 \quad 1.07576$

Online

1.5823

$\begin{array}{lll}1.15034 & -0.612 & .542\end{array}$

Face to face $\quad 1.7813 \quad 1.03906$

Online

1.9241

$\begin{array}{lll}0.87372 & -0.738 & .462\end{array}$

Face to face

2.9063

0.29614

Online

2.9367

0.29727

$-0.495 \quad .622$

Face to face $2.7813 \quad 0.55267$

Online 2.8987

$\begin{array}{lll}0.30361 & -1.434 & .154\end{array}$

Face to face 3.0000

$0.00000^{\mathrm{a}}$

Online

3.0000

$0.00000^{\mathrm{a}}$ 


\begin{tabular}{|c|c|c|c|c|c|}
\hline $\begin{array}{l}\text { Collaborating with others on } \\
\text { individually assigned work }\end{array}$ & $\begin{array}{l}\text { Face to face } \\
\text { Online }\end{array}$ & $\begin{array}{l}1.2500 \\
1.6203\end{array}$ & $\begin{array}{l}0.95038 \\
1.00389\end{array}$ & -1.787 & .077 \\
\hline $\begin{array}{l}\text { Doing less than your share of work } \\
\text { on a group assignment }\end{array}$ & $\begin{array}{l}\text { Face to face } \\
\text { Online }\end{array}$ & $\begin{array}{l}2.1563 \\
2.3038\end{array}$ & $\begin{array}{l}0.72332 \\
0.73997\end{array}$ & -0.958 & .340 \\
\hline $\begin{array}{l}\text { Using a program to manipulate } \\
\text { the length of a paper }\end{array}$ & $\begin{array}{l}\text { Face to face } \\
\text { Online }\end{array}$ & $\begin{array}{l}2.1875 \\
2.1519\end{array}$ & $\begin{array}{l}0.69270 \\
0.75258\end{array}$ & 0.231 & .818 \\
\hline
\end{tabular}

a. $t$ cannot be computed because the standard deviations of both groups are 0 .

\section{Research Question 2}

The second research question queried how accurately undergraduates in online classes reported their cheating in online classes. Hypothesis 2 posited that students would not accurately report their cheating in online classes. In this study, the researcher labeled any participant a "cheater" if he/she was able to answer any or all of three questions on the reading quiz: "Who was the drummer for the band," "In the recording, what sounds are heard at the start of "It's All Good in the Rexosphere, Johnny'," and "Who did the Marlofes attempt to sue for playing Wagner's wedding march on the Flash Gordon soundtrack." Findings show that $n=15$ students cheated by gaining correct answers to one $(n=2)$, two $(n=4)$, or all three $(n=9)$ of these questions.

Table 2

Cheating Frequency by Class Type

\begin{tabular}{|c|c|c|c|c|}
\hline \multirow{2}{*}{\multicolumn{2}{|c|}{ Cheat Level }} & \multicolumn{2}{|c|}{ Class Type } & \multirow[b]{2}{*}{ Total } \\
\hline & & Face-to-Face & Online & \\
\hline \multirow[t]{2}{*}{0} & Count & 29 & 67 & 96 \\
\hline & $\%$ within class & $90.6 \%$ & $84.8 \%$ & $86.5 \%$ \\
\hline 1 & Count & 1 & 1 & 2 \\
\hline
\end{tabular}




\begin{tabular}{|c|c|c|c|c|}
\hline & $\%$ within class & $3.1 \%$ & $1.3 \%$ & $1.8 \%$ \\
\hline \multirow[t]{2}{*}{2} & Count & 1 & 3 & 4 \\
\hline & $\%$ within class & $3.1 \%$ & $3.8 \%$ & $3.6 \%$ \\
\hline \multirow[t]{2}{*}{3} & Count & 1 & 8 & 9 \\
\hline & $\%$ within class & $3.1 \%$ & $10.1 \%$ & $8.1 \%$ \\
\hline \multirow[t]{2}{*}{ Total } & Count & 32 & 79 & 111 \\
\hline & $\%$ within class & $100 \%$ & $100 \%$ & $100 \%$ \\
\hline
\end{tabular}

Table 3

Cheating Admission by Class Type

\begin{tabular}{lllll}
\hline Admit to Cheating & $\begin{array}{c}\text { Class Type } \\
\text { Face-to-Face }\end{array}$ & Online & Total \\
\hline No $\quad \begin{array}{lll}\text { Count } \\
\text { \% within class }\end{array}$ & 29 & 67 & 96 \\
& & $90.6 \%$ & $84.8 \%$ & $86.5 \%$ \\
Yes & $\begin{array}{l}\text { Count } \\
\text { \% within class }\end{array}$ & 3 & 12 & 15 \\
\multirow{2}{*}{ Total } & Count & $9.4 \%$ & $15.2 \%$ & $13.5 \%$ \\
& $\%$ within class & 32 & 79 & 111 \\
\hline
\end{tabular}

Of the $n=15$, only $n=11$ of the cheaters reported their cheating (73.3\%), and $n=$ 4 non-cheaters reported cheating. Therefore, in Table 3 , apparently all $n=15$ cheaters reported their cheating, though they did not. The researcher discusses this finding in Chapter 5, and Table 4, below, shows this. 
Table 4

Accuracy of Cheating Admission by Class Type

\begin{tabular}{lccc}
\hline Accuracy Level & $\begin{array}{c}\text { Class Type } \\
\text { Face-to-Face }\end{array}$ & Online & Total \\
\hline Did not cheat, did not admit & 28 & 64 & 92 \\
Did not cheat, did admit & 1 & 3 & 4 \\
Cheated, did admit & 2 & 9 & 11 \\
Cheated, did not admit & 1 & 3 & 4 \\
Total Cheaters & 3 & 12 & 15 \\
Total Non-Cheaters & 29 & 67 & 96 \\
\hline
\end{tabular}

In relation to Research Question 2 and Hypothesis 2, of the cheaters, $n=12$ were online students, and $n=3$ were face-to-face students, as seen in Table 4 above. Of the online cheaters, $n=9(75 \%)$ of the cheaters admitted to their cheating, and $n=3(25 \%)$ did not. Because there was no risk to participants for admitting their cheating in this study, the researcher expected everyone who cheated to admit that he/she did so. With this in mind, the researcher fails to reject $\mathrm{H}_{2}$ : students in online classes did not accurately report their cheating.

\section{Research Question 3}

The third and final research question investigated whether associations between the background variables and undergraduates' cheating behaviors in online classes existed. The researcher made four hypotheses concerning this question, each based on the variable's prevalence in prior literature: male students will cheat more than female students in online classes $\left(\mathrm{H}_{3}\right)$, business students will cheat more than all other students 
in online classes $\left(\mathrm{H}_{4}\right)$, Greek students will cheat more than non-involved students in online classes $\left(\mathrm{H}_{5}\right)$, and students with lower GPAs will cheat more than other students in online classes $\left(\mathrm{H}_{6}\right)$.

According to data analysis via $t$-tests, the researcher found no significant differences between cheaters and non-cheaters in online classes. Additionally, the researcher computed Pearson's correlations and found no significant associations between cheating behavior and background variables. Thus, the researcher rejected $\mathrm{H}_{3}$, $\mathrm{H}_{4}, \mathrm{H}_{5}$, and $\mathrm{H}_{6}$.

Table 5

Differences in Background Variables Among Online Students

\begin{tabular}{|c|c|c|c|c|c|}
\hline $\begin{array}{l}\text { Background } \\
\text { Variable }\end{array}$ & Cheating Status & Mean & $\mathrm{SD}$ & $t(77)$ & $p$ \\
\hline \multirow[t]{2}{*}{ Sex } & Non-cheaters & 0.7761 & 0.41999 & & \\
\hline & Cheaters & 0.7500 & 0.45227 & 0.196 & .845 \\
\hline \multirow[t]{2}{*}{ Age } & Non-cheaters & 2.23888 & 1.37168 & & \\
\hline & Cheaters & 1.8333 & 1.11464 & 0.967 & .337 \\
\hline \multirow[t]{2}{*}{ Class Year } & Non-cheaters & 2.6269 & 1.30077 & & \\
\hline & Cheaters & 2.2500 & 1.21543 & 0.933 & .354 \\
\hline \multirow[t]{2}{*}{ GPA } & Non-cheaters & 5.6716 & 1.34151 & & \\
\hline & Cheaters & 5.5000 & 1.44600 & 0.404 & .688 \\
\hline \multirow[t]{2}{*}{ Student Status } & Non-cheaters & 0.7761 & 0.41999 & & \\
\hline & Cheaters & 0.8333 & 0.38925 & -0.439 & .662 \\
\hline \multirow[t]{2}{*}{ Financial Aid } & Non-cheaters & 0.3881 & 0.49099 & & \\
\hline & Cheaters & 0.5833 & 0.51493 & -1.260 & .212 \\
\hline Parent/Guardian & Non-cheaters & 0.3881 & 0.49099 & & \\
\hline Financial Support & Cheaters & 0.5833 & 0.51493 & -1.260 & .212 \\
\hline Hours Worked & Non-cheaters & 2.1493 & 1.66291 & & \\
\hline
\end{tabular}




\begin{tabular}{llllll} 
& Cheaters & 1.7500 & 1.60255 & 0.770 & .444 \\
Living & Non-cheaters & 1.9701 & 0.60227 & 1.122 & .266 \\
Accommodations & $\begin{array}{l}\text { Cheaters } \\
\text { Involvement }\end{array}$ & 1.7500 & 0.75378 & & \\
& Non-cheaters & 0.4328 & 0.49921 & & \\
& Cheaters & 0.5833 & 0.51493 & -0.957 & .341 \\
Greek & Non-cheaters & 0.1045 & 0.30819 & & \\
& Cheaters & 0.0833 & 0.28868 & 0.231 & .820 \\
& & & & & \\
\hline
\end{tabular}

Table 6

Associations between Background Variables and Cheating in Online Students

\begin{tabular}{lll} 
Background Variable & Pearson's $r$ & Sig. (2-tailed) \\
\hline Cheating Level & 1.00 & \\
Cheating Admission & 0.635 & .000 \\
Gender & 0.002 & .986 \\
Age & -0.084 & .460 \\
Class Year & -0.089 & .434 \\
GPA & -0.069 & .546 \\
Student Status & 0.022 & .851 \\
Living Accommodations & -0.107 & .350 \\
Involvement & 0.076 & .505 \\
Greek & -0.050 & .663 \\
\hline
\end{tabular}




\section{Qualitative Data}

The researcher asked participants five open-ended questions that varied depending upon how they responded to questions about the type of class they were accessing the study through (face-to-face or online, Item 1) or if they self-reported as cheaters while in college (Item 46). For each question, the researcher used the constant comparative method, which allowed attention to be directed toward any categories that emerged through open, axial, and selective coding. The researcher divided each participant's answers into segments of meaning. During open coding, the researcher made connections and found any relationships that existed in the data and assigned all carded data to a category or several categories (Creswell, 1998). Through axial coding, the researcher compiled these categories, clustered them and reviewed them for emerging concepts, typifications, themes, and patterns (Creswell). Once these relationships emerged from the data, using selective coding, the researcher constructed a narrative that described the relationship (Creswell). Using the constant comparative method allowed findings to be grounded in the raw data (Creswell).

\section{Definitions of Cheating}

After answering all questions concerning background variables and their attitudes toward and practices of cheating behaviors, all participants responded to the question, "In your own words, how might students cheat? What 'counts' as cheating?" Analysis of $n=$ 111 answers revealed $n=110$ valid responses to the question and 10 themes that emerged from the data: basic dishonesty, dishonest behavior that gives an advantage, using others' work without permission or referencing, copying answers, collaborating when not 
allowed, cheat sheets, submitting another's work as your own, breaking rules and/or policies, using technology when not appropriate, and using other sources.

The researcher noted that $n=3$ responses did not fit into these categories but were worthy of reporting, nevertheless. One participant simply stated, "I think cheating is complicated to define," which is apparent in the varied answers received for this item. Another stated, "Cheating is being academically dishonest," which while vague is not inaccurate. Last, a third respondent shared that "cheating would be taking the easy way around things." These three answers sum up much of what was said by the other $n=107$ participants who completed this item.

Basic dishonesty. A little more than $10 \%$ of the answers $(n=11)$ at their core resonated the idea that cheating is simply not being honest. Some participants shared that cheating was "lying" or "doing anything dishonest" or "... wrong." Others were more specific and defined cheating as "getting a good grade in a dishonest manner" or "when you do something you wouldn't want anyone else to find out you did," hinting at guilt or shame being associated with such actions. Another shared that cheating behaviors are those that students know are "inappropriate," with one participant stating that he/she knows that cheating has taken place, "When I get a grade for work I did not do or obtain by my own honest merit." These answers are accurate, but they are not specific. Some participants were more specific in their reporting on other themes that emerged.

Dishonest behavior that gives an advantage. Six participants responded that cheating is any behavior that give an advantage that other students would not have, with $n$ $=4$ specifically using the word "advantage," and $n=3$ of those calling cheating an "unfair" advantage. One participant defined cheating as "using information for personal 
gain," and another shared that cheating is "anything done to obtain a grade that didn't involve your own knowledge or retrieval of the information due to studying." Another said that the advantage was only "unfair" if "prohibited by the teachers/professors that are teaching the material," suggesting that sometimes effort may account for an advantage, and that is not cheating.

\section{Using others' work without permission or referencing. Participants}

overwhelmingly defined cheating broadly to be using others' work without permission or referencing ( $n=68$ ), with $n=8$ of those respondents specifically citing plagiarism as the definition of or an example of a cheating behavior. Variations of this idea came most commonly as simply saying "using someone else's work" $(n=17)$. While $n=13$ shared that not citing information taken from other sources was cheating, and $n=8$ named plagiarism cheating, $n=1$ participant was adamant that "using someone's EXACT words as your own [is cheating]. Using someone's ideas is not cheating," which suggests the student may not completely understand what cheating, or plagiarism, is. Another participant suggested, "[W]hen more then [sic] 25 percent of something isn't your work" then a person has cheated, again showing room for improvement in educating students about what constitutes cheating.

Some responses indicated a narrower view of the definition of a cheating behavior. For example, $n=1$ participant stated, "anything that doesn't come out of your own head is cheating in my opinion," making the researcher wonder if citing a source would be cheating by such standards? Another stated that "turning in for a grade anything that would lead the instructor to believe that you know more than you really do" is cheating. Also cited as a definition of cheating was "any act of dishonesty in which you 
gave an answer to any proposed question that did not originate within your own mind or within resources you are allowed to use." Only $n=1$ participant defined cheating by saying what it is not: "I do not think it is cheating to look up information to help you learn. You go to the library to study, you use a dictionary to find the meanings of certain things... anything that will help you learn is not cheating [in those circumstances]." Copying answers. A dozen participants gave the example of copying from someone else, or getting answers from others, as how to define cheating. As for testing, $n$ $=6$ students specifically cited that "looking off someone's test" or "copying test answers" was cheating. Others were more broad $(n=6)$, not naming a test specifically but mentioning methods of cheating such as "copy[ing] from the student seated next to you" or "providing answers that are not your own."

Collaborating when not allowed. Several students considered working together in certain circumstances to be the definition of cheating. "Cheating' is basically using others' answers when you know you are not supposed to be working in groups," was one respondent's reply. Asking a student seated nearby for answers $(n=2)$ was another way that participants defined cheating. One participant suggested that "talking to other students about a test or quiz answers without studying myself just to hear their answers" was what cheating meant to him/her. Sharing answers $(n=3)$ was how some participants described cheating, while $n=1$ simply said, "Using ... friends for help" to get answers was cheating.

Cheat sheets. Cheat sheets are as old as cheating students, and today's students seem to still be using them, according to $n=6$ responses. Some responses referred to oldfashioned paper cheat sheets $(n=4)$, while others referred to more technologically savvy 
cheat sheets $(n=1)$. A single respondent suggested that cheating is "laying a paper out ... on another desk and using it," while another was more vague in stating that cheating is "using materials with the answers in them during a test."

Submitting another's work as your own. Many participants defined cheating as submitting papers not written by themselves $(n=5)$. However, as one participant shared, "having a peer look over your paper and giving you advice on it is not" cheating. Another looked away from papers and toward homework assignments, stating that cheating was "borrowing a homework assignment from a friend so you will get credit for the assignment."

Breaking rules and/or policies. Nearly $30 \%(n=31)$ of participants defined cheating as somehow breaking rules, avoiding policies, or ignoring instructions on assignments. Sometime this meant using sources or materials not allowed by the teacher $(n=19)$; another participant defined cheating as working collaboratively when asked to work alone $(n=1)$. One participant responded in all caps, "cheating is using outside sources for your own benefit when you are only supposed to be using information you already know," which is an example of not following the "rules" or "instructions" of the assignment $(n=5)$. The participants who felt this way about cheating repeated the words "permission" $(n=4)$, "permitted" $(n=2)$, "allowed" $(n=2)$, "forbidden" $(n=2)$, "prohibited" ( $n=3)$, "banned" $(n=2)$, and "disallowed" $(n=2)$ in their responses in reference to the types of sources, materials, and help teachers do or do not let them use. One participant suggested that individual instructors might define cheating for their classes: "Cheating is doing anything that the individual is aware the teacher would consider cheating for the assignment." 
Using technology when not appropriate. Becoming as popular as talking on a cell phone and texting on a cell phone is using this ubiquitous device to cheat. Participants cited texting to obtain answers as their definition of cheating $(n=7)$. Also mentioned were using the Internet $(n=5)$, email $(n=1)$, and social networking sites $(n=1)$.

Using other sources. Some participants had not yet ventured into using technology in their definition of cheating, and their thoughts on dishonest behavior reflected more traditional means. Books $(n=3)$ and notes $(n=2)$ used during tests or any other time when not permitted was how $n=4$ participants defined cheating.

\section{How Students Can Cheat in Online Classes}

The researcher asked participants who answered that they were online students on Item 1 of the questionnaire to respond to the question, "In an online class, how might students cheat? Can you give some examples?" Analysis of the $n=75$ valid responses resulted in the emergence of five themes: attitudes toward cheating in online classes, nontechnical methods, cheating using technology, collaborative methods of cheating, and the difficulty of cheating in online classes.

Attitudes toward cheating in online classes. One participant stated clearly that "it is easy to cheat in online classes," a sentiment echoed by another who said, "Their [sic] is no teacher to watch if they are cheating or not so they can use whatever resources they want to pass the class." A third student shared that one can use what one wants: "The only way it is cheating is if the teacher states that they did not want the students to do that." One respondent shared that he/she was not sure how to cheat in an online class because he/she had never thought of doing it. 
Cheating using non-technical methods. Many participants $(n=29)$ stated that a person could use the class textbook, use notes $(n=8)$, use "other course materials" ( $n=$ 7), or "look stuff up" $(n=2)$ when taking assessments. One student reported that a person could cheat "same as in class. Look up the answers..." Two participants specifically stated that a person could plagiarize, as well.

Cheating using technology. The most prevalent answer to this item was that students could use the Internet ( $n=47)$, with $n=7$ of those respondents specifically mentioning Google.com, to cheat. One student suggested using a wiki, and $n=5$ stated that students could open multiple browsers or tabs to look up answers while test-taking. A single participant stated that one could use "desktop photos" to cheat, too. Participants also mentioned using social networking sites $(n=2)$ to cheat, texting $(n=2)$, or chatting $(n=1)$ with others for answers.

Collaborative methods of cheating. The most prevalent answer falling under this theme was to get someone else to do coursework rather than the person enrolled in the course $(n=8)$, or to use someone else's work $(n=3)$. There were more truly collaborative methods mentioned, such as working together on assignments $(n=2)$, emailing others for assistance $(n=5)$, asking others for assistance $(n=4)$, asking for answers $(n=8)$ or for questions ( $n=2)$, calling someone $(n=1)$, or taking tests together $(n=5)$ as collaborative ways of cheating in online classes.

Difficulty of cheating in online classes. Two students mentioned that they felt cheating in online classes was difficult. One felt that because people do not generally get to know one another in online classes, working collaboratively to cheat would be more 
difficult. Another stated that cheating is more difficult during online tests because most of them are timed, implying that there is not time to look up answers.

How Teachers Might Decrease Cheating in Online Classes

Due to a problem with the survey software that went undetected in testing of the instrument before data collection, there are no data on this item.

\section{How Students Can Cheat in Face-to-Face Classes}

Participants who reported enrollment in face-to-face courses for Item 1 responded to the question, "In a face-to-face class, how might students cheat? Can you give some examples?" Analysis of $n=29$ answers revealed the emergence of four themes from the data: methods of cheating when the teacher is not present, cheating using non-technical methods, cheating using technology, and collaborative methods of cheating. A single participant stated that he/she did not know of any ways to cheat in a face-to-face course.

Methods of cheating when the teacher is not present. Two participants specifically mentioned waiting for the teacher to leave the room before cheating. One method of cheating suggested was to then look in the textbook for answers $(n=1)$. The other participant stated that students could talk to one another to ask for answers or to get help when the teacher was not present $(n=1)$.

Cheating using non-technical methods. Participants shared a variety of methods for cheating without the use of technological devices. A popular method mentioned was to look at other students' papers $(n=15)$, with one of those suggesting doing this while the teacher's back was turned. Participants also suggested using notes $(n=1)$, keeping the answers needed in one's backpack $(n=1)$, or going to the restroom to look up answers ( $n$ $=1$ ). Several participants shared different types of methods that might all be categorized 
as "cheat sheets" as ways to cheat, including stating the use of cheat sheets $(n=5)$, using a note card with the answers on it $(n=1)$, writing on the underside of a baseball cap bill ( $n=1)$, writing on the soles of shoes $(n=1)$, writing on the insides of the ankles $(n=1)$, writing on the hand $(n=1)$, programming answers into calculators $(n=1)$, writing the answers on the inside of a calculator cover $(n=1)$, or writing answers on the actual test sheet, such as on the back of a Scranton answer sheet brought to class $(n=1)$. This last participant noted that he/she had seen such a thing done when a classmate wrote answers in pencil on the back of the form and then erased them before submitting it.

Cheating using technology. While college students are often chastised for texting in class, many instructors may not realize that students are cheating using that method beside more traditional methods. The most prevalent answer of how students can cheat in a face-to-face class was to text $(n=12)$ to get answers, with one student naming a specific Web site, http://www.chacha.com/. Cha-cha is a site that claims to have "real people answering your questions," where visitors can submit a question, and then the site displays sample answers. If the answer the visitor needs is not there, and that visitor has or sets up a cha-cha account (or has a Twitter account), the question can be emailed to a "guide" who will attempt to find the correct answer for the visitor and text it back.

Other participants noted using their cell phones $(n=1)$, or more specifically, using the phone to use the Internet $(n=2)$ as a way to cheat. Another respondent stated that students could store answers in cell phones $(n=1)$ or simply email to get answers ( $n$ $=1)$. 
Collaborative methods of cheating. Participants reported two ways of cheating in face-to-face classes that involved active collaboration: asking students for answers $(n=3)$ and telling other students answers to questions $(n=5)$.

How Teachers Might Decrease Cheating in Face-to-Face Classes

Participants who reported enrollment in face-to-face courses for Item 1 responded to the question, "What would you recommend that teachers do to decrease cheating in face-to-face classes?" Analysis of $n=30$ valid responses revealed two themes in the data: policy changes and changes in teachers' actions. One participant responded, 'I don't know if there is really a good way to decrease cheating. I think people if they want to cheat are always going to find some way to cheat." Another participant could not state any ways to curb cheating.

Policy changes. Many participants suggested policies for testing, including stricter penalties for being caught $(n=2)$, to decrease cheating in face-to-face courses. Some recommended not allowing phones during tests $(n=4)$ or other electronic devices $(n=1)$ or even collecting phones $(n=1)$. Simple policies of making students clear their desks ( $n=2)$, having them take off baseball caps $(n=1)$, and making them place backpacks either at the front of the room or against the walls of the room $(n=2)$ might curb cheating behaviors, as well. Forcing students to sit apart from each other $(n=9)$ was a common suggestion, and coupled with giving different versions of tests $(n=7)$, especially from year to year $(n=1)$ might also result in less cheating in face-to-face classes.

Changes in teachers' actions. Participants reported concern of how teachers' behavior could influence cheating in their classrooms. Respondents made calls for 
teachers to pay more attention to what was happening in the classroom $(n=4)$, possibly from the back of the room $(n=1)$. Participants encouraged teachers to walk around the room $(n=8)$, although one proponent of this strategy suggested this might make his/her own test anxiety greater $(n=1)$. Another suggestion was for teachers to ensure they had a clear view of the room $(n=1)$ and to watch for hands under tables or desks $(n=1)$, which could signal texting.

\section{Reasons Cheaters Cheat}

Participants who reported themselves to be cheaters in college in Item 46 answered the question, "Why do you cheat? Can you give some reasons?" Analysis of $n$ $=15$ answers revealed four themes: lack of preparation, pressure to succeed, poor knowledge, and disrespect of a course. One participant who reported to be a cheater in Item 46 denied on this question that he/she cheated.

Lack of preparation. The most common answer given was a variation on the idea that there was simply not enough time to prepare for coursework $(n=6)$, with one participant being specific in saying work took up time that would otherwise be spent preparing for a class. One participant reported simply forgetting to do work or prepare.

Pressure to succeed. Participants in this study who reported cheating also reported a variety of pressures which led them to cheat in order to succeed. A single participant responded that he/she cheated to "make my parents happy," while $n=2$ respondents reported general pressure drove them to cheat. Five students reported on a theme of grade achievement, with $n=2$ stating they did not wish to fail, and $n=3$ cited the desire to make good grades as the reason they cheated. 
Poor knowledge. Perhaps linked to a lack of preparation time was the theme of participants cheating simply because they were not sure of the answers $(n=2)$ or not able to guess them $(n=1)$. Another participant noted that sometimes students cheat because the subjects in which they choose to cheat are "weak" ones for them, and then he/she shared the specific example of an art student in a math class. Last, a single participant reported that he/she sometimes cheats because he/she "feel[s] insecure about my own abilities on an assignment."

Disrespect of a course. Five participants cited three different reasons that they cheated, all relating to a lack of respect for a course. One participant cited that if a test was "ridiculously" hard, he/she would cheat. If students do not feel the class is important, $n=2$ participants reported that they cheat for that reason. Sometimes students cheat out of laziness: $n=2$ participants reported cheating because they then had to do less work for better grades.

\section{When Cheaters Consider Cheating Acceptable}

Participants who responded to Item 46 that they cheated in college responded to the question, "When is it considered acceptable to cheat?" Analysis of $n=15$ answers revealed no clear themes but several repeated answers that reveal many students feel justified in cheating in certain circumstances. Two participants claimed that cheating is acceptable when teachers allow it, such as on certain assignments when students can help one another, with another participant stating that "I don't feel that students helping each other in a class is cheating because I can help a student obtain information if they are talking about it with another student." Others stated that cheating is acceptable if it helps students to learn $(n=1)$, if there is a "ridiculous assignment that has no relevance to the 
class or what they are learning" $(n=1)$, if "it is in your own words" $(n=1)$, if a question arises to which the answer is unknown $(n=1)$, or when the cheating "doesn't have a significant impact on the grade, student image, or the image of the person being cheated" $(n=1)$. Some participants $(n=7)$ said cheating is never acceptable, with one adding, "[B]ut I do it anyways."

\section{Reasons Non-Cheating Students Do Not Cheat}

Participants who answered that they did not cheat in college to Item 46 responded to the question, "Why do you choose not to cheat?" Analysis of $n=92$ responses revealed seven themes: variations on why/how cheating is wrong, emotion-related, consideration of consequences, against learning goals, religion and personal beliefs, financial reasons, and no need to cheat.

Variations on why/how cheating is wrong. Participants mentioned a variety of synonyms and phrases associated with why something is "wrong," with $n=15$ of them stating plainly that cheating is wrong as the reason they do not cheat. The next most common answer on this theme was that cheating was "dishonest" $(n=6)$, followed by "immoral" $(n=5)$, "not fair" $(n=3)$, "and "stupid" $(n=1)$. Comments such as, "Cheating goes against what I was taught as a child about being honest and working hard to be an intelligent and respectable person so that you can have pride in your accomplishments," and, "I think it's about a person's morals, and I am an honest person," emphasized the conviction of the participants. Others cited that they are honest people ( $n$ $=3)$, that their upbringing taught them otherwise $(n=2)$, and that their personal integrity kept them from doing so $(n=2)$. 
Emotion-related. Several participants responded that cheating or not cheating had emotionally affected them, and that was why they chose not to engage in such behaviors. Several stated they would rather receive a poor grade than resort to cheating $(n=6)$, and following that idea, $n=1$ respondent stated that being honest and achieving good grades made her proud: "My family's future is important, and I want to be able to look back and say WOW! I did this on my own." Two participants stated that they would feel bad if they cheated, with $n=1$ simply writing "conscience" to sum up why he/she chose not to cheat.

Consideration of consequences. Participants were aware of the consequences awaiting them should they choose to cheat; $n=19$ cited this is as the main reason they did not behave in such a way. Others $(n=4)$ simply did not wish to be caught, while another $(n=1)$ stated that though most of his/her professors do not specify if books can be used or not on exams, "I follow the rules when they do [give them] because they may have specific software to track browser history." A single respondent simply wrote, "The circumstances are not worth it."

Against learning goals. Many respondents shared that they were in college to learn, not to cheat and get by. Responses common to this theme included, "I want to earn it" $(n=10)$, and "I want to learn" $(n=9)$. Several participants $(n=12)$ were concerned that if they cheated, they might not gain the knowledge they needed for graduate or professional schools or for their future careers, with one participant stating, "I would not want to get anywhere in life knowing I did not earn it." Others stated that there was no need to cheat, as they got good grades already $(n=2)$ and that they like to figure things out for themselves $(n=1)$. Three shared that they enjoyed learning, and $n=4$ felt that 
cheating was against the core of what education was all about, with one participant sharing, "I feel as though it would degrade the experience of learning."

Religion and personal beliefs. Of the $n=92$ responses to this question, $n=3$

participants specifically cited their Christian beliefs as the reason that they did not cheat, each citing in one way or another that cheating is a "sin." One stated, "God is watching." Others also cited their personal beliefs as to why they do not cheat $(n=3)$ but did not say that the beliefs related to any religious convictions they held.

Financial considerations. With the cost of college rising each year, several participants said their reasons for not cheating involved the fact that they were paying to learn $(n=8)$ and that to cheat is a waste of money $(n=-2)$. Some simply said, "I'm paying for my education," while another shared, "I am 36 years old and am paying for my education. I chose to go to college to learn, not because it was expected of me."

No need to cheat. Surprisingly, $n=5$ participants share that they do not cheat simply because they do not need to. One shared, "I get good enough grades already... [but] the main reason is that I don't trust others' work to be good enough to cheat off of." This echoed two other participants ideas, who stated, "I don't see the point," and that a person will "gain nothing" from cheating. Another said simply doing one's own work or studying is easier than cheating $(n=1)$.

\section{What Might Cause Non-Cheaters to Cheat}

The final question asked of those who reported not cheating in Item 46 was "Since you don't cheat now, what can you think of that might cause you to cheat in the future?" Analysis of $n=90$ valid responses revealed four emergent themes: grade-related reasons, pressure, reasons at the course level, and would not cheat. 
Grade-related reasons. Many non-cheaters felt that they would cheat in circumstances where they were not achieving the grades they needed or desired for a course or to keep up their GPAs $(n=6)$. For some, simply doing poorly in the class $(n=$ 6) would be enough to drive them to cheat. For others, only a pass/fail situation, if they were on the edge of one grade or the other, would make them cheat $(n=5)$.

Pressure. Participants cited many types of pressures that might cause them to cheat in college. One person simply cited "pressure," while others were more specific in their reporting: $n=6$ stated that stress might make them cheat, $n=6$ said that lack of time to prepare for a test or assignment might lead to dishonesty, and $n=2$ shared that deadlines might make them cheat. One participant shared that feeling desperate could cause him/her to cheat, while $n=2$ cited laziness might lead them to cheating in the future.

Reasons at the course level. Several participants cited reasons directly related to courses and coursework as to why they might cheat in the future. One shared that if he/she disliked the teacher, that sentiment might lead him/her to cheat. Others were less personal in their reasoning for why they might cheat and directed their ideas to assignments, particularly if assignments were difficult $(n=3)$ or had poor directions $(n=$ 1). Others commented on assessments, stating that "surprise tests" $(n=1)$ and "online tests" $(n=1)$ might be reasons to cheat at a later date.

Would not cheat. Many non-cheaters in this study were adamant that nothing would ever cause them to cheat $(n=43)$, while others were less sure $(n=3)$ or could not think of a reason that they might cheat $(n=8)$. Two felt that they would not cheat unless someone's life was on the line. One participant said, "Hopefully I will not put myself in a 
situation that will make me feel pressured to cheat." Another shared that the consequences possible were enough to keep him/her from cheating. 


\section{CHAPTER V}

\section{DISCUSSION}

While the sample size in this study $(n=111)$ was small, and there were no significant findings, the researcher can still compare this sample with prior studies to see where she can draw parallels and to seek refinement of the methodology to prepare for future research.

\section{Research Question 1}

While the researcher did not expect the data to show that online and face-to-face students do not differ significantly in their attitudes toward cheating behaviors, some interesting findings are present. On all but two items ("Texting to get help/answers" and "Using a program to manipulate the length of a paper"), online students rated the behaviors as more serious than their face-to-face peers (see Table 1). For most behaviors, participants rated them in the "2" range of "somewhat serious, with a few exceptions.

As a teacher of composition of nearly 13 years, the researcher agrees that "having someone look over your paper before you submit it" $(M=0.3750$, face-to-face students and $M=0.5063$, online students) is not cheating; indeed, every English teacher preaches that peer review is part of the process of good writing. This corroborates Brown's (1996) finding that students in his study also did not consider this a cheating behavior.

Also of interest is that students do not consider "using a paper for more than one class" to be very dishonest $(M=1.4375$, face-to-face students and $M=1.5823$, online students). Many instructors, including the researcher, expect original work from students 
in their classes, not revised papers tweaked to fulfill the requirements of another course. Some instructors make this standard clear, but if this is an expectation of more instructors, they need to educate students to this and why they consider reusing a paper academically dishonest. Making this finding more interesting is the current concern in academia about "self-plagiarism," or submitting one's own work to more than one journal for publication. Literature discussed in Chapter 2 shows that students may not clearly understand what constitutes plagiarism (e.g., Ashworth \& Banister, 1997; Love \& Simmons, 1998; Pickard, 2006; \& Roig, 1997) or consider self-plagiarism to be an issue (Love \& Simmons, 1998), but that those who receive educational literature on plagiarism do consider it to be more serious (Brown \& Howell, 2001). Students do, however, seem to know that plagiarism is not acceptable and is a form of cheating, with more than half $(n=68)$ of the participants in the current study stating generally that to use others' work without permission or referencing is cheating, and $n=8$ listing plagiarism specifically as part of or their whole definition of cheating.

"Sharing homework answers" also rated as a bit higher than "not very serious" but not quite "somewhat serious" by participants ( $M=1.7813$, face-to-face students and $M=1.9241$, online students). Likewise, "Collaborating with others on individually assigned work" also scored as less than "somewhat serious" ( $M=1.2500$, face-to-face students and $M=1.6203$, online students). These are other behaviors that could be considered cheating, but only when instructors are clear that assignments are meant to be individual, and not collaborative, work. Some participants noted that this was clear to them in their open-ended item responses by defining cheating as collaboration on homework and other individually assigned work. Again, clarification of expectations for 
students can lead to clearer understanding of what is cheating and what is acceptable behavior.

Five behaviors rated quite highly as to how serious the participants considered them. "Copying and pasting from the Web without citing/referencing" ( $M=2.8750$, faceto-face students and $M=2.9241$, online students) echoed open-ended item responses that most students feel this to be very serious, indeed, and the epitome of the definition of cheating. While students know this is not right, many instructors will admit to catching students practicing this behavior each term. Making documentation practices easier to comprehend might encourage students to take the time to cite sources, or using tools like TurnItIn.com or Blackboard's SafeAssign for students to submit papers to see how bad their plagiarism is (whether deliberate or accidental) may deter this behavior.

A pair of items both rated quite high, with one netting the only "perfect score" of "very serious" cheating of all the behaviors queried: "submitting another student's paper as your own with their permission" $(M=2.7813$, face-to-face students and $M=2.8987$, online students) and "submitting another student's paper as your own without their permission" ( $M=3.00$, both face-to-face and online students). The researcher considers these findings curious: simply because permission is involved, some of the participants felt it was more acceptable to present work not their own to a teacher for a grade. A focus group of students to discuss this finding would have been beneficial to discover the thinking of what makes one of these two cheating practices more acceptable than the other.

Another item that gained high rating was "purchasing a paper from a Web site" ( $M=2.9063$, face-to-face students and $M=2.9367$, online students). Paper mills, as they 
are known, are the bane of many instructors' existence. The fortunate fact is that so often these papers are either so well-written that they stand out as not representative of the rest of a student's body of work that instructors will submit them to plagiarism detection software and catch the student, or they are of such poor quality that even if the instructor does not detect the cheating, the grade does not reward the student for such behavior. The redeeming quality is that like the students in Etter et al. (2006), most students found this to be a "very serious" cheating behavior, and perhaps if more instructors shared with students how aware they are of such businesses, students might feel less inclined to employ them.

The final item to note that gained a very high rating from both groups $(M=$ 2.7813 , face-to-face students and $M=2.7342$, online students) was "texting to get help/answers" in a testing situation. As the responses to the open-ended questions show, this is a prevalent behavior within the undergraduate population. Students know cheating is wrong. Instructors should demand that students turn off phones and take them off desktops, or even to turn them in at the start of class as one participant suggested, and that instructors who do not wish to do that should be vigilant in their watching of students during exams and other individual work.

\section{Research Question 2}

The researcher failed to reject $\mathrm{H}_{2}$ in this study: online students did not accurately report their cheating, with only $75 \%(n=9)$ admitting to their dishonest behavior. For this study, the confidence level for this hypothesis was quite high: $100 \%$. There was no risk whatsoever for the participants to admit that they had cheated. Therefore, the 
researcher expected all cheaters to state on Item 72 that they had, indeed, cheated if they did.

The cheating that occurred in this study was no surprise to the researcher. What the researcher did not expect was that so few cheated and that, despite such a high confidence level, so many reported themselves as cheaters. Still, that was not the most interesting finding concerning the self-reporting of cheating in this study.

Curiously, $n=4$ participants who did not cheat according to the criteria set reported that they did cheat. While this could mean that some participants attempted to cheat by guessing the answers to one or all three of the questions but did so incorrectly is plausible, this does not appear to be the case. Examination of the data revealed that all answers on the items that required cheating for a correct response were either correct or were some variation of, "I don't know," or, "That information is not given." The researcher found no off-base or incorrect answers to the three questions in the data.

Another possible explanation of this finding might be that participants accessed the study more than once and confounded findings of the study, especially in regard to this question where $n=4$ participants reported cheating but did not by the standard of the study. Perhaps a participant could have cheated the first time and reported such behavior, and then the second time not have cheated by not answering the questions correctly but reported that he/she did cheat because of the first instance of participation, thus explaining the findings of $n=4$ participants who said they cheated but did not. The only two avenues for investigating this idea, since survey data were anonymous, were to look at the IP addresses and submitted student ID numbers for the incentive to look for duplication. 
After revisiting the raw data for this study, the researcher found that there was no duplication of student ID numbers and only a single duplication of IP address. While one of these participants did admit to cheating when he/she had, in fact, not, the other did not cheat and did not admit to it, either. The only data that the two participants had in common aside from the IP address of the computer from which they took the survey was that they were both students in the same psychology course.

How, then, if all other data suggested that they were not the same person, could they have had the same IP address? When institutions, such as universities, have many computers on their campuses, there is a fixed number of IP addresses assigned to each lab or building. When someone logs on to the system, the DNS router assigns an IP address to that log-in, which gets returned to the pool of available addresses when the user logs off. The two participants in question participated six days apart, but on the same regional campus (which the researcher discovered via a reverse DNS lookup on the Internet), hence the reasoning for the same IP address. The researcher feels confident that the possibility that a participant took the quiz, cheated, and reported it, and then retook the quiz and did not cheat, but reported it, is highly unlikely as a way of explaining the $n=4$ participants who reported cheating but did not.

However, the researcher may have found an explanation for the non-cheaters who admitted to cheating through examination of the server logs for the full online version of the reading quiz article, located online at http://www.byzant.com/Wonders. Table 7 shows for each date how often the Index.html page for the article was accessed, which the researcher fully cited on the instrument as an example of good practice, as well as how many hits the main folder received, which visitors can reach by doing a Google 
search. Additionally, the researcher has provided in Table 7 how many cheaters participated in the study on each date, and how many non-cheaters who admitted to cheating participated in the study on each date.

Table 7

Server Logs for http://www.byzant.com/Wonders

\begin{tabular}{lllll}
\hline Date & Hits to Index.html & Hits to Index Total & Cheaters & Non-Cheaters \\
& Page via Default & Admitted & Who Admitted
\end{tabular}

$\begin{array}{llllll}4-23-10 & 0 & 1 & 1 & 0 & 0 \\ 4-24-10 & 0 & 0 & 0 & 0 & 0 \\ 4-25-10 & 3 & 0 & 3 & 1 & 2 \\ 4-26-10 & 4 & 5 & 9 & 6 & 0 \\ 4-27-10 & 3 & 1 & 4 & 3 & 0 \\ 4-28-10 & 3 & 1 & 4 & 2 & 0 \\ 4-29-10 & 0 & 0 & 0 & 0 & 0 \\ 4-30-10 & 2 & 0 & 2 & 1 & 0 \\ 5-01-10 & 0 & 0 & 0 & 0 & 0 \\ 5-02-10 & 0 & 1 & 1 & 0 & 0 \\ 5-03-10 & 0 & 1 & 1 & 0 & 0 \\ 5-04-10 & 3 & 0 & 3 & 2 & 0 \\ 5-05-10 & 0 & 0 & 0 & 0 & 0 \\ 5-06-10 & 1 & 0 & 1 & 0 & 0 \\ 5-07-10 & 1 & 0 & 1 & 0 & 1 \\ 5-08-10 & 0 & 1 & 1 & 0 & 0 \\ 5-09-10 & 0 & 2 & 2 & 0 & \\ \end{array}$

While garnering who accessed the site when is not possible (random searches vs. true access by study participants vs. search engine spiders), the table shows clearly that on some dates, there were only as many accesses as there were cheaters. One can deduce from these data that some of the participants who did not cheat but reported doing so considered looking at the full article although they did not report the correct answers on 
the quiz to be cheating; giving the right answers would have made them cheaters by the standard of the study.

This unexpected finding of $n=4$ participants who stated that they cheated but did not by the standard of the study leads the researcher to believe that some people may be more honest than might normally be expected, that they could be hypersensitive to what cheating is, or that they are truly unclear of what cheating is. Again, educating students about what constitutes cheating and being clear in expectations for honesty may help to alleviate some cheating behaviors.

\section{Research Question 3}

The researcher expected the cheating discovered in this study, but not some of the other findings about the cheaters, some hypothesized and some not, concerning age, attitudes toward cheating, and personal beliefs of honesty. While none of the findings for Research Question 3 were significant (just as in Jordan, 2001), the researcher compared simple frequencies within the current data on background variables to see how they matched findings of prior studies.

For instance, there were more women $(n=86)$ who participated in the current study than men $(n=25)$; proportionally, however, women $(n=13$ in total, $n=10$ online $)$ still cheated more than men ( $n=2$ in total, $n=2$ online), although there was no significant association found between gender and cheating $(r=.002, p=.986)$. This finding is contrary to many prior studies that found gender (men) to be a predictor of cheating (Brown \& Choong, 2003; Iyer and Eastman, 2006; Rakovski \& Levy, 2007; Smyth \& Davis, 2003; Underwood \& Szabo, 2003; \& Whitley, 1998), especially Lanier's (2006) finding that men are more likely to cheat in online courses. On the other hand, the 
current finding does back up Leming's (1980) finding that women are more likely to cheat in low-risk situations, such as the one offered in this study.

Of particular concern to this study is the ethical behavior and attitudes of today's college students and future workers because of concerns voiced nearly a century ago by the Bureau of Education (1928), a decade later by the American Council on Education (1937), and more recently by the National Leadership Council for Liberal Education and America's Promise (LEAP) (2007). Of the cheaters, all reported that they consider themselves honest people, and they also reported not cheating in college, and most $(n=$ 10) reported never cheating in high school. The researcher found those who considered themselves honest but still consider cheating appropriate even in certain circumstances such as this study to be interesting.

Though the researcher made no hypotheses concerning age, class ranking, or student status, findings agreed with prior literature on each of these variables. This study was congruent with Whitley's (1998) finding that younger students are more likely to cheat than older students, with $n=6$ of the $n=12$ online cheaters falling into the $18-21$ age range and $n=2$ reporting their age is $22-25$ years old, though the association with age and cheating was not significant $(r=-.084, p=.460)$. Concerning ranking in school, the current study also agreed with past studies by Jordan (2001) and Iyer and Eastman (2006) that younger students cheat more than older students, as $n=4$ of the cheaters were members of the freshman class, and $n=3$ reported themselves sophomores, which in combination is more than half of all the online cheaters, though again, no significant correlation existed between class year and cheating $(r=-.089, p=.434)$. 
When examining student status, only $n=3$ of the cheaters were part-time students, thus reinforcing Smyth and Davis's (2003) finding that full-time students cheat more, despite no significant correlation between cheating and student status $(r=.022, p=$ .851). Another background variable upon which the researcher posed no hypothesis was the influence of living accommodations. Whitley (1998) found that on-campus students cheated more. In the current study, only $n=5$ of the online cheaters lived on campus, in disagreement with Whitley's finding, though the current finding was not significant $(r=-$ $.107, p=.350)$. Lastly, though not a significant finding $(r=-.050, p=.663)$, opposite of Williams and Janosik (2007), Greek students $(n=1)$ did not cheat more than other involved students $(n=1)$ in the current study.

Concerning Online Cheaters and Other Ideas about Cheating Behaviors One of the main philosophical foundations of the current study was that academic dishonesty can lead to workplace dishonesty. Contrary to Harding (2004), Nonis and Swift (2001), and Sims (1993), online cheaters in this study reported overwhelmingly (n $=12$ ) of having never cheated or acted dishonestly in the workplace. This finding should be reassuring to the $56 \%$ of employers who desire honesty and ethical behavior in employees according to the LEAP (2008) report, as well as to the authors of both the Cardinal Principles of Secondary Education (Bureau of Education, 1928) and the Student Personnel Point of View (American Council on Education, 1937).

Looking to peer perception and its influence on cheating, all but one cheater in this study believed that their peers cheat, as well, despite reporting that they themselves do not in Item 46: $n=7$ believed their peers cheat "rarely," and $n=4$ reported that they thought their peers cheated "often." This leads to questions of this phenomenon of peer 
perception, as discussed by Chapman (2004), Grijalva et al. (2006), Jordan (2001), and McCabe, Trevino, and Butterfield (2002): those who think their peers cheat are more likely to engage in cheating themselves, and those who think their peers cheat more are more likely to cheat more. Could the participants in the current study have cheated because they believed their peers would be doing the same, although they reported themselves to not normally be cheaters and to be honest people? An interesting consideration for future studies would be to inquire about why those same students cheated during the study if they do not in college or did not in high school, as $100 \%$ of the cheaters in this study reported. Was the motivation on this quiz different for them (the possibility of the $\$ 400$ Visa gift card incentive), were they not being truthful, or was there another reason? Amending the instrument by adding an item to ask such would be an easy way to gather such information.

Finally, many of the online cheaters $(n=5)$ and many of the entire study's participants ( $n=64,57.7 \%$ ) responded that cheating would be easier in an online class compared with a face-to-face class, which agrees with Kennedy's (2000) study. Unfortunately, because of a software failure, there are no data to share how students think one can cheat in an online class so that educators and administrators might combat such behaviors via policies and assignment design. This is most certainly an item to query again in future studies.

\section{Concerning the Qualitative Responses}

Studies of the past (Ashworth \& Banister, 1997; Brown, 1996; Brown \& Choong, 2003; Love \& Simmons, 1998; and Roig, 1997) looked into whether an understanding of what cheating is can lead to less cheating in both undergraduate and graduate education, 
and some found that less understanding is a predictor of more cheating (Ashworth \& Banister, 1997; Love \& Simmons, 1998; and Roig, 1997), which is not surprising. Participants in the current study revealed, like Chapman et al. (2004) that they have clear ideas in mind of what they believe cheating is. However, while these responses hint that today's students have a basic grasp of what constitutes academic dishonesty, many do not, such as the participant who responded that "taking others' ideas" was not, or anything less than "25 percent" was okay. Educators and administrators should carefully consider the implications of the answers found through the simple questions asked and find ways to remedy the behaviors that are surely prevalent on more than just the campus utilized in this study.

Participants also revealed here how instructors might combat cheating: clearer instructions and linkage of assignments to learning outcomes, intolerance of cheating through stricter policies concerning dishonesty, and maintenance of a strong presence during assessments are just a few of the ideas offered by current undergraduates. Educators should consider these students' ideas with care and either implement them or use them as a springboard for discussion within their departments or with their own students the next time the topic of cheating arises, perhaps on the first day of a course or upon the introduction of each assignment. Many participants shared that when they know what their instructors consider cheating and help them to understand coursework, they will avoid academically dishonest behaviors.

\section{Implications Response Rate}

This small sample size in this study imposed a number of limitations on it concerning external, internal, construct, and statistical validity. Because of the low 
response rate $(8 \%)$ and small sample size $(n=111)$, the findings of this study are not likely generalizable to other institutions or college students as a population. The researcher's examination of the demographic data available for the institution used in the study and the sample's background variables found some similarities, as seen in Table 8 below.

Table 8

Demographics of the Institution Studied and the Study's Sample Compared

\begin{tabular}{llll}
\hline Variable & & Institution $^{\mathrm{a}}$ & Sample \\
\hline \multirow{2}{*}{ Gender } & Male & $40.70 \%$ & $23.00 \%$ \\
& Female & $59.30 \%$ & $77.00 \%$ \\
Mean Age & & & \\
& & 23 years old & $53.00 \%=18-25$ \\
Class Year & Freshmen & $29.77 \%$ & $32.40 \%$ \\
& Sophomores & $18.24 \%$ & $25.00 \%$ \\
& Juniors & $18.44 \%$ & $14.40 \%$ \\
& Seniors & $24.35 \%$ & $22.50 \%$ \\
Student Status & Full-time & $79.47 \%$ & $82.90 \%$ \\
& Part-time & $20.52 \%$ & $17.10 \%$ \\
International & & & \\
Students & & $00.01 \%$ & $00.09 \%$ \\
& & & \\
\hline
\end{tabular}

$\overline{\mathrm{a}}$ From Western Kentucky University (2010)

While there are more women participants than men in the current sample than in the institution as a whole, Dillman (2006) found that women are more likely to check email and be respondents than men, and the researcher encouraged instructors who agreed to assist with this study to email the study invitation to their students as one way of it reaching them. The researcher could not accurately assess the true mean age of study participants due to having them report in categories rather than as a true numbers, but the 
majority of study participants fall in the same age bracket as the main age of the institution's population. Class year distribution is also roughly the same, with the sample skewed a bit in favor of younger students compared to the institution as a whole. The sample's small international student content is comparable to the institution's small undergraduate international student ratio. In short, the findings may be generalizable to the institution.

Because the sample size is small, this also causes concerns about statistical power. The researcher had to amend her planned analyses of the data due to the small sample. The study needed at least three times as many participants to run factor analysis and other multivariate analyses. Such a small sample also raises the possibility of Type I and Type II errors in assessment of the hypotheses posited.

The sample size also leads to concerns of construct validity. The researcher chose Underwood and Szabo's (2003) Cheat QTR because it queried ideas related to online learning and cheating using technology that related to the current study. However, she found no validity or reliability information on this instrument, nor did the Underwood and Szabo respond to requests for such information. The current sample lacks the power to determine the amended Cheat QTR's validity. Additionally, the amended form included sixteen items that queried how serious of cheating behaviors the participants felt each item to be, as well as the reading quiz. While the reading quiz measured in definite form a certain type of cheating, showing some internal validity of that portion of the amended Cheat QTR, the findings of $n=4$ participants doing something other than what the study ranked as cheating but their reporting that they had cheated shows there is room 
for improvement on this portion of the scale. This would improve the instrument's overall validity in duplication of the study's design.

Implications for Educators and Administrators

Participants in this study revealed many methods by which student cheat in both face-to-face and online courses, and these are items both educators and administrators should take note of and work to improve. The researcher sat in amazement as she read of teachers leaving rooms during exams, of phones being allowed to be left on in classrooms, and of the suggestion that exams for online courses were not set in proctored environments. Additionally, educators and administrators should consider the idea that while the findings in this study were not significant, the data pointed toward face-to-face and online students having no differences between them in their attitudes about academic dishonesty. The underlying suspicion of online students is that since they are not monitored, they are more likely to be dishonest and more likely to be amenable to cheating behaviors; however, the data here indicate they are no more likely to be as such than their face-to-face counterparts.

The data suggest that simple changes can eliminate some cheating, and both educators and administrators should consider implementing such changes, most of which are cost-free. For example, while instructors cannot be "present" when students take online exams to discourage cheating, proctored exams through the instructor, an institution's testing center, or an approved off-campus site can be a requirement of each course offered online. Such a setting would allow for proof of the identity of the person taking the exam and for the monitoring that both Kerkvliet and Sigmund (1999) and 
Leming (1980) found helpful in reducing cheating and that face-to-face students normally receive. Participants of this study echoed this idea in their open-response answers.

Perhaps knowing what limits cheating face-to-face students, and coupling such a finding with the idea that online students feel much the same way about cheating, might lead to new solutions for how to promote honest and ethical behavior in online classes. Maybe instructors giving warnings in online classes about what constitutes honesty and dishonesty during assignments, or posting a single item atop online exams asking students to answer whether they commit to not cheating, would stave off possible cheaters if proctoring is not appealing to the instructors; giving a warning about cheating showed a decrease in dishonesty in Leming's (1980) study with face-to-face students. Looking to what works in face-to-face courses to discourage cheating and how those same techniques can be translated into Web-based courses may yield educators and administrators more success in combating academic dishonesty than they had previously imagined.

Additionally, the researcher held the very high standard of $100 \%$ accuracy in selfreporting cheating. The implication of this high standard is that by expecting students to be completely honest (even about dishonest behavior), educators could work toward building more ethical graduates to pass on to the business world, which the National Leadership Council's (2008) LEAP report states is a desire of the majority of today's employers. This would also be fulfilling the Cardinal Principles (Bureau of Education, 1928) and the Student Personnel Point of View (American Council on Education, 1937). Should educators be able to encourage such honesty in their students when they are 
caught in acts of academic dishonesty, perhaps the level of actual cheating would fall, as well.

Another finding of interest with implications for higher education concerned participants considering self-plagiarism to be "not very serious" ( $M=1.4375$ for face-toface students, $M=1.5823$ for online students). Despite more undergraduates progressing to graduate education each year, this behavior is one that perhaps educators and administrators overlook in crafting their honor codes and both personal and institutional definitions of cheating. Today's undergraduates who become tomorrow master's and doctoral students should receive education now on the implications of how such behavior could ruin their careers should they desire a future in academia, a behavior that Love and Simmons (1998) found their graduate students did not take very seriously.

Those working in supervisory roles in higher education might also consider the findings of the open-ended questions. Not only were participants of all age groups happy to share their opinions, but they also appeared to do so honestly. Chapman et al. (2004) found that students were willing to share ideas about cheating quite openly, as well, and this aided in the development of the instrument for their study. Surely having such discussions on academic dishonesty on any campus would yield useful results as the current researcher and Chapman et al. enjoyed. Looking to the source of the problem for a solution is common in other fields. Why should educators and administrators not do the same--ask students about what would cause them to cheat less---to help solve this age-old quandary that is cheating? 


\section{Significance}

Few studies have documented actual cheating rates, and while the instrument used in this study was not a true classroom assignment, the data does document that with the motivation of a significant cash prize, much like that of a good grade, students will cheat. Furthermore, the findings show that most students who cheat are honest about their behavior. Students also are able to label cheating behaviors as such, though their perceptions of severity may be different from that of their instructors, just as Pickard (2006) discovered. However, this leaves room for education on academic dishonesty and what behaviors constitute cheating, bearing in mind that this may differ from campus to campus or instructor to instructor, but on the whole the definition of cheating is much the same at its core. Educators and administrators should work together and with students to eliminate the drive to cheat deliberately and cheating that occurs innocently, without knowledge that the behavior is cheating.

\section{Considerations for Repetition of the Current Design}

To replicate this study, several changes can be made to make the findings more valid. These relate to the sampling frame, participant solicitation, consent considerations, disclosure as to the true purpose of the study, and items on the questionnaire.

\section{Sample Considerations}

First, while general education courses typically hold the best variety of students on any campus, this is true to only a certain extent. Few upperclassmen are often in these courses, yet information on their cheating attitudes and behaviors is just as valid and important as that of underclassmen. Therefore, the researcher suggests that future incarnations of this study include more student variety in the sample, that a broader 
selection of classes be solicited, and at certain institutions, possibly the entire student body should receive an invitation to participate.

The researcher also limited this study to undergraduates, but more institutions are offering graduate programs either partially or wholly online. Because of this, future incarnations of this study should consider inclusion of graduate students, as well.

\section{Contacting Possible Participants}

In the current study, the researcher contacted instructors to ask permission to include their students in the study and asked them to send out the invitation and reminder emails for students to participate. This was a grave error, and the researcher did not realize how this decreased her chances of reaching possible participants until the study was in progress. At that point, she could make no changes without stopping data collection and returning to the Review Board for permission to change her method of solicitation.

The current researcher does not believe that most of the instructors who agreed to help solicit their students' participation sent both of the emails, if either of them at all, due to the very poor response rate. Examination of the list of classes whose instructors said they would help with the study in comparison to the names of courses given by participants (Item 2) gives much credibility to this idea. Assessment of how many of the ENG $1 \mathrm{XX}, 2 \mathrm{XX}$, and $3 \mathrm{XX}$ instructors truly invited their students to participate due to instructors of multiple sections of each course having agreed to participate is not possible. However, analysis of Item 2 data revealed that there were no participants who reported accessing the study through $n=4$ of the online general education courses whose instructors had said they would assist with the study, possibly eliminating $n=196$ 
participants from the sample. Granted, the study took place at a poor time in the semester (the final two weeks of classes), but with an incentive such as the one offered in this study, the researcher feels more students would have been interested if they were indeed contacted by their instructors as their instructors had promised to do.

While this is purely speculation, such thoughts lead to the next recommendation. In future studies, the researcher should gain permission to contact potential participants directly rather than going through faculty members who are not vested in the process.

\section{Consent Considerations}

After completion of Review Board requirements, the researcher discovered that informed consent was not required for this study as it was a deception study, and in fact the Board granted a waiver of informed consent. However, the forms submitted to the Review Board were the ones that the researcher had to send to participants. These were three pages long and followed the template of the Review Board's preference. In future studies, since no true informed consent is required, the researcher should use a much shorter "consent" document that emphasizes the anonymous nature of the data and the chance at the incentive prize to gain more participants.

\section{Changes to the Questionnaire}

In future studies, the researcher should consider adding or amending certain items to help clarify the findings in this first instance of this study, and the researcher should consider deleting some items because of their irrelevance.

Items to Delete. At times, deleting items that yield no useful or relevant data so that participants answer fewer questions and are less likely to suffer from survey fatigue can be helpful. While at this time there is not enough evidence to omit the questions 
recommended in this section due to the lack of power as a result of a small sample, should future researchers duplicate this design, obtain a larger sample, and be able to complete item analysis, researchers might consider the following items for deletion from the instrument.

Item 2, "What is the name or number of the course through which you are accessing this study," would only be meaningful if the researcher were to compare certain courses and their cheating behaviors and/or attitudes. The only meaningful data collected from this item in the current study were to show which classes lacked representation in the sample though their instructors stated they would advertise the study. Since the item offers no meaningful data beyond this, the researcher should consider it for deletion.

Item 29, "How often do you use the Internet," should be deleted. Nearly all participants answered "daily" $(n=26)$ or "several times daily" $(n=84)$, with only a single participant stating he/she used the Internet "at least once a week." Internet usage is so ubiquitous with being a college student that this question is outdated and provides no meaningful information.

One might consider deletion of Item 41, "Does your school have a policy for cheating and/or plagiarism," which rated a 100\% "yes" answer from participants of this study and yielded no useful data, though such an item does confirm participants' awareness of such a policy.

Items to Amend. Should institutions used in future implementations of the instrument have many international or immigrant students, the researcher may choose to change Item 16 , or perhaps consider it for deletion if it does not seem relevant to the sampling frame. The question currently reads, "Are you an American citizen or legal 
resident OR an International student" and should be changed to read "What is your citizenship or immigration status?" and to have five options: (a) an American citizen (natural born), (b) an American citizen (naturalized), (c) a legal resident ("green card holder" or pending status change), (d) a non-resident alien, (e) an international student (student visa). In a larger sample, this would help to clarify possible cultural differences between American and non-American/native born participants in their attitudes toward and behaviors of cheating. The literature shows that different cultures consider some behaviors appropriate that Americans consider cheating. However, the current researcher also recognizes that this may deter some participants from responding who may be in the country illegally.

Additionally, Item 4, which queries participants' age, should be changed to the entry of a raw number rather than as a choice of category, to allow for average age calculations and to compare to institutional data to help determine how generalizable the sample is to the student body of the university.

Items to Add. To supplement the current Item 16, future researchers might consider adding a question querying nationality, open-ended, to those answering anything but "an American citizen (natural born)." If the researcher adds an item like this, he/she could expand the literature review to examine scholarship on cheating beliefs in other cultures compared to American beliefs, such as the study done by Taylor-Bianco and Deeter-Schmelz (2007), who found differences in cheating behaviors and attitudes of American and Indian students.

To supplement the current Item 72, which reads, "Consider the reading quiz you took at the start of this survey. Did you use any source other than information in the 
excerpt provided for you?" an item should be added immediately after to gather more specific data. A follow up question of "What information did you use, and how did you use it?" for those who answer "yes" to Item 72 would help to clarify what participants consider cheating behavior outside the parameter set by the quiz answers in the current design.

Disclosure of True Purpose of Study

In this deception study, the Review Board did not allow true deception of the participants. This is despite reasoning from Sales and Folkman (2000) and the Belmont Report supporting the use of deception in such circumstances as were present in the current study. When data are completely anonymous, as in this study, disclosure should be at the conclusion of the study, not prior to data submission. There should not be a possibility for the withdrawal of submitted data, especially in a circumstance where researchers are collecting sensitive data, such as those concerning cheating behaviors, to allow for a more accurate capture of attitudes and behaviors. If future studies could omit disclosure of the true nature of the study prior to data submission, as well as a chance to withdraw data after submission, perhaps future researchers could obtain a better response rate and results.

\section{Future Research}

One of the purposes of the current study was to determine student attitudes toward cheating, and the researcher gathered interesting data on that topic. Future studies, both survey-based and qualitative, should work more toward learning students' perspectives of academic dishonesty. Participants in this study seemed to be open, and some gave quite detailed answers about their beliefs and practices of cheating. By continuing to seek such 
introspective data, this will help educators and administrators alike to combat future students from either falling prey to cheating violations due to being improperly educated about what constitutes academic dishonesty, or can help educate students to an understanding of why cheating is wrong and cannot be tolerated. If this can decrease cheating even a little, then the Cardinal Principles (Bureau of Education, 1928), the Student Personnel Point of View (American Council on Education, 1937), and the National Leadership Council's vision in the LEAP Report (2007) can be closer to being fulfilled in the area of promoting a good ethical and moral character in today's graduates. Additionally, each week, one news venue or academic resource or another is sharing news about or findings of a new technique or tool to prevent cheating, and many of these ideas concern online learning. Future studies should work to learn how effective new counter-cheating techniques and software are in combating academic dishonesty in college classes, both face-to-face and online. With students in possession of technology that makes cheating easier on them and makes catching cheating harder on faculty, knowing what tools are available and how they work will protect the integrity of the degrees that institutions grant each term.

\section{Implications of the Research}

While the findings showed no statistical significance, this study still shows that students will cheat and be surprisingly honest about their cheating, something few studies before have been able to do. This study also reveals important ideas about what students consider cheating to be, why students cheat or choose not to engage in academic dishonesty, methods students use to cheat in both face-to-face and online courses of which instructors may not previously have been aware, and suggestions of how to prevent 
cheating. The findings also show what students consider to be cheating or not via the questionnaire items concerning cheating behaviors; all behaviors queried in the questionnaire may be considered cheating, depending on the course or the institution in which a student might enroll, yet many participants in this study reported behaviors not to be cheating or not to be very serious. These findings point in an important direction, and future researchers should consider them. 


\section{REFERENCES}

American Council on Education. (1937). The student personnel point of view (Series I, Volume 1, Number 3). Washington, DC: U. S. Government Printing Office.

Ashworth, P., \& Bannister, P. (1997, June). Guilty in whose eyes? University students' perceptions of cheating and plagiarism in academic work and assessment. Studies in Higher Education, 22, 187-204. Retrieved April 25, 2008, from Academic Search Premier database.

Brown, B. (1996). A comparison of the academic ethics of graduate business, education, and engineering students. College Student Journal, 30, 294-301. Retrieved April 25, 2008, from Academic Search Premier database.

Brown, B. S., \& Choong, P. (2003). A comparison of academic dishonesty among business students in a public and private Catholic university. Journal of Research on Christian Education, 12, 27-48. Retrieved June 10, 2008, from Academic Search Premier database.

Brown, B. S., \& Emmett, D. (2001). Explaining variations in the level of academic dishonesty in college students: Some new evidence. College Student Journal, 35, 529-539. Retrieved February 10, 2008, from Academic Search Premier database.

Brown, V. J., \& Howell, M. E. (2001). The efficacy of policy statements on plagiarism: Do they change students' views? Research in Higher Education, 42, 103-118. Retrieved February 10, 2008, from Academic Search Premier database. 
Bureau of Education. (1928). Cardinal principles of secondary education (Bulletin, 1918,

No. 35). Washington, DC: U. S. Government Printing Office.

Caracelli, V. J., \& Greene, J. C. (1997). Crafting mixed-methods evaluation designs. New Directions for Evaluation, 74, 19-31.

Chapman, K. J., Davis, R., Toy, D., \& Wright, L. (2004). Academic integrity in the business school environment: I'll get by with a little help from my friends. Journal of Marketing Education, 26, 236-249. Retrieved April 25, 2008, from Ebscohost.

Costello, A. B., \& Osborne, J. W. (2005). Best practices in exploratory factor analysis: Four recommendation for getting the most from your analysis. Practical Assessment, Research, \& Evaluation, 10(7), 1-0.

Creswell, J. W. (1998). Qualitative inquiry and research design. Thousand Oaks, CA: Sage.

De Bruin, G. P., \& Rudnick, H. (2007). Examining the cheats: The role of conscientiousness and excitement seeking in academic dishonesty. South African Journal of Psychology, 37, 153-164. Retrieved January 30, 2008, from Academic Search Premier database.

Dillman, D. A. (2006) Mail and Internet surveys: The tailored design method (2nd ed.). Hoboken, NJ: Wiley.

Erlandson, D. A., Harris, E. L., Skipper, B. L., \& Allen, S. D. (1993). Doing naturalistic inquiry: A guide to methods. Newbury Park: Sage. 
Etter, S., Cramer, J. J., \& Finn, S. (2006). Origins of academic dishonesty: Ethical orientations and personality factors associated with attitudes about cheating with information technology. Journal of Research on Technology in Education, 39, 133-155. Retrieved January 25, 2008, from Academic Search Premier.

Finn, K. V., \& Frone, M. R. (2004). Academic performance and cheating: Moderating role of school identification and self-efficacy. The Journal of Educational Research, 97(3): 115-122. Retrieved February 10, 2008, from Academic Search Premier database.

Flynn, S., Reichard, M., \& Slane, S. (1987). Cheating as a function of task outcome and Machiavellianism. Journal of Psychology, 121, 423-427. Retrieved July 12, 2008, from Academic Search Premier.

Grijalva, T. C., Nowell, C., \& Kerkvliet, J. (2006). Academic honesty and online courses. College Student Journal, 40, 180-185. Retrieved February 2, 2008, from Academic Search Premier.

Groves, R. M., Fowler, F. J., Couper, M. P., Lepkowski, J. M., Singer, E., \& Tourangeau, R. (2004). Survey methodology. Hoboken, NJ: Wiley.

Harding, T. S., Carpenter, D. D., Finelli, C. J., \& Passow, H. J. (2004). Does academic dishonest relate to unethical behavior in professional practice? An exploratory study. Science and Engineering Ethics, 10, 311-324. Retrieved February 10, 2008, from Academic Search Premier database.

Iyer, R., \& Eastman, J. K. (2006). Academic dishonesty: Are business students different from other college students? Journal of Education for Business, 82(2): 101-110. Retrieved January 30, 2008, from Academic Search Premier database. 
Jordan, A. E. (2001). College student cheating: The role of motivation, perceived norms, attitudes, knowledge, and institutional policy. Ethics and Behavior, 11, 233-247. Retrieved February 10, 2008, from Academic Search Premier database.

Keith-Speigel, P. C., Tabachnick, B. G., \& Allen, M. (1993). Ethics in academia: Students' views of professors' actions. Ethics \& Behavior, 3, 149-162. Retrieved April 25, 2008, from Academic Search Premier database.

Kennedy, K., Nowak, S., Raghuraman, R., Thomas, J., \& Davis, S. F. (2000). Academic dishonesty and distance learning: Student and faculty views. College Student Journal, 34, 309-314. Retrieved February 10, 2008, from Academic Search Premier database.

Kerkvliet, J., \& Sigmund, C. L. (1999). Can we control cheating in the classroom? Journal of Economic Education, 30, 331-343. Retrieved June 1, 2008, from Academic Search Premier database.

Lanier, M. (2006). Academic integrity and distance learning. Journal of Criminal Justice Education, 17, 244-261. Retrieved January 30, 2008, from Academic Search Premier database.

Leming, J. S. (1980). Cheating behavior, subject variables, and components of the internal-external scale under high and low risk conditions. Journal of Educational Research, 74, 83-87. Retrieved April 25, 2008, from Academic Search Premier database.

Levy, E. S., \& Rakovski, C. C. (2006). Academic dishonesty: A zero tolerance professor and student registration choices. Research in Higher Education, 47, 735-754. Retrieved February 10, 2008, from Academic Search Premier database. 
Love, P. G., \& Simmons, J. (1998). Factors influencing cheating and plagiarism among graduate students in a college of education. College Student Journal, 32, 539-550. Retrieved April 25, 2008, from Academic Search Premier database.

Mark, M. M., \& Shotland, R. L. (Eds.) (1987). Multiple methods in program evaluation. New Directions for Program Evaluation, no. 35, (pp. 23-42). San Francisco: Jossey-Bass, Inc.

Maxwell, J. A. \& Loomis, D. M. (2003). Mixed methods design: An alternative approach. In A. Tashakkori \& C. Teddlie (Eds.) Handbook of mixed-methods in social and behavioral research (pp. 241-271). Thousand Oaks, CA: Sage Inc.

McCabe, D. L., \& Trevino, L. K. (1997). Individual and contextual influences on academic dishonesty: A multicampus investigation. Research in Higher Education, 38, 379-396. Retrieved February 10, 2008, from Academic Search Premier database.

McCabe, D. L., Trevino, L. K., \& Butterfield, K. D. (2002). Honor codes and other contextual influences on academic integrity: A replication and extension to modified honor code settings. Research in Higher Education, 43, 357-378. Retrieved February 10, 2008, from Academic Search Premier database.

Morse, J. M. (1991). Approaches to qualitative-quantitative methodological triangulation. Nursing Research, 40(2), 120-123.

National Leadership Council for Liberal Education \& America's Promise (LEAP). (2007). College learning for the new global century. Washington, DC: Association of American Colleges and Universities. 
National Leadership Council for Liberal Education \& America's Promise (LEAP). (2008). Executive summary: College learning for the new global century. Washington, DC: Association of American Colleges and Universities.

Nonis, S., \& Swift, C. O. (2001). An examination of the relationship between academic dishonesty and workplace dishonesty: A multicampus investigation. Journal of Education for Business, 77, 69-77. Retrieved April 25, 2008, from Academic Search Premier database.

Passow, H. J., Mayhew, M. J., Finelli, C. J., Harding, T. S., \& Carpenter, D. D. (2006). Factors influencing engineering students' decisions to cheat by type of assessment. Research in Higher Education, 47, 643-684. Retrieved February 10, 2008, from Academic Search Premier database.

Pickard, J. (2006). Staff and student attitudes to plagiarism at University College Northampton. Assessment \& Evaluation in Higher Education, 31, 215-232. Retrieved February 10, 2008, from Academic Search Premier database.

Rawwas, M., Swaidan, Z., \& Isakson, H. (2007). A comparative student of ethical beliefs of master of business administration students in the United States with those in Hong Kong. Journal of Education for Business, 82, 146-158. Retrieved January 30, 2008, from Academic Search Premier database.

Rakovski, C., \& Levy, E. (2007). Academic dishonesty: perceptions of business students. College Student Journal, 41, 466-481. Retrieved February 10, 2008, from Academic Search Premier database. 
Rettinger, D. A., \& Jordan, A. E. (2005). The relations among religion, motivation, and college cheating: A natural experiment. Ethics \& Behavior, 15, 107-129. Retrieved July 12, 2008, from Academic Search Premier.

Roig, M. (1997). Can undergraduate students determine whether text has been plagiarized? Psychological Record, 47, 113-122. Retrieved April 25, 2008, from Academic Search Premier database.

Roig, M., \& Ballew, C. (1994). Attitudes toward cheating of self and others by college students and professors. Psychological Record, 44, 3-12. Retrieved April 25, 2008, from Academic Search Premier database.

Sales, B. D., \& Folkman, S. (Eds.). (2000). Ethics in research with human participants. Washington: APA.

Sims, R. (1993). The relationship between academic dishonesty and unethical business practices. Journal of Education for Business, 68, 207-211. Retrieved July 12, 2008, from Academic Search Premier database.

Smyth, M., \& Davis, J. (2003). An examination of student cheating in the two-year college. Community College Review, 31, 17-33. Retrieved April 25, 2008, from Academic Search Premier database.

Stevens, J. (1992). Applied multivariate statistics for social sciences. (2nd ed.). Hillsdale, NJ: Laurence Erlbaum Assoc.

Tabachnick, B. G., \& Fidell, L. S. (1996). Using multivariate statistics. (3rd ed.). New York: Harper Collins. 
Tashakkori, A. \& Teddlie, C. (1998). Mixed methodology: Combining qualitative and quantitative approaches. Applied Social Research Methods Series, 46. Thousand Oaks, CA: Sage.

Taylor-Bianco, A., \& Deeter-Schmelz, D. (2007). An exploration of gender and cultural differences in MBA students' cheating behavior. Journal of Teaching in International Business, 18, 81-99. Retrieved July 22, 2010, from Academic Search Premier database.

Thomas, R. M. (2003). Blending qualitative and quantitative research methods in theses and dissertations. Thousand Oaks, CA: Sage.

Underwood, J., \& Szabo, A. (2003). Academic offences and e-learning: Individual propensities in cheating. British Journal of Educational Technology, 34, 467-477. Retrieved February 10, 2008, from Academic Search Premier database.

Ward, D. A., \& Beck, W. L. (1990). Gender and dishonesty. Journal of Social Psychology, 130, 333-339. Retrieved April 25, 2008, from Academic Search Premier database.

Western Kentucky University. (2010). Fact book 2010. Bowling Green, KY: Western Kentucky University.

Whitley, Jr., B. E. (1998). Factors associated with cheating among college students. Research in Higher Education, 39, 235-274.

Williams, A. E., \& Janosik, S. M. (2007). An examination of academic dishonesty among sorority and nonsorority women. Journal of College Student Development, 48, 706-714. 
Appendix A:

Full-text of Hymenosaurs Rex Web page 


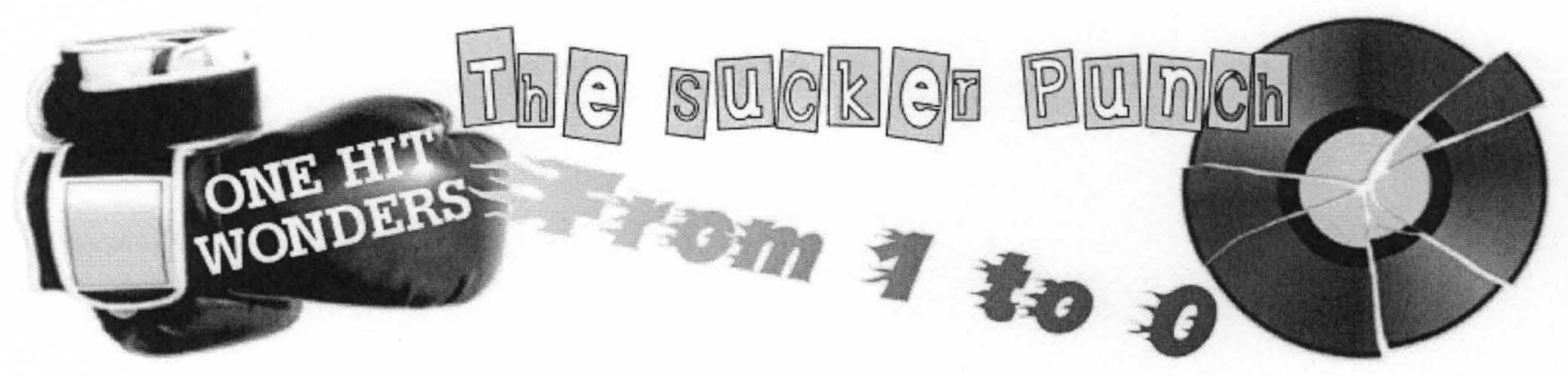

\section{Hymenosaurus Rex}

\section{It's All Good In The Rexosphere, Johnny}

In the annals of rock, Hymenosaurus Rex is a bizarre and little-known footnote. Right from the start the band was in trouble, saddled with a name that was supposed to reflect and amplify the strong family values of husband-and-wife vocalists Roy and Lindi Marlofe (Hymen being the Greek god of marriage), but which came across more as a deflowerer on the rampage. They had only a single hit record, the controversial riposte to John Lennon's "Imagine," "It's All Good In The Rexosphere, Johnny," which made the resounding lack of success that followed all the more destructive.

Roy Marlofe and Lindi Booker had, individually, been stalwarts of the pub circuit in Birmingham, England before they married in 1970, at which point they resolved to form a band together. They began performing with an ever-changing set of backing musicians, including, briefly, the drummer Brian Hoorn, better known in later years as Faff Ferocious of Dutch punk pioneers The Rotter Damns. The Marlofes' band was the inimitable Hymenosaurus Rex: squeaky clean, bombastic and sorely lacking an accurate self image. Their first singles, "In Slickness and In Stealth" and "Till Death Us Do Party," both imbued with their unique and unpalatable folk-funk fusion, sank without trace. Then Lennon released "Imagine" in 1971, and Roy was incensed. He figured his state of marital bliss was so amazing, how dare some divorcee tell him to imagine anything better? So Roy penned the eight-minute extravaganza, "It's All Good In The Rexosphere, Johnny." Here's a small taste of the lyrics:

I love my possessions,

I share them with my wife.

Two in one's my profession, It's how I live my life.

It's all good in the Rexosphere, Johnny. Yoo-hoo-hoo-yah-yay! 
I'm livin' it up with my honey.

Hymenosaurus hey!

And if the lyrics weren't bad enough, the production was worse, employing a children's choir in the chorus and a hurdy-gurdy doubling the vocals in each verse. The record company released a three-minute cut of the song (the full, extended horror could be found on the "RexaRoy Loves Lindi" album). Our link to whole track has been removed at the request of Roy Marlofe's attorneys, but "fair use" allows us to present the opening of this abomination: just click the link below! The track begins, harmlessly enough, with genuine English wedding bells, into which Roy injects the aural virus that is a muffled, electric guitar version of Wagner's famous wedding march from "Lohengrin." The descent from there is swift: seventies power chords and ham-fisted drumming herald the arrival of Roy's reedy tenor and Lindi on the hurdy-gurdy.

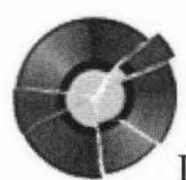

It's All Good In The Rexosphere, Johnny (introduction)

In the weird British tradition of the hit novelty record, "It's All Good" hit number one in the UK charts and stayed there for four weeks. The only rational explanation for this is that genuine music-lovers were buying the singles to burn them: an act of mercy for the sake of future generations.

Success went to the Marlofes' heads (their follow-up single was entitled "Kiss My (Wedding) Ring") but was never to be repeated. Dropped by their record company after dismal sales of their album, the pair quit singing altogether, returning briefly to notoriety only when they tried, unsuccessfully, to sue Queen for playing Wagner's wedding march on their Flash Gordon soundtrack album. With the royalties from their hit, they had already moved to America and opened a second-hand book store in Chicago. It was not a great success, though urban legend has it that Lindi sold a copy of "The Catcher in the Rye" to one Mark David Chapman.

The formatting seen here is not as it as seen online at

http://www.byzant.com/Wonders/Index.html 
Appendix B:

Amended Cheat QTR Questionnaire (full copy) 
This instrument will be administered in via an online program; thus, questions may not appear here as they will appear when entered into that program.

1. Is the course through which you are accessing this study:

- A face-to-face class

- An online class

2. What is the name or number of the course through which you are accessing this study? (Example: Advanced Math or WKU 195 or UNIV 247) (text box for entry)

3. What is your gender?

- Male

- Female

4. What is your age?

- $18-21$

- $22-25$

- 26-35

- 36-45

- over 45

5. Your current academic year according to credit hours earned is:

- freshman

- sophomore

- junior

- senior

- fifth year or beyond

6. What is your major? (text box for entry)

7. What is your current overall (cumulative) GPA?

- $0.0-1.50$

- $1.51-2.00$

- 2.01-2.50

- 2.51-2.75

- 2.76-3.00

- 3.01-3.50

- $3.51-4.0$ 
8. What is your current relationship status?

- single

- married/living with partner

- separated

- divorced

- widowed

9. What is your current student status?

- a full time student (12 credit hours or more)

- a part time student (11 credit hours or less)

10. Which campus at WKU is your "home" campus?

- Main Campus-Bowling Green

- South Campus-BGCC-Bowling Green

- Glasgow

- Elizabethtown/Ft. Knox/Radcliff

- Owensboro

11. Do you receive financial support from your parent(s)/guardian(s)?

- Yes

- No

12. Are you a recipient of any of the following types of financial aid (check all that apply)?

- loan

- grant

- scholarship

- I receive none of these types of financial aid

13. How many hours do you work in a week?

- 0: I do not work

- $1-10$

- 11-20

- 21-30

- more than 30 hours

14. Where do you live while at school?

- on campus

- off campus with parent(s)/guardian(s)

- off campus NOT with parent(s)/guardian(s) 
15. How much time each week do you spend studying?

- I do not study

- less than 5 hours

- 5-10 hours

- 11-15 hours

- more than 15 hours

16. Are you

- an American citizen or legal resident

- an International Student

17. Are you involved in extra- or co-curricular activities?

- Yes

- No

Next question will only be asked to those who answer YES to \#17

18. What type(s) of organization(s) are you involved in? (Choose all that apply)

- Social Fraternity or Sorority/Greek Life

- Service Fraternity or Sorority

- Student Government Association

- Honor Society

- Religious club

- Political club

- Intramurals

- NCAA student-athlete

- Program/Field-related club or organization

- Just for fun/Social club

- Other

\section{Reading Quiz}

Please read the selection below and then answer the questions to the best of your ability. To encourage you to do your best, those who submit their data and earn the highest scores will be entered into a drawing for a \$400 Visa gift card.

In the annals of rock, Hymenosaurus Rex is a bizarre and little-known footnote. Right from the start the band was in trouble, saddled with a name that was supposed to reflect and amplify the strong family values of husband-and-wife vocalists Roy and Lindi Marlofe (Hymen being the Greek god of marriage), but which came across more as a deflowerer on the rampage. They had only a single hit record, the controversial riposte to John Lennon's "Imagine," "It's All Good In The Rexosphere, Johnny," which made the resounding lack of success that followed all the more destructive. 
Roy Marlofe and Lindi Booker had, individually, been stalwarts of the pub circuit in Birmingham, England before they married in 1970, at which point they resolved to form a band together and began performing with an ever-changing set of backing musicians. That band was the inimitable Hymenosaurus Rex: squeaky clean, bombastic and sorely lacking an accurate self image. Their first singles, "In Slickness and In Stealth" and "Till Death Us Do Party," both imbued with their unique and unpalatable folk-funk fusion, sank without trace. Then Lennon released "Imagine" in 1971, and Roy was incensed. He figured his state of marital bliss was so amazing, how dare some divorcee tell him to imagine anything better? So Roy penned the eight-minute extravaganza, "It's All Good In The Rexosphere, Johnny." Here's a small taste of the lyrics:

\author{
I love my possessions, \\ I share them with my wife. \\ Two in one's my profession, \\ It's how I live my life. \\ It's all good in the Rexosphere, Johnny. \\ Yoo-hoo-hoo-yah-yay! \\ I'm livin' it up with my honey. \\ Hymenosaurus hey!
}

And if the lyrics weren't bad enough, the production was worse, employing a children's choir in the chorus and a hurdy-gurdy doubling the vocals in each verse. The record company released a three-minute cut of the song (the full, extended horror could be found on the "RexaRoy Loves Lindi" album), and in the weird British tradition of the hit novelty record, "It's All Good" hit number one in the UK charts and stayed there for four weeks. The only rational explanation for this is that genuine music-lovers were buying the singles to burn them: an act of mercy for the sake of future generations.

Success went to the Marlofe's heads (their follow-up single was entitled "Kiss My (Wedding) Ring") but was never to be repeated. Dropped by their record company after dismal sales of their album, the pair quit singing altogether. With the royalties from their hit, they moved to America and opened a second-hand book store in Chicago. It was not a great success, though urban legend has it that Lindi sold a copy of "The Catcher in the Rye" to one Mark David Chapman.

The original and complete version of this article is cited below:

Hymenosaurus Rex. (2009). One hit wonders: The sucker punch. Retrieved October 9, 2009, from http://www.byzant.com/Wonders/Index.html

Please answer the following 10 questions using only the information provided in the excerpt above.

19. What is the band Hymenosaurus Rex named after?

20. Where is the band from?

21. Who was the drummer for the band? 
22. What John Lennon song angered Roy?

23. "It's All Good in the Rexosphere, Johnny" was how long time-wise?

24. In the recording, what sounds are heard at the start of "It's All Good in the Rexosphere, Johnny"?

25. To whom did Lindi sell a copy of "Catcher in the Rye"?

26. Their first singles were filled with a fusion. Fill in the blanks.

27. Who did the Marlofes attempt to sue for playing Wagner's wedding march on the Flash Gordon soundtrack?

28. Why does the author think that the single "It's All Good in the Rexosphere, Johnny"? did so well on the charts?

29. How often do you use the Internet?

- Never

- Once a month or less

- A few times a month

- At least once a week

- More than once a week

- Daily

- Several Times Daily

30. How often do you use information from the Internet in preparing your assignments?

- Never

- Rarely

- Often

- Always

31. How often do you use information from the Internet without modification and/or proper referencing, into your assignments?

- Never

- Rarely

- Sometimes

- Always

32. If it could save you from failing an assignment, would you use information from the Internet without modification and/or proper referencing, in an assignment?

- No

- Maybe

- Probably

- Yes 
33. Under which of the following conditions would you use information readily available on the Internet to hand in as your work or assignment? Choose all that apply.

- at any time

- if an assignment is too difficult

- if I need to meet an urgent deadline

- if an assignment is too laborious

- only if it would save me from failing

- under no circumstances

34. Do you think that your teachers' expertise in using the Internet would enable them to find out whether you have used information taken directly from the Internet, without referencing, in your assignment?

- No

- Maybe

- Probably

- Yes

35. Do you think that your teachers would find out if you handed in an assignment that contains information directly taken from the Internet?

- No

- Maybe

- Probably

- Yes

36. Could the benefits of using information from the Internet as your own work outweigh the risk of being caught cheating/plagiarizing?

- No

- Maybe

- Probably

- Yes

37. Do you think that some of your classmates use (or have used) information obtained from the Internet, in an unmodified format and without referencing, in their assignments?

- No

- Maybe

- Probably

- Yes

38. Would you feel guilty about using information taken from the Internet as your work?

- No

- Maybe

- Probably

- Yes 
39. Would you tell anyone if you were to cheat or plagiarize by using information from the Internet?

- No

- Maybe

- Probably

- Yes

40. Do your teachers have policies in their syllabi concerning cheating and/or plagiarism?

- All of them do

- Some of them do

- None of them do

- I don't know

41. Does your school have a policy for cheating and/or plagiarism?

- Yes

- No

- I Don't Know

42. How aware of or familiar with your school's policy on cheating and/or plagiarism do you consider yourself to be?

- Unaware

- Somewhat aware/familiar

- Very aware/familiar

43. Do you understand what is considered to be cheating and/or plagiarism at your school?

- Yes

- No

- I'm not sure

44. Do you consider yourself to be an honest person?

- Yes

- Somewhat

- No

45. Did you cheat in high school?

- Never

- Rarely

- Often

- Always 
46. How often do you cheat in college?

- Never

- Rarely

- Often

- Always

Questions 47-49 will only be asked if they answer other than NEVER to \#46

47. How often have you cheated in face-to-face classes?
o Never
- Rarely
o Often
○ Always

48. How often have you cheated in online classes?
o Never
○ Rarely
o Often
- Always
- I have never taken an online class

49. Which type of classes do you cheat more in?

- General education classes

- Classes for my major/program

- I cheat about equally in both types of classes

50. How easy/difficult to you think it would be to cheat in an online class compared to a face-to-face class?

- Easier

- About the same

- More difficult

51. Have you often do you act dishonestly/cheat in a work/employment situation?

- Never

- Rarely

- Often

- Always

- I have never had a job

52. How often do you think your peers/classmates cheat?

- Never

- Rarely

- Often

- Always 
53. Have you personally witnessed cheating in college?

- Yes

- No

54. Which is more important to you in general education classes?

- Learning the information

- Getting a good grade

- Neither of these

- Both of these

55. Which is more important to you in classes related to your major/program of study?

- Learning the information

- Getting a good grade

- Neither of these

- Both of these

For the next six questions, imagine that you are taking a test, and you've been told to not use materials other than those that have been provided to you-no books, no notes, etc. In such circumstances, how serious of cheating behaviors do you consider the following activities to be?

56. Looking up information on the Web to get help/answers.

- Very Serious

- Somewhat serious

- Not very serious

- I don't consider this cheating

57. Texting to get help/answers.

- Very Serious

- Somewhat serious

- Not very serious

- I don't consider this cheating

58. Emailing to get help/answers.

- Very Serious

- Somewhat serious

- Not very serious

- I don't consider this cheating

59. Using MySpace, Twitter, Facebook or another social networking Web site to get help/answers.

- Very Serious

- Somewhat serious

- Not very serious

- I don't consider this cheating 
60. Telling students in other classes the test questions.

- Very Serious

- Somewhat serious

- Not very serious

- I don't consider this cheating

61. Telling students in other classes the test answers.

- Very Serious

- Somewhat serious

- Not very serious

- I don't consider this cheating

For the next 10 questions, imagine you've been given an assignment. How serious do you consider the following cheating behaviors to be?

62. Copying and pasting info from WWW without citing/referencing it.

- Very Serious

- Somewhat serious

- Not very serious

- I don't consider this cheating

63. Having someone look over a paper for you before you submit it..

- Very Serious

- Somewhat serious

- Not very serious

- I don't consider this cheating

64. Using a paper for more than one class.

- Very Serious

- Somewhat serious

- Not very serious

- I don't consider this cheating

65. Sharing homework answers.

- Very Serious

- Somewhat serious

- Not very serious

- I don't consider this cheating

66. Purchasing a paper from a Web site.

- Very Serious

- Somewhat serious

- Not very serious

- I don't consider this cheating 
67. Submitting another student's paper as your own with their permission.

- Very Serious

- Somewhat serious

- Not very serious

- I don't consider this cheating

68. Submitting another student's paper as your own without their permission.

- Very Serious

- Somewhat serious

- Not very serious

- I don't consider this cheating

69. Collaborating with other students on individually assigned work.

- Very Serious

- Somewhat serious

- Not very serious

- I don't consider this cheating

70. Doing less than your share of work on a group assignment.

- Very Serious

- Somewhat serious

- Not very serious

- I don't consider this cheating

71. Using a program to manipulate the length of a paper.

- Very Serious

- Somewhat serious

- Not very serious

- I don't consider this cheating

72. Did you use any source other than the excerpt provided for you on the reading quiz that you took as part of this study?

- Yes

- No

\section{Open Ended Questions}

Depending on participants' answers to Items 1 and 46, certain open-ended questions will appear after the survey portion of the instrument:

All participants will be asked:

73. In your own words, how would you define cheating? What "counts" as cheating? 
Participants who self-report accessing the study through an online class in Item 1 will be asked:

74. In an online class, how might students cheat? Can you give some examples?

75. What would you recommend that teachers to do decrease cheating in online classes?

Participants who self-report accessing the study through a face-to-face class in Item 1 will be asked:

76. In a face-to-face class, how might students cheat? Can you give some examples?

77. What would you recommend that teachers to do decrease cheating in face-to-face classes?

Participants who self-report as cheaters on Item 46 will be asked:

78. Why do you cheat? Can you give some reasons?

79. When is it considered acceptable to cheat?

Participants who self-report as non-cheaters on Item 46 will be asked:

80. Why do you choose not to cheat now?

81. Since you don't cheat now, what can you think of that might cause you to cheat in the future?

82. Thank you for answering my questions. The answers you have given are completely anonymous, not linked to you in any way.

As you may have guessed by now, this study was actually about student attitudes and behaviors concerning academic dishonesty in online learning. Your answers will be very useful in finding ways to help students avoid academic dishonesty issues, most of which are caused by students' simply not understanding what constitutes academic dishonesty. In order to keep your answers anonymous and not traceable to you in any way, once you finish this survey and submit your data, you will be redirected to a second, separate survey to enter in your WKU ID number to be eligible for the $\$ 400$ gift card drawing. Should you wish to withdraw from the study, you may do so below. Thanks again for your participation.

(o) Please SUBMIT my answers

(o) Please DELETE my answers 
For participants who answer "Please DELETE my answers," the next question will be as below:

83. This is to confirm that you want to remove your data from the study.

(o)Remove my data

(o) Keep my data

For participants who answer "Remove my data" for 74 , questions 75 and 76 will be as below:

84. Although you've requested that we remove your data from the study, I would like to keep your demographic answers from the first section of the survey (gender, age, etc) to see what types of people are withdrawing from the study. May I keep your demographic data only?

(o) Yes, you may keep my demographic data.

(o) No, delete all of my data.

85 . Would you share why you are choosing to withdraw from the study?

(o) I simply changed my mind about participating.

(o) Even though I've been told the data is confidential and anonymous, I am concerned it is not.

(o) I reported that I cheat and don't want anyone to know.

(o) Some other reason not listed here.

(o) I don't want to tell why. 
Appendix C: Reading Quiz 
This instrument will be administered in via an online program; thus, questions may not appear here as they will appear when entered into that program.

\section{Reading Quiz}

Please read the selection below and then answer the questions to the best of your ability. To encourage you to do your best, those who submit their data and earn the highest scores will be entered into a drawing for a $\$ 400$ Visa gift card.

In the annals of rock, Hymenosaurus Rex is a bizarre and little-known footnote. Right from the start the band was in trouble, saddled with a name that was supposed to reflect and amplify the strong family values of husband-and-wife vocalists Roy and Lindi Marlofe (Hymen being the Greek god of marriage), but which came across more as a deflowerer on the rampage. They had only a single hit record, the controversial riposte to John Lennon's "Imagine," "It's All Good In The Rexosphere, Johnny," which made the resounding lack of success that followed all the more destructive.

Roy Marlofe and Lindi Booker had, individually, been stalwarts of the pub circuit in Birmingham, England before they married in 1970, at which point they resolved to form a band together and began performing with an ever-changing set of backing musicians. That band was the inimitable Hymenosaurus Rex: squeaky clean, bombastic and sorely lacking an accurate self image. Their first singles, "In Slickness and In Stealth" and "Till Death Us Do Party," both imbued with their unique and unpalatable folk-funk fusion, sank without trace. Then Lennon released "Imagine" in 1971, and Roy was incensed. He figured his state of marital bliss was so amazing, how dare some divorcee tell him to imagine anything better? So Roy penned the eight-minute extravaganza, "It's All Good In The Rexosphere, Johnny." Here's a small taste of the lyrics:

I love my possessions,

I share them with my wife.

Two in one 's my profession,

It's how I live my life.

It's all good in the Rexosphere, Johnny.

Yoo-hoo-hoo-yah-yay!

I'm livin' it up with my honey.

Hymenosaurus hey!

And if the lyrics weren't bad enough, the production was worse, employing a children's choir in the chorus and a hurdy-gurdy doubling the vocals in each verse. The record company released a three-minute cut of the song (the full, extended horror could be found on the "RexaRoy Loves Lindi" album), and in the weird British tradition of the hit novelty record, "It's All Good" hit number one in the UK charts and stayed there for four 
weeks. The only rational explanation for this is that genuine music-lovers were buying the singles to burn them: an act of mercy for the sake of future generations.

Success went to the Marlofe's heads (their follow-up single was entitled "Kiss My (Wedding) Ring") but was never to be repeated. Dropped by their record company after dismal sales of their album, the pair quit singing altogether. With the royalties from their hit, they moved to America and opened a second-hand book store in Chicago. It was not a great success, though urban legend has it that Lindi sold a copy of "The Catcher in the Rye" to one Mark David Chapman.

The original and complete version of this article is cited below:

Hymenosaurus Rex. (2009). One hit wonders: The sucker punch. Retrieved October 9, 2009, from http://www.byzant.com/Wonders/Index.html

Please answer the following 10 questions using only the information provided in the excerpt above.

19. What is the band Hymenosaurus Rex named after?

20. Where is the band from?

21. Who was the drummer for the band?

22. What John Lennon song angered Roy?

23. "It's All Good in the Rexosphere, Johnny" was how long time-wise?

24. In the recording, what sounds are heard at the start of "It's All Good in the Rexosphere, Johnny"?

25. To whom did Lindi sell a copy of "Catcher in the Rye"?

26. Their first singles were filled with a fusion. Fill in the blanks.

27. Who did the Marlofes attempt to sue for playing Wagner's wedding march on the Flash Gordon soundtrack?

28. Why does the author think that the single "It's All Good in the Rexosphere, Johnny"? did so well on the charts? 
Appendix D: Open-ended Questions 
This instrument will be administered in via an online program; thus, questions may not appear here as they will appear when entered into that program.

Depending on participants' answers to Items 1 and 46 on the amended Cheat QTR (Appendix B), certain open-ended questions will appear after the survey portion of the instrument:

All participants will be asked:

73. In your own words, how would you define cheating? What "counts" as cheating?

Participants who self-report accessing the study through an online class in Item 1 will be asked:

74. In an online class, how might students cheat? Can you give some examples?

75. What would you recommend that teachers to do decrease cheating in online classes?

Participants who self-report accessing the study through a face-to-face class in Item 1 will be asked:

74. In a face-to-face class, how might students cheat? Can you give some examples?

75. What would you recommend that teachers to do decrease cheating in face-to-face classes?

Participants who self-report as cheaters on Item 46 will be asked:

76. Why do you cheat? Can you give some reasons?

77. When is it considered acceptable to cheat?

Participants who self-report as non-cheaters on Item 46 will be asked:

76. Why do you choose not to cheat now?

77. Since you don't cheat now, what can you think of that might cause you to cheat in the future? 
Appendix E: Debriefing Statement 
82. Thank you for answering my questions. The answers you have given are completely anonymous, not linked to you in any way.

As you may have guessed by now, this study was actually about student attitudes and behaviors concerning academic dishonesty in online learning. Your answers will be very useful in finding ways to help students avoid academic dishonesty issues, most of which are caused by students' simply not understanding what constitutes academic dishonesty. In order to keep your answers anonymous and not traceable to you in any way, once you finish this survey and submit your data, you will be redirected to a second, separate survey to enter in your WKU ID number to be eligible for the $\$ 400$ gift card drawing. Should you wish to withdraw from the study, you may do so below. Thanks again for your participation.

(o) Please SUBMIT my answers

(o) Please DELETE my answers 
Appendix F: Original Cheat QTR Questionnaire with Scoring Guide 


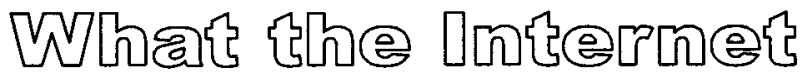

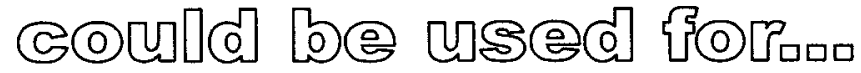

Please answer the following questions honestly. Your identity will remain anonymous and no effort will be made to identify you. Your co-operation is greatly appreciated.

1)How familiar are you with using the Internet? (tick one box only)

1 not familiar at all

3 know how search and save/copy information

2 know how to search information

4 know all aspects of the Internet

2) How often do you browse the Internet?

1 never 2 a few times a year 3 about once a month 4 about once a week 5 more than once a week

3) How often do you use information from the Internet in preparing your assignments?

1 never 2 a few times a year 3 about once a month 4 about once a week 5 more than once a week

4) How often do you use the COPY / PASTE function to embed information from the Internet, without modification and/or proper referencing, into your assignments?

1 never 2 a few times a year 3 about once a month 4 about once a week 5 more than once a week

5) If it could save you from failing a module, would you use the COPY / PASTE function to use the readily available information from the Internet, without modification and/or proper referencing, into your assignment?

1 no 2 probably $\quad 3$ yes

6) Under which of the following conditions would you use information readily available on the Internet to hand in as your work or assignment? (tick one box only)

6 at any time

4 if $I$ need to meet an urgent deadline

5 if an assignment is too difficult

2 only if it would save me from failing

3 if an assignment is too laborious

1 under no circumstances

7) Do you think that your tutor's expertise in using the Internet would enable him/her to find out whether you have used information taken directly from the Internet, without referencing, in your assignment?

1 no 2 probably 3 yes

8) Do you think that the lecturer(s) would find out if you would hand in an assignment that contains information directly taken from the Internet?

1 no 2 probably 3 yes

9) Could the benefits of using information from the Internet, as your own work, outweigh the risk of being caught with plagiarism?

1 no 2 probably $\quad 3$ yes

10) Do you think that some of your classmates use (or have used) information obtained from the Internet, in an unmodified format and without referencing, in their assignments?

1 no 2 probably 3 yes

11) Would you feel guilty about using information taken from the Internet as your work?

1 no 2 probably 3 yes

12) Would you tell anyone (i.e., friends) if you were to plagiarise information from the Internet?

1 no 2 probably 3 yes 
13) Your level of mastery of the English language is:

1 No English at all

2 Very poor (few words only)

3 Basic English

4 Intermediate/Good English

5 Excellent/Proficient English

You are a: 1 male 2 female

Your current academic year is: 1 first year 2 second year 3 third year 
Appendix G: Attitude and Behavior Questions from Amended Cheat QTR 
This instrument will be administered in via an online program; thus, questions may not appear here as they will appear when entered into that program.

29. How often do you use the Internet?

- Never

- Once a month or less

- A few times a month

- At least once a week

- More than once a week

- Daily

- Several Times Daily

30. How often do you use information from the Internet in preparing your assignments?

- Never

- Rarely

- Often

- Always

31. How often do you use information from the Internet without modification and/or proper referencing, into your assignments?

- Never

- Rarely

- Sometimes

- Always

32. If it could save you from failing an assignment, would you use information from the Internet without modification and/or proper referencing, in an assignment?

- No

- Maybe

- Probably

- Yes

33. Under which of the following conditions would you use information readily available on the Internet to hand in as your work or assignment? Choose all that apply.

- at any time

- if an assignment is too difficult

- if I need to meet an urgent deadline

- if an assignment is too laborious

- only if it would save me from failing

- under no circumstances 
34. Do you think that your teachers' expertise in using the Internet would enable them to find out whether you have used information taken directly from the Internet, without referencing, in your assignment?

- No

- Maybe

- Probably

- Yes

35. Do you think that your teachers would find out if you handed in an assignment that contains information directly taken from the Internet?

- No

- Maybe

- Probably

- Yes

36. Could the benefits of using information from the Internet as your own work outweigh the risk of being caught cheating/plagiarizing?

- No

- Maybe

- Probably

- Yes

37. Do you think that some of your classmates use (or have used) information obtained from the Internet, in an unmodified format and without referencing, in their assignments?

- No

- Maybe

- Probably

- Yes

38. Would you feel guilty about using information taken from the Internet as your work?

- No

- Maybe

- Probably

- Yes

39. Would you tell anyone if you were to cheat or plagiarize by using information from the Internet?

- No

- Maybe

- Probably

- Yes 
40. Do your teachers have policies in their syllabi concerning cheating and/or plagiarism?

- All of them do

- Some of them do

- None of them do

- I don't know

41. Does your school have a policy for cheating and/or plagiarism?

- Yes

- No

- I Don't Know

42. How aware of or familiar with your school's policy on cheating and/or plagiarism do you consider yourself to be?

- Unaware

- Somewhat aware/familiar

- Very aware/familiar

43. Do you understand what is considered to be cheating and/or plagiarism at your school?

- Yes

- No

- I'm not sure

44. Do you consider yourself to be an honest person?

- Yes

- Somewhat

- No

45. Did you cheat in high school?

- Never

- Rarely

- Often

- Always

46. How often do you cheat in college?

- Never

- Rarely

- Often

- Always 
Questions 47-49 will only be asked if they answer other than NEVER to \#46

47. How often have you cheated in face-to-face classes?

- Never

- Rarely

- Often

- Always

48. How often have you cheated in online classes?

- Never

- Rarely

- Often

- Always

- I have never taken an online class

49. Which type of classes do you cheat more in?

- General education classes

- Classes for my major/program

- I cheat about equally in both types of classes

50. How easy/difficult to you think it would be to cheat in an online class compared to a face-to-face class?

- Easier

- About the same

- More difficult

51. Have you often do you act dishonestly/cheat in a work/employment situation?

- Never

- Rarely

- Often

- Always

- I have never had a job

52. How often do you think your peers/classmates cheat?

- Never

- Rarely

- Often

- Always

53. Have you personally witnessed cheating in college?

- Yes

- No 
54. Which is more important to you in general education classes?

- Learning the information

- Getting a good grade

- Neither of these

- Both of these

55. Which is more important to you in classes related to your major/program of study?

- Learning the information

- Getting a good grade

- Neither of these

- Both of these

For the next six questions, imagine that you are taking a test, and you've been told to not use materials other than those that have been provided to you-no books, no notes, etc. In such circumstances, how serious of cheating behaviors do you consider the following activities to be?

56. Looking up information on the Web to get help/answers.

- Very Serious

- Somewhat serious

- Not very serious

- I don't consider this cheating

57. Texting to get help/answers.

- Very Serious

- Somewhat serious

- Not very serious

- I don't consider this cheating

58. Emailing to get help/answers.

- Very Serious

- Somewhat serious

- Not very serious

- I don't consider this cheating

59. Using MySpace, Twitter, Facebook or another social networking Web site to get help/answers.

- Very Serious

- Somewhat serious

- Not very serious

- I don't consider this cheating 
60. Telling students in other classes the test questions.

- Very Serious

- Somewhat serious

- Not very serious

- I don't consider this cheating

61. Telling students in other classes the test answers.

- Very Serious

- Somewhat serious

- Not very serious

- I don't consider this cheating

For the next 10 questions, imagine you've been given an assignment. How serious do you consider the following cheating behaviors to be?

62. Copying and pasting info from WWW without citing/referencing it.

- Very Serious

- Somewhat serious

- Not very serious

- I don't consider this cheating

63. Having someone look over a paper for you before you submit it.

- Very Serious

- Somewhat serious

- Not very serious

- I don't consider this cheating

64. Using a paper for more than one class.

- Very Serious

- Somewhat serious

- Not very serious

- I don't consider this cheating

65. Sharing homework answers.

- Very Serious

- Somewhat serious

- Not very serious

- I don't consider this cheating

66. Purchasing a paper from a Web site.

- Very Serious

- Somewhat serious

- Not very serious

- I don't consider this cheating 
67. Submitting another student's paper as your own with their permission.

- Very Serious

- Somewhat serious

- Not very serious

- I don't consider this cheating

68. Submitting another student's paper as your own without their permission.

- Very Serious

- Somewhat serious

- Not very serious

- I don't consider this cheating

69. Collaborating with other students on individually assigned work.

- Very Serious

- Somewhat serious

- Not very serious

- I don't consider this cheating

70. Doing less than your share of work on a group assignment.

- Very Serious

- Somewhat serious

- Not very serious

- I don't consider this cheating

71. Using a program to manipulate the length of a paper.

- Very Serious

- Somewhat serious

- Not very serious

- I don't consider this cheating

72. Did you use any source other than the excerpt provided for you on the reading quiz that you took as part of this study?

- Yes

- No 
Appendix H: Permission to use Cheat QTR 
From: "Underwood, Jean" > jean.underwood@ntu.ac.uk>

Subject: RE: Instrument Inquiry

Date: Sat, 25 Oct 2008 20:08:08 +0100

To: $\quad$ "Wren Mills"<wren.mills@wku.edu>

ju

I will contact Dr Szabo and ask him to forward it to you.

-----Original Message-----

From: Wren Mills [mailto:wren.mills@wku.edu]

Sent: Sat 10/25/2008 5:48 PM

To: Underwood, Jean

Subject: Instrument Inquiry

Dear Professor Underwood,

I am doctoral student with the University of Louisville in Louisville, Kentucky, USA. I am interested in learning more about the instrument you used in your 2003 study with Attila Szabo, 'Academic offences and e-learning: individual propensities in cheating.' It is possible that your instrument, from the description in the article, may be a good fit for my dissertation, which will examine cheating in online learning.

Would it be possible for me to see a copy of the instrument and any reliability and/or validity data that you may have for it?

Thank you for your time and help.

Sincerely,

Wren Mills 
Appendix I: Questions dealing with background variables 
This instrument will be administered in via an online program; thus, questions may not appear here as they will appear when entered into that program.

1. Is the course through which you are accessing this study:

- A face-to-face class

- An online class

2. What is the name or number of the course through which you are accessing this study? (Example: Advanced Math or WKU 195 or UNIV 247) (text box for entry)

3. What is your gender?

- Male

- Female

4. What is your age?

- $18-21$

- $22-25$

- 26-35

- $36-45$

- over 45

5. Your current academic year according to credit hours earned is:

- freshman

- sophomore

- junior

- senior

- fifth year or beyond

6. What is your major? (text box for entry)

7. What is your current overall (cumulative) GPA?

- $0.0-1.50$

- $1.51-2.00$

- 2.01-2.50

- 2.51-2.75

- 2.76-3.00

- 3.01-3.50

- $3.51-4.0$

8. What is your current relationship status?

- single

- married/living with partner

- separated

- divorced

- widowed 
9. What is your current student status?

- a full time student (12 credit hours or more)

- a part time student (11 credit hours or less)

10. Which campus at WKU is your "home" campus?

- Main Campus-Bowling Green

- South Campus-BGCC-Bowling Green

- Glasgow

- Elizabethtown/Ft. Knox/Radcliff

- Owensboro

11. Do you receive financial support from your parent(s)/guardian(s)?

- Yes

- No

12. Are you a recipient of any of the following types of financial aid (check all that apply)?

- loan

- grant

- scholarship

- I receive none of these types of financial aid

13. How many hours do you work in a week?

- 0: I do not work

- $1-10$

- 11-20

- 21-30

- more than 30 hours

14. Where do you live while at school?

- on campus

- off campus with parent(s)/guardian(s)

- off campus NOT with parent(s)/guardian(s)

15. How much time each week do you spend studying?

- I do not study

- less than 5 hours

- 5-10 hours

- 11-15 hours

- more than 15 hours

17. Are you

- an American citizen or legal resident

- an International Student 
17. Are you involved in extra- or co-curricular activities?

- Yes

- No

Next question will only be asked to those who answer YES to \#17

18. What type(s) of organization(s) are you involved in? (Choose all that apply)

- Social Fraternity or Sorority/Greek Life

- Service Fraternity or Sorority

- Student Government Association

- Honor Society

- Religious club

- Political club

- Intramurals

- NCAA student-athlete

- Program/Field-related club or organization

- Just for fun/Social club

- Other 
Appendix J: Tables of Descriptive Statistics for Background Variables 
Table 9

Class Type of Participants

\begin{tabular}{lll}
\hline Class Type & $\mathrm{N}$ & $\%$
\end{tabular}

$\begin{array}{lll}\text { Face to face } & 32 & 28.8\end{array}$

$\begin{array}{lll}\text { Online } & 79 & 71.2\end{array}$

Table 10

Gender of Participants

\begin{tabular}{lcc}
\hline Gender & $\mathrm{N}$ & $\%$ \\
\hline Male & 22 & 22.5 \\
Female & 86 & 77.5 \\
\hline
\end{tabular}

Table 11

Age of Participants

\begin{tabular}{lcc}
\hline Age & $\mathrm{N}$ & $\%$ \\
\hline $18-21$ & 61 & 55 \\
$22-25$ & 16 & 14.4 \\
$26-35$ & 17 & 15.3 \\
$36-45$ & 10 & 9.0 \\
46 or older & 7 & 6.3 \\
\hline
\end{tabular}


Table 12

Class Year of Participants

\begin{tabular}{lcc}
\hline Class Year & $\mathrm{N}$ & $\%$ \\
\hline Freshman & 36 & 32.4 \\
Sophomore & 28 & 25.2 \\
Junior & 16 & 14.4 \\
Senior & 25 & 22.5 \\
Fifth Year or Beyond & 6 & 5.4 \\
\hline
\end{tabular}

Table 13

Grade Point Average of Participants

\begin{tabular}{lcc}
\hline GPA & $\mathrm{N}$ & $\%$ \\
\hline $0.00-1.50$ & 1 & 0.9 \\
$1.51-2.00$ & 3 & 2.7 \\
$2.01-2.50$ & 11 & 9.9 \\
$2.51-2.75$ & 7 & 6.3 \\
$2.76-3.00$ & 23 & 20.7 \\
$3.01-3.50$ & 28 & 25.2 \\
$3.51-4.00$ & 38 & 34.2 \\
\hline
\end{tabular}


Table 14

Student Status of Participants

\begin{tabular}{lcc}
\hline Student Status & $\mathrm{N}$ & $\%$ \\
\hline Part-time (fewer than 12 credit hours) & 19 & 17.1 \\
Full-time (12 credit hours or more) & 92 & 82.9 \\
\hline
\end{tabular}

Table 15

Campus Affiliation of Participants

\begin{tabular}{lcc}
\hline Campus & $\mathrm{N}$ & $\%$ \\
\hline Elizabethtown/Ft. Knox/Radcliff & 5 & 4.5 \\
Glasgow & 10 & 9 \\
Main Campus & 93 & 83 \\
Owensboro & 3 & 2.7 \\
South Campus & 0 & 0
\end{tabular}

Table 16

Study Habits of Participants

\begin{tabular}{lcc}
\hline Hours Studied & N & $\%$ \\
\hline I do not study & 1 & 0.9 \\
Fewer than 5 hours & 30 & 27 \\
$5-10$ hours & 50 & 45 \\
$11-15$ hours & 19 & 17.1 \\
More than 15 hours & 11 & 9.9 \\
\hline
\end{tabular}


Table 17

Major Program of Study of Participants (by College)

\begin{tabular}{lcc}
\hline College & $\mathrm{N}$ & $\%$ \\
\hline Arts and Letters & 10 & 9 \\
Business College & 8 & 7.2 \\
Community College & 1 & .09 \\
Education and Behavioral Sciences & 15 & 13.5 \\
Health and Human Services & 13 & 11.7 \\
Honors College & 1 & .09 \\
Science and Mathematics & 16 & 14.4 \\
University College & 8 & 7.2 \\
Double major across colleges & 15 & 13.5 \\
Undecided major & 3 & 2.7 \\
\hline
\end{tabular}

Table 18

Participants Receiving Financial Support from Parents/Guardians

\begin{tabular}{lcc}
\hline Receiving Financial Report & $\mathrm{N}$ & $\%$ \\
\hline Yes & 55 & 49.5 \\
No & 56 & 50.5
\end{tabular}


Table 22

Extra- and Co-curricular Involvement of Participants

\begin{tabular}{lcc}
\hline Involved & $\mathrm{N}$ & $\%$ \\
\hline Yes & 48 & 43.2 \\
No & 63 & 56.8 \\
\hline
\end{tabular}

Table 23

Types of Extra- and Co-curricular Involvement of Participants

\begin{tabular}{lll}
\hline Type of Involvement & $\mathrm{N}$ & $\%$
\end{tabular}

Social sorority/fraternity/Greek life

10

9

Service sorority/fraternity

3

2.7

Student Government Association

0

0

Honor society

8

7.2

Religious club

9

8.1

Political club

2

1.8

Intramurals

8

7.2

NCAA student-athlete

0

0

Major/degree/career-related

Just for fun/social club

14

12.6

Other

19.8 
Table 24

Living Accommodations of Participants

\begin{tabular}{lcc}
\hline Living Accommodation & $\mathrm{N}$ & $\%$ \\
\hline Live on campus/residence hall & 33 & 29.7 \\
$\begin{array}{l}\text { Live off campus/with parents/guardians } \\
\text { Life off campus/NOT with parents/ }\end{array}$ & 19 & 17.1 \\
guardians & 59 & 53.2 \\
\hline
\end{tabular}

Table 25

Marital Status of Participants

\begin{tabular}{lcc}
\hline Marital Status & $\mathrm{N}$ & $\%$ \\
\hline Single & 73 & 65.8 \\
Married/living with partner & 33 & 29.7 \\
Separated & 0 & 0 \\
Divorced & 5 & 4.5 \\
Widowed & 0 & 0 \\
\hline
\end{tabular}


Appendix K: Email to Faculty to Solicit Class Participation 


\section{Dear WKU Faculty,}

Some of you may know me as the new Instructional Coordinator at FaCET here on campus, while others have had me as a student or have taught with me here at WKU. I am writing to you to seek your assistance in the collection of data for my doctoral dissertation. I am soliciting the help of faculty members who are teaching general education courses, both face-to-face and online. You have been contacted because you are one of these persons.

My topic is academic dishonesty (cheating) in online learning, but the study will be presented to students as a study on testing formats in online learning. It is a deception study due to the sensitive nature of the true topic in an attempt to avoid participants giving "socially desirable" answers or behaving in a "socially desirable" way rather than how they would answer or act under normal circumstances. ${ }^{*}$ It is verv important that you do not disclose the true topic of the study to students before thev participate. ${ }^{* *}$ The purpose of the study is to determine the accuracy of undergraduate student self-reports of cheating and to determine if the same types of students report cheating in online classes as in face-to-face classes. In the study, the students have a chance to cheat to achieve a higher score on a reading quiz that they will complete; they will also answer questions concerning several background variables (i.e., gender, age, major), attitudes toward cheating, and personal behaviors involving academic dishonesty. A $\$ 400$ Visa gift card will be offered as an incentive to encourage students to do their best on the quiz.

Students will participate in the study its entirety online: no class time will be forfeited unless you choose to promote the study in your course or to remind students to participate in class.

If you are willing to give the students in your class(es) the chance to participate, at the start of the study, I will provide you with an email to send to your class(es) (with a link to the study in it) or to post as an announcement for your class on Blackboard, or you may do both. One week after the start of data collection, I will provide you with a reminder email/announcement to send to students. If you wish, I will happily notify you of my findings upon the study's completion, as well.

This study has been approved as a deception study through both WKU's Human Subjects Review Board and the University of Louisville's Institutional Review Board. Full details of the study are available if you wish to review them. My chair is Dr. Ric Keaster in the department of Educational Administration, Leadership, and Research, and you can reach him at 270-745-7088.

If you are amenable to allowing your students to participate, simply reply to this email, and I will contact you soon with the email for your students to access the study. If you have any questions, I am happy to answer those, as well, as is Ric Keaster.

I look forward to hearing from you by Friday, April 23rd so that I may collect my data and finish my dissertation this summer. 
Sincerely,

Wren Mills, Doctoral Candidate

Cooperative Doctoral Program

Western Kentucky University and University of Louisville 
Appendix L: Email to Students Via Faculty to Solicit Participation 
Dear Student,

You are invited to participate in a project conducted through Western Kentucky University and the University of Louisville.

The investigators will explain to you in detail the purpose of the project, the procedures to be used, and the potential benefits and possible risks of participation. You may ask him/her any questions you have to help you understand the project. A basic explanation of the project is written below. Please read this explanation and discuss with the researcher any questions you may have before participating in the study.

If you decide to participate in the project, please click the link at the end of this consent. If you would like a copy of this informed consent to keep, simply print or save a copy of this email.

If you do not wish to participate, you may simply ignore this notice.

\section{SUBJECT INFORMED CONSENT DOCUMENT}

Title of the research study: Testing Formats in Online Learning

IRB assigned number: WKU HSRB 10-176, UofL IRB 10-0120

Investigator(s) name \& address:

Keaster, Richard, TPH 403B, Western Kentucky University, 1906 College Heights Blvd. \#41031, Bowling Green, KY 42101-1031.

Site(s) where study is to be conducted: Western Kentucky University

Phone number for subjects to call for questions: If you have any questions, concerns, or complaints about the research study, please contact Wren Mills at (270) 745-6507.

\section{Introduction and Background Information}

Students: You are invited to participate in a research study. The study is being conducted by Dr. Ric Keaster/Professor/Ph.D. and Wren Mills/M.A./M.A.E. The study is sponsored by the University of Louisville (Department of Leadership, Foundations, and Human Resource Education) and Western Kentucky University (College of Education and Behavioral Sciences). The study will take place at Western Kentucky University. Persons enrolled in online general education classes and face-to-face sections of English 100, 200, 
and 300 at WKU will be invited to participate.

\section{Purpose}

The purpose of this study is to determine if a certain testing format is effective in online classes and for which types of students it is considered beneficial

\section{Procedures}

Participants will first answer questions about their backgrounds, such as gender, age, and major/program of study. Then participants will take a short reading quiz. This will include reading a short passage (excerpted from a longer one, a citation of which is provided) and answer 10 open-ended questions about it. Then participants will answer questions concerning attitudes toward learning and use of the internet. To encourage ' participants to do their best on the quiz, those who submit their data and earn the highest scores will be given a chance to enter into a drawing for a $\$ 400 \mathrm{Visa}$ gift card. It is estimated that it will take participants 45 minutes to participate in this study, from the time they log in to the time they completely finish and log out.

\section{Potential Risks}

Participants may feel anxious if they are unable to answer the questions. There may be unforeseen risks. Other than this, no discomfort or risks are anticipated.

\section{Benefits}

Findings from this study may help teachers of online classes to improve testing formats for their students, improving the quality of online education for all students.

\section{Compensation}

You will not be compensated for your time, inconvenience, or expenses for your participation in this study. However, participants who submit their data will have an opportunity to submit their WKU ID numbers in a separate survey to be eligible for a one-time $\$ 400$ gift card drawing.

\section{Voluntary Participation}

Taking part in this study is voluntary. You may choose not to take part at all. If you decide to be part of this study you may stop taking part in the survey at any time. If you become uncomfortable at any time while answering the questionnaire and do not wish to continue, you may simply close or "X" out of your browser, and no data will be submitted; however, this means you will not have the chance to enter the drawing for the $\$ 400$ gift card. If you decide not to be in this study or if you stop taking part at any time, you will not lose any benefits for which you may qualify. 


\section{Contact Persons}

If you have any questions, concerns, or complaints about the research study, please contact Wren Mills at (270) 745-6507 or wren.mills@wku.edu.

\section{Research Subject's Rights}

If you have any questions about your rights as a research subject, you may call the Human

Subjects Protection Program Office at (502) 852-5188. You can discuss any questions about

your rights as a research subject, in private, with a member of the Institutional Review Board

(IRB). You may also call this number if you have other questions about the research, and you

cannot reach the study doctor, or want to talk to someone else. The IRB is an independent committee made up of people from the University community, staff of the institutions, as well

as people from the community not connected with these institutions. The IRB has reviewed this research study.

\section{Concerns and Complaints}

If you have concerns or complaints about the research or research staff and you do not wish to give your name, you may call 1-877-852-1167. This is a 24-hour hot line answered by people who do not work at the University of Louisville.

\section{Acknowledgment and Signatures}

This informed consent document is not a contract. If you wish to retain a copy of this consent, please print or save this email. This document tells you what will happen during the study if you choose to take part. You are not giving up any legal rights by participating in this study. Your continued participation in the study (i.e., completing the survey and quiz) indicates that this study has been explained to you, that your questions have been answered, and that you agree to take part in the study. Using the link provided to enter the survey constitutes your signature and consent to participate in the study.

https://www.wku.edu/Dept/Support/Tech/itdiv/infotech/atech/apps/phpESP/public/s urvey.php?name $=$ TestingFormatsInOnlineLearning 
Appendix M: Reminder Email to Students via Faculty to Solicit Participation 
Dear Student,

One week ago, you were invited to participate in a study on Testing Formats in Online Learning by Wren Mills and Dr. Ric Keaster. If you have participated, we thank you for doing so, and should you win the $\$ 400$ Visa gift card drawing, we will be in touch to let you know how to collect your prize.

However, if you've not yet had time to participate and want to do so, please read the important information below and complete the study no later than DATE OF CLOSING OF DATA COLLECTION HERE to be eligible for the $\$ 400$ Visa gift card drawing.

Thank you again for your time and consideration and for participating in our study.

Sincerely,

Wren Mills and Dr. Ric Keaster

You are invited to participate in a project conducted through Western Kentucky University and the University of Louisville.

The investigators will explain to you in detail the purpose of the project, the procedures to be used, and the potential benefits and possible risks of participation. You may ask him/her any questions you have to help you understand the project. A basic explanation of the project is written below. Please read this explanation and discuss with the researcher any questions you may have before participating in the study.

If you decide to participate in the project, please click the link at the end of this consent. If you would like a copy of this informed consent to keep, simply print or save this email.

If you do not wish to participate, you may simply ignore this notice.

\section{SUBJECT INFORMED CONSENT DOCUMENT}

Title of the research study: Testing Formats in Online Learning

IRB assigned number: WKU HSRB 10-176, UofL IRB 10-0120

Investigator(s) name \& address:

Keaster, Richard, TPH 403B, Western Kentucky University, 1906 College Heights Blvd. 
\#41031, Bowling Green, KY 42101-1031.

Site(s) where study is to be conducted: Western Kentucky University

Phone number for subjects to call for questions: If you have any questions, concerns, or complaints about the research study, please contact Wren Mills at (270) 745-6507.

\section{Introduction and Background Information}

Students: You are invited to participate in a research study. The study is being conducted by Dr. Ric Keaster/Professor/Ph.D. and Wren Mills/M.A./M.A.E. The study is sponsored by the University of Louisville (Department of Leadership, Foundations, and Human Resource Education) and Western Kentucky University (College of Education and Behavioral Sciences). The study will take place at Western Kentucky University. Persons enrolled in online general education classes and face-to-face sections of English 100, 200, and 300 at WKU will be invited to participate.

\section{Purpose}

The purpose of this study is to determine if a certain testing format is effective in online classes and for which types of students it is considered beneficial

\section{Procedures}

Participants will first answer questions about their backgrounds, such as gender, age, and major/program of study. Then participants will take a short reading quiz. This will include reading a short passage (excerpted from a longer one, a citation of which is provided) and answer 10 open-ended questions about it. Then participants will answer questions concerning attitudes toward learning and use of the internet. To encourage participants to do their best on the quiz, those who submit their data and earn the highest scores will be given a chance to enter into a drawing for a $\$ 400 \mathrm{Visa}$ gift card. It is estimated that it will take participants 45 minutes to participate in this study, from the time they $\log$ in to the time they completely finish and log out.

\section{Potential Risks}

Participants may feel anxious if they are unable to answer the questions. There may be unforeseen risks. Other than this, no discomfort or risks are anticipated.

\section{Benefits}

Findings from this study may help teachers of online classes to improve testing formats for their students, improving the quality of online education for all students. 


\section{Compensation}

You will not be compensated for your time, inconvenience, or expenses for your participation in this study. However, participants who submit their data will have an opportunity to submit their WKU ID numbers in a separate survey to be eligible for a one-time $\$ 400$ gift card drawing.

\section{Voluntary Participation}

Taking part in this study is voluntary. You may choose not to take part at all. If you decide to be part of this study you may stop taking part in the survey at any time. If you become uncomfortable at any time while answering the questionnaire and do not wish to continue, you may simply close or " $\mathrm{X}$ " out of your browser, and no data will be submitted; however, this means you will not have the chance to enter the drawing for the $\$ 400$ gift card. If you decide not to be in this study or if you stop taking part at any time, you will not lose any benefits for which you may qualify.

\section{Contact Persons}

If you have any questions, concerns, or complaints about the research study, please contact Wren Mills at (270) 745-6507 or wren.mills@wku.edu.

\section{Research Subject's Rights .}

If you have any questions about your rights as a research subject, you may call the Human

Subjects Protection Program Office at (502) 852-5188. You can discuss any questions about

your rights as a research subject, in private, with a member of the Institutional Review Board

(IRB). You may also call this number if you have other questions about the research, and you

cannot reach the study doctor, or want to talk to someone else. The IRB is an independent committee made up of people from the University community, staff of the institutions, as well

as people from the community not connected with these institutions. The IRB has reviewed this research study.

\section{Concerns and Complaints}

If you have concerns or complaints about the research or research staff and you do not wish to give your name, you may call 1-877-852-1167. This is a 24-hour hot line answered by people who do not work at the University of Louisville. 


\section{Acknowledgment and Signatures}

This informed consent document is not a contract. If you wish to retain a copy of this consent, please print or save this email. This document tells you what will happen during the study if you choose to take part. You are not giving up any legal rights by participating in this study. Your continued participation in the study (i.e., completing the survey and quiz) indicates that this study has been explained to you, that your questions have been answered, and that you agree to take part in the study. Using the link provided to enter the survey constitutes your signature and consent to participate in the study.

https://www.wku.edu/Dept/Support/Tech/itdiv/infotech/atech/apps/phpESP/public/s urvey.php?name $=$ TestingFormatsInOnlineLearning 


\section{CURRICULUM VITAE}

NAME

BUSINESS ADDRESS

2009

2004

1999

1996
Wren Allen Mills

Western Kentucky University

Faculty Center for Excellence in Teaching 1906 College Heights Blvd. \#11095

Bowling Green, Kentucky 42101

Western Kentucky University

University of Louisville

Joint Doctoral Program (Ph.D.)

Higher Education Administration

Western Kentucky University

Certificate, International Student Services

Student Affairs in Higher Education

Bowling Green, Kentucky

Western Kentucky University

Master of Arts, Education

Student Affairs in Higher Education

Bowling Green, Kentucky

Western Kentucky University

Master of Arts, English

Writing and the Teaching of Writing

Bowling Green, Kentucky

Western Kentucky University

Bachelor of Arts, History

Bowling Green, Kentucky

\section{PROFESSIONAL EXPERIENCE}

January 2010 Instructional Coordinator

Faculty Center for Excellent in Teaching

Western Kentucky University, Bowling Green, Kentucky 
August 2005 Assistant Professor, English and Humanities

General Education and Enrichment Division

Bowling Green Technical College, Bowling Green, Kentucky

\section{LEADERSHIP APPOINTMENTS}

Two-Year College English Association of Kentucky (TYCA-KY)

- Vice Chair and Chair-Elect (2010-2012)

Bowling Green Technical College

- Faculty Senate, Secretary (2008-2009)

- Faculty Senate, Vice Chair (2006-2008)

- Advisor, National Technical Honor Society (2007-2009)

- Recorder, Division Advisory Board (2005-2007)

- Chair, Constitution Day (2005)

Kentucky Community and Technical College System

- Chair, System English Curriculum Committee (2009)

- College Representative, Humanities Curriculum Committee (2006-2007)

- College Representative, Developmental Transitional Pathways Committee (20052006)

Sigma Kappa Sorority

- Collegiate Province Officer (2004-present)

- Advisory Board Chairman, Epsilon Zeta Chapter (2003- 2004)

- Advisor, Scholarship and Alumnae Relations, Epsilon Zeta Chapter (2000- 2003)

- Southern Kentucky Alumnae Chapter, past President and Secretary; current Alumnae-Collegiate Liaison

Delta Tau Delta Fraternity

- Faculty Advisor to Epsilon Xi chapter, WKU (2005-present)

WKU VOX of Planned Parenthood

- Faculty Advisor (2010-present)

\section{RESEARCH AND CREATIVE ACTIVITIES}

\section{Publications}

Mills, W. (2008). Hazing in intercollegiate athletics: Concerns, considerations, and solutions. In T. Lara (Ed.), Contemporary Issues, Problems, and Opportunities: Law in Student Affairs in Higher Education. Bowling Green, KY: WKU. 


\section{Presentations}

Mills, W., \& Wilkins, D. (2009). Diversifying assessment. Presented at New Horizons Conference, Louisville, KY.

Mills, W., \& Wilkins, D. (2009). Diversifying assessment. Presented at Kentucky Conference on the Scholarship of Teaching and Learning, Lexington, KY.

Mills, W. (2008). Introducing critical thinking skills in your classroom. Presented at New Horizons Conference, Lexington, KY. 